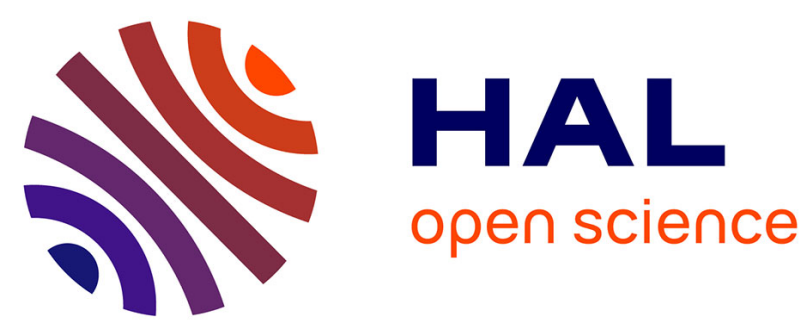

\title{
Assessing the impact of climate variation on survival in vertebrate populations
}

\author{
V. Grosbois, J.-M. Gaillard, Roger Pradel, C. Barbraud, J. Clobert, A. \\ Møller, H. Weimerskirch, Olivier Gimenez
}

\section{- To cite this version:}

V. Grosbois, J.-M. Gaillard, Roger Pradel, C. Barbraud, J. Clobert, et al.. Assessing the impact of climate variation on survival in vertebrate populations. Biological Reviews, 2008, 83 (3), pp.357-399. 10.1111/j.1469-185X.2008.00047.x . hal-03515165

\section{HAL Id: hal-03515165 \\ https://hal.science/hal-03515165}

Submitted on 6 Jan 2022

HAL is a multi-disciplinary open access archive for the deposit and dissemination of scientific research documents, whether they are published or not. The documents may come from teaching and research institutions in France or abroad, or from public or private research centers.
L'archive ouverte pluridisciplinaire HAL, est destinée au dépôt et à la diffusion de documents scientifiques de niveau recherche, publiés ou non, émanant des établissements d'enseignement et de recherche français ou étrangers, des laboratoires publics ou privés. 


\section{Assessing the impact of climate variation on survival in vertebrate}

\section{populations}

Grosbois V. ${ }^{1,2^{*}}$, Gimenez O. ${ }^{1,3}$, Gaillard, J.-M. ${ }^{2}$, Pradel, R. ${ }^{1}$, Barbraud, C. ${ }^{4}$, Clobert, J. ${ }^{5}$, Møller, A. P. ${ }^{6}$ and Weimerskirch, H. $^{4}$

${ }^{1}$ Centre d'Ecologie Fonctionnelle et Evolutive, UMR 5175, 1919 Route de Mende, F-34293 Montpellier Cedex 5, France ;

${ }^{2}$ Laboratoire Biométrie et Biologie Evolutive, UMR 5558, Bat. 711. Université Claude Bernard Lyon 1, 43 Boulevard du 11 novembre 1918, F-69622 Villeurbanne Cedex, France ;

${ }^{3}$ University of St Andrews, the Observatory, Buchanan Gardens, St Andrews, FIFE, Scotland, KY16 9LZ.

${ }^{4}$ Centre d'Etude Biologique de Chizé, CNRS UPR 1934, F-79360 Villiers en Bois, France ;

${ }^{5}$ Laboratoire Evolution et Diversité Biologique, Station Biologique du CNRS a Moulis, Moulis, F-09200 Saint-Girons, France;

${ }^{6}$ Laboratoire de Parasitologie Evolutive, CNRS UMR 7103, Université Pierre et Marie Curie, Bâtiment A, 7ème étage, 7 quai St. Bernard, Case 237, F-75252 Paris Cedex 05, France ;

Author for correspondence at address 2: Tel: 0033 (0)4 724481 70; Fax: 0033 (0)4 724313 88; E-mail: vladimirgrosbois@ hotmail.com

Received 13 February 2007; revised 8 April 2008 


\section{ABSTRACT}

The impact of the ongoing rapid climate change on natural systems is a major issue for human societies. An important challenge for ecologists is to identify the climatic factors that drive temporal variation in demographic parameters, and, ultimately, the dynamics of natural populations. The analysis of long-term monitoring data at the individual scale is often the only available approach to estimate reliably demographic parameters of vertebrate populations. We review statistical procedures used in these analyses to study links between climatic factors and survival variation in vertebrate populations.

We evaluated the efficiency of various statistical procedures from an analysis of survival in a population of white stork, Ciconia ciconia, a simulation study and a critical review of 78 papers published in the ecological literature. We identified six potential methodological problems: $(i)$ the use of statistical models that are not well-suited to the analysis of long-term monitoring data collected at the individual scale; (ii) low ratios of number of statistical units to number of candidate climatic covariates; (iii) collinearity among candidate climatic covariates; (iv) the use of statistics, to assess statistical support for climatic covariates effects, that deal poorly with unexplained variation in survival; (v) spurious detection of effects due to the co-occurrence of trends in survival and the climatic covariate time series; and (vi) assessment of the magnitude of climatic effects on survival using measures that cannot be compared across case studies. The critical review of the ecological literature revealed that five of these six methodological problems were often poorly tackled. As a consequence we concluded that many of these studies generated hypotheses but only few did provided solid evidence for impacts of climatic factors on survival or reliable measures of the magnitude of such impacts. 
We provide practical advice to solve efficiently most of the methodological problems identified. The only frequent issue that still lacks a straightforward solution was the low ratio of the number of statistical units to the number of candidate climatic covariates. In the perspective of increasing this ratio and therefore of producing more robust analyses of the links between climate and demography, we suggest leads to improve the procedures for designing field protocols and selecting a set of candidate climatic covariates. Finally, we present recent statistical methods with potential interest for assessing the impact of climatic factors on demographic parameters.

Key words: Bayesian modelling, birds, capture-mark-recapture, demography, effect size, information theory, statistics, mortality, mammals, null hypothesis testing, weather. 


\section{CONTENTS}

I. Introduction

II. Objectives of investigations of climatic impacts on vertebrate survival

III. Data characteristics

(1) Survival estimated from encounter histories

(2) Climatic covariates

IV. Procedures for assessing the potential impact of climatic factors on survival

(1) Defining structural reference models

(2) Building models relating survival to climatic factors

(3) Measuring statistical support for the effect of climatic factors

(a) The null hypothesis testing approach

(i) Conceptual framework

(ii) Setting the $\alpha$-level

(iii) The multiple test issue

(iv) Test statistics derived from fixed-effects models

(v) Test statistics derived from mixed-effects models

(b) Information-theoretic approach

(i) Conceptual framework

(ii) Criteria for identifying influential climatic factors

(c) Bayesian approach

(i) Conceptual framework

(ii) Criteria for identifying influential climatic factors

(d) Detecting influential climatic factors in the presence of temporal trends

(4) Performances of distinct statistical approaches for detecting potentially influential climatic factors from statistical support: a simulation study

(a) Methods

(b) Results

(c) Conclusions

(5) Measuring the magnitude of the effects of climatic factors

(a) Fraction of temporal variation accounted for by climatic factors

(b) Slopes

(c) Measures of magnitude for comparative studies

(6) Impact of climatic factors on white stork survival: conclusions

V. Discussion

(1) The limits of observational studies of impacts of climatic factors on vertebrate survival

(2) Improvement of the balance between the number of statistical units and the number of candidate climatic factors

(a) Field protocol design

(b) Selection of data sets used for documenting survival variation

(c) Selection of a set of climatic factors

(3) Better exploitation of statistical tools

(a) A priori power analyses

(b) Integrated modelling

(c) Cross validation

(d) Tools for addressing complex causal pathways

(e) Multi-model inference

(f) IT selection criterion for models including random effects

$(g)$ Incorporation of prior knowledge 
VI. CONCLUSIONS

VII. ACKNOWLEDGEMENTS

VIII. APPENDICES

(1) Case studies

(2) Bayesian modelling

IX. REFERENCES 


\section{INTRODUCTION}

The modifications of natural systems induced by the ongoing climate change is a major issue for human societies (Easterling et al., 2000; Clark et al., 2001; Hulme, 2005; King, 2005; Schlesinger, 2006; IPCC, 2007). Empirical investigations of the influences of climate change during the 20th Century on extinction rates (Thomas et al., 2004; Thomas, Franco \& Hill, 2006), range shifts (Harrington, Woiwod \& Sparks, 1999; Parmesan \& Yohe, 2003; Hays, Richardson \& Robinson, 2005; Thomas et al., 2006), population dynamics (Balmford, Green \& Jenkins, 2003; Forsman \& Mönkkönen, 2003) and ecosystem functioning ( Smith et al., 1999; Doran et al., 2002; Peñuelas, Filella \& Comas, 2002; Hays et $a l ., 2005)$ have developed rapidly over the last 10 years and have revealed important impacts on natural systems (Walther et al., 2002; Parmesan \& Yohe, 2003; Böhning-Gaese \& Lemoine, 2004; Hays et al., 2005; Parmesan, 2006).

Under realistic socio-economic scenarios, global warming will go on, possibly at a faster pace, at least until the end of the 21st Century and will result in dramatic changes in all regional climates (Easterling et al., 2000; IPCC, 2007). A major challenge for ecologists is the development of models to predict the resulting changes in species ranges and extinction risks (Clark et al., 2001; Hulme, 2005; Sutherland, 2006; Jetz, Wilcove \& Dobson, 2007). Until now, most predictive models have relied on a phenomenological (i.e. non-mechanistic) approach where the future range of a species is defined as the area(s) where climatic conditions in the future, as predicted by climate models, are similar to those prevailing in the current range of the species (Peterson et al., 2002; Thomas et al., 2004; Guisan \& Thuiller, 2005; Hartley, Harris \& Lester, 2006). However, models that explicitly integrate the processes through which climate influences population dynamics would be much more informative (Sæther, Sutherland \& Engen, 2004; Hulme, 2005; Sutherland, 2006). Process-based models have already been developed for predicting the future state of the vegetation component in 
terrestrial ecosystems (Kleidon \& Mooney, 2000; Chuine \& Beaubien, 2001; Guisan \& Thuiller, 2005; Moorcroft, 2006). To our knowledge there has yet been no attempt to build range prediction models based on processes for vertebrate species. A prerequisite for their development is to achieve an understanding of the influence of climatic factors on temporal variation of the demographic parameters underlying population dynamics (Coulson et al., 2001; Jenouvrier, Barbraud \& Weimerskirch, 2003; Dunn, 2004; Møller \& Merilä, 2004; Sæther et al., 2004; Ludwig et al. 2006; Sutherland, 2006).

Long-term monitoring data collected at the individual scale, mainly using capturemark-recapture (CMR) sampling either of live (Clobert, Lebreton \& Allainé, 1987; Lebreton et al., 1992; Sandercock, 2006) or dead individuals (Brownie et al., 1985), contain information on most demographic parameters: survival (Lebreton et al., 1992), transitions among reproductive states (Nichols, 1994; Viallefont, Cooke \& Lebreton, 1995; Cam et al., 1998), dispersal rates among study sites (Arnason, 1973; Brownie et al., 1993; Schwarz, Schweigert \& Arnason, 1993), recruitment rate of new breeders into a population (Clobert et al., 1994; Pradel, 1996; Pradel \& Lebreton, 1999, Nichols et al., 2000), and frequency of reproduction in species with intermittent breeding (Cam et al., 1998). Analysis of such data is an efficient, and often the only available, approach to estimate reliably demographic parameters in free-living animal populations (Nichols, 1992).

The aim of the present work is to review statistical procedures to address the impact of variation in climatic factors on survival of vertebrates through the analysis of monitoring data collected at the individual scale. We specifically focus on procedures aiming at $(i)$ detecting relationships between patterns of temporal variation in survival and in climatic covariates; (ii). evaluating the chance that such relationships result from pure coincidence or from genuine impacts of climatic factors on survival (i.e. evaluating statistical support); (iii) evaluating the impact of temporal variation in climatic factors on survival in the time period 
covered by the empirical data in hand (i.e. evaluating effect sizes). The statistical tools involved are regression-like models that in their basic form are routinely employed in ecological and evolutionary studies (Mitchell-Olds \& Shaw, 1987; Sokal \& Rohlf, 1995). However, their correct use is context-dependent. Relating variation in survival estimated from CMR data to variation in climatic factors implies avoiding a number of pitfalls that arise from the characteristics of these two types of data. Beyond the description of the procedures we thus aim to identify potential problems encountered in studies of climate impacts on survival and to provide practical advice to solve efficiently these problems.

We first present the objectives pursued in studies assessing the link between survival and climatic factors in vertebrate populations. Second, we summarize the properties of CMR and climatic data that must be carefully considered in order to carry out robust statistical analyses. Third, we present the main types of regression models and associated statistics that can be used to explore reliably the relationships between climatic factors and survival. In this section, results obtained from a simulation study are used to evaluate the performance of alternative procedures to assess statistical support. Fourth, we provide advice both for designing field protocols to collect survival data and for selecting sets of candidate climatic covariates. Finally, we present existing but seldom applied or recent statistical methods with potential interest for assessing the impact of climate change on demographic parameters.

Throughout the paper, the revisitation of an investigation by Kanyamibwa et al. (1990) of the relationship between climatic factors and adult survival of white storks Ciconia ciconia breeding in Baden-Württemberg (Germany), and a critical review of 78 papers published from 1985 to 2006 included in ecological journals referenced in Current Contents are used for illustrative purposes. These papers that address, through analyses of monitoring data at the individual scale, the influence of climatic factors on the survival of any age class in freeranging vertebrate were gathered from our personal bibliographical databases, and in the 
course of our routine survey of the literature. Although this survey of the ecological literature is neither exhaustive nor based on rigorous bibliographical methods; it certainly constitutes a large and representative sample of the articles treating our focal subject. We evaluated this reviewed literature globally, and referred to particular studies only when they illustrated proper use of statistical methods. The 78 reviewed papers are listed in Appendix 1 which summarizes the evaluation for each paper of potential pitfalls in the analysis. We hereafter refer to this set of reviewed papers as ESR (i.e. ecological studies reviewed). In all the ESR, as well as in all the analyses presented, correlations between climatic factors and survival were addressed. However, the methodological problems identified and the advice expressed here are relevant to investigations of relationships between climatic factors and any demographic parameter that can be estimated through the analysis of monitoring data collected at the individual scale.

\section{OBECTIVES OF INVESTIGATIONS OF CLIMATIC IMPACTS ON VERTEBRATE SURVIVAL}

In the present paper, we focus on the statistical modelling of monitoring data at the individual scale that aims ultimately at describing in the form of mathematical models the mechanisms through which climatic and other environmental and intrinsic factors generate temporal variation in survival in a focal vertebrate population (Burnham \& Anderson, 2002; Ginzburg \& Jensen, 2004; Johnson \& Omland, 2004; Hobbs \& Hilborn, 2006; Stephens, Buskirk \& del Rio, 2007). Such mathematical models can then be used to evaluate the relative importance of these various factors as drivers of temporal variation in survival and to predict the impacts of changes in the distribution (mean and variance) of these factors on survival. However, the possibility of reaching these objectives depends to a large extent on the quantity 
and quality of the information available on the processes generating temporal variation in survival prior to the initiation of the statistical analysis.

In roughly half of the $78 \mathrm{ESR}$, prior knowledge of the study system seemed good enough for the investigators to define a priori a limited set (i.e. less than five) of environmental (including climatic) candidate covariates that included the main drivers of temporal variation in survival (i.e. at least one of the models considered turned out to account for most of the variation in survival). In such situations, it is possible to evaluate the relative weight of evidence in the data for a limited number of models depicting a priori well-founded competing hypotheses about the processes through which temporal variation in climatic factors and other drivers induce temporal variation in survival (Burnham \& Anderson, 2002; Johnson \& Omland, 2004; Hobbs \& Hilborn, 2006; Stephens et al., 2007). Furthermore, it is possible to assess the relative importance of various drivers of variation in survival and to build predictive models with methods that account for uncertainty about processes when more than one model is strongly supported by the data (Burnham \& Anderson 2002; Hobbs \& Hilborn, 2006; Johnson \& Omland, 2004; Stephens et al., 2007). We will not focus on this type of situation because the relevant concepts and procedures have recently been described in detail (see Burnham \& Anderson, 2002 for a full treatment).

In the case of white storks breeding in Baden-Württemberg, little prior information is available on the processes generating temporal variation in survival. For instance, the causes of death are unknown, and so are the time of year when the highest mortality occurs and the relative importance of alternative food resources and climatic factors likely to influence the availability of these resources. Prior knowledge is limited to a series of demographic patterns reported in this and other Western European white stork populations. Like all Western European white stork populations, the studied population has declined sharply from the 1960s to the 1990s (Kanyamibwa et al., 1990). These declines have motivated investigations of the 
relative impact of climate variation in the wintering areas and on the breeding grounds on white stork population dynamics (Kanyamibwa et al., 1990; Schaub, Kania \& Köppen, 2005; Sæther et al., 2006). While the white stork population collapsed, the Sahel region experienced severe droughts (Grist \& Nicholson, 2001). As for several other bird species wintering in Western Africa (Cavé, 1983; Peach, Baillie \& Underhill, 1991; Cowley \& Siriwardena, 2005), a relationship between rainfall in the Sahel and adult survival of white storks has been detected (Kanyamibwa et al., 1990; Barbraud, Barbraud \& Barbraud, 1999). Furthermore, indications have also been obtained that local climate in breeding areas could influence the demography of Western European white stork populations (Schaub et al., 2005; Sæther et al., 2006). Based on this limited knowledge, many climatic factors can be considered as potential covariates of adult survival of storks. In addition, the shape of the relationship linking these potential climatic covariates to survival remains to be identified. Although most studies focused on linear relationships, quadratic relationships could occur if white storks perform best under average climatic conditions. The white stork survival is an exploratory analysis in which a set of potentially influential covariates is considered rather than a study that would allow challenging cautiously designed research hypotheses on the processes (including climatic forcing) that generate temporal variation in survival (Anderson \& Burnham, 2002; Robinson \& Wainer, 2002; Guthery et al., 2005; Stephens et al., 2005; Stephens et al., 2007). Our proximate aims are thus to detect relationships between patterns of temporal variation in survival and in candidate climatic covariates; to evaluate the chance that such relationships result from pure coincidence or from genuine impacts of climatic factors on survival (i.e. to evaluate statistical support); and to quantify, under the hypothesis of genuine effects, the impact of temporal variation in climatic factors on survival within the time period covered by the available data (i.e. to assess the potential biological significance). Ultimately, this type of study can help to generate hypotheses on the processes underlying the influence of climatic 
factors on survival (Robinson \& Wainer, 2002; Guthery et al., 2005; Stephens et al., 2005; Stephens et al., 2007). However, further evaluation of these hypotheses would imply either specifically designed experiments or analyses of independent data sets (Robinson \& Wainer, 2002; Roback \& Askins, 2005; Link \& Barker, 2006). In roughly half of the 78 ESR the investigators could not restrict the set of potential drivers of temporal variation in survival to less than five candidate covariates and/or failed to define a model that accounted for most of the temporal variation in survival. In the present paper, we emphasize the numerous and often poorly addressed issues arising in such exploratory studies. However, most of these issues are also relevant to situations where prior knowledge of the study system is good enough for confronting competing hypotheses about processes.

\section{DATA CHARACTERISTICS}

\section{(1) Survival estimated from encounter histories}

In a minority of the ESR (five out of 78), the field protocol consisted of nearly continuous monitoring of individuals by radio-tracking, and the information used in the analysis was the date of death. We will not present the statistical models for the analysis of such data but refer the reader to the excellent overview of the models and procedures for analysing continuous individual monitoring data provided in Murray (2006). In the majority (73 out of 78) of the ESR as well as in the Baden-Württemberg white stork population, one encounter history for each individual summarized the outcome (detected/not detected) of discrete capture occasions. Survival of white storks was thus estimated using specific statistical methods (hereafter referred to as CMR methods) in which the likelihood of the encounter histories of 321 individuals ringed as chicks and resighted at least once as adults was expressed as a function of survival and detection probabilities (Lebreton et al., 1992; Nichols, 1992; Williams, Nichols \& Conroy, 2002; Sandercock, 2006). This type of model must be used 
whenever the probability of detection of marked individuals is lower than 1. Statistical procedures that do not account for the probability that a marked individual remains undetected were used in only seven out of the 65 ESR relying on the analysis of CMR data.

Since survival is not measured directly in CMR studies, the value of a given survival probability is almost never known with certainty (survival estimates and associated confidence intervals for the white storks are displayed in Fig. 1) and the precision with which it is estimated has to be accounted for when investigating the factors underlying its variation (Clobert \& Lebreton, 1985). In only nine of the $78 \mathrm{ESR}$, was the precision of survival estimates ignored. Furthermore, survival and/or detection probabilities can vary among the individuals sampled. Heterogeneity among individuals in survival and/or detection probabilities can lead to biased survival estimates (Carothers, 1973, 1979; Buckland, 1982; Prévot-Julliard, Lebreton \& Pradel, 1998; Pledger, Pollock \& Norris, 2003). For instance, heterogeneity in detection probability can lead to underestimated survival, especially towards the end of the time series (Carothers, 1973, 1979) and can thus generate spurious temporal trends in survival estimates (Devineau, Choquet \& Lebreton, 2006). It is thus important to address heterogeneity among individuals, in particular with goodness-of-fit tests (see below), and, if necessary, to account for such heterogeneity when assessing the impact of climatic factors on survival.

As in all ESR reviewed, the white stork data were obtained from observations rather than from a strict experimental design. As a consequence, factors that might influence survival, but whose impacts are not considered worth investigating, could not be randomised or kept constant. Given these uncontrolled conditions, observed variation in survival estimates might come from the influence of multiple factors, some unsuspected by the investigator (Burnham \& Anderson, 2002; Schwarz, 2002). 
As in most of the ESR (63 out of 78), the time interval between two successive encounter occasions was one year in the stork study, so that any variation in survival at finer time scales could not be measured (but see Lahti et al., 1998; Lima et al., 2001; Conroy, Senar \& Domènech, 2002; Lima, Merrit \& Bozinovic, 2002; Piper, 2002; Tavecchia et al., 2002; Barbraud \& Weimerskirch, 2003; Sendor \& Simon, 2003; Hallet et al., 2004; Schaefer et al., 2006 for protocols on vertebrates permitting investigations at seasonal scales). Then, the number of points available to plot survival against climatic factors (i.e. the number of statistical units) is usually the number of years of monitoring. The white stork data set covered 16 years and thereby provided 16 estimates of annual survival (Fig. 1). Only six of the 78 ESR covered more than 30 years and thus provided $\geq 30$ estimates of annual survival (Catchpole et al., 1999; Peach, Siriwardena \& Gregory, 1999; Perdeck, Visser \& Van Balen, 2000; Grosbois \& Thompson, 2005; Jenouvrier, Barbraud \& Weimerskirch, 2005a; Altwegg et al., 2006). An important limitation when investigating relationships between survival and climatic factors is thus the usually small number of years.

\section{(2) Climatic covariates}

Local climate is expected to exert a strong, relatively direct influence on survival in wild populations (Newton, 1998). Numerous covariates such as temperature, air pressure, humidity, cloudiness, precipitation, wind direction and speed are needed for a thorough description of local climate. Furthermore several distinct critical periods and seasonal or monthly covariates may be relevant (Clobert \& Lebreton, 1985; Newton, Wyllie \& Rothery, 1992; Franklin et al., 2000; Cowley \& Siriwardena, 2005; Brouwer et al., 2006; Grosbois et al., 2006; Nevoux \& Barbraud, 2006) and local climatic factors in distinct geographic locations are important for migratory or highly mobile populations (e.g. Møller \& Szep, 2005; Schaub et al., 2005). Hence, assessing the relationship between local climate and survival 
requires considering large sets of covariates (e.g. Hallett et al., 2004; Catchpole et al., 1999; Grosbois et al., 2006; Kéry, Madsen \& Lebreton, 2006). Accordingly five or more candidate climatic covariates were considered in 22 out of the 78 ESR. The white stork example also illustrates the issue of having to deal with many candidate covariates. Based on results reported in the literature (Kanyamibwa et al., 1990; Barbraud et al., 1999; Schaub et al., 2005; Sæther et al., 2006), two geographic locations (the wintering and the breeding areas) and three periods of year (the wintering, the pre-breeding, and the breeding periods) have to be considered for a complete investigation of the influence of climatic factors on adult survival of white storks. Moreover, the wintering area (defined by the location of recoveries of dead white storks; Kanyamibwa et al., 1990) covers a wide area $\left(10^{\circ} \mathrm{N}-17^{\circ} \mathrm{N} 15^{\circ} \mathrm{W}-10^{\circ} \mathrm{E}\right)$ so that rainfall obtained from 15 weather stations needs to be considered. Finally, whereas rainfall is likely to be the most influential climatic factor in the Sahel area, we could not identify a priori the climatic covariate that was likely to be the most influential in the breeding area. As a consequence our initial set of covariates included 15 time series of rainfall for the Sahel region (see Table 1 for a list of the corresponding weather stations), two series (one for the pre-breeding period: March to May; and one for the breeding period: June to August) for rainfall in the breeding area (i.e. $6^{\circ} 50^{\prime}-9^{\circ} 50^{\prime} \mathrm{E} / 46^{\circ} 50^{\prime}-48^{\circ} 50^{\prime} \mathrm{N}$ ) and two series for temperature in the breeding area.

Teleconnection (i.e. remote connection) indices capture large spatial-scale patterns in climatic factors that result from global atmospheric and oceanic circulation phenomena (Hurrell, 1995; Holmgren et al., 2001; Ottersen et al., 2001; Stenseth et al., 2002, 2003). They are increasingly used in ecological studies as integrative proxies for local climate. Teleconnection indices have been considered as candidate covariates in 21 of the 78 ESR (Appendix 1). Such indices are correlated with numerous local climatic covariates over large geographic areas, although in different ways for different sites. Teleconnection indices are 
often noisy representations of the actual causal factors (Almaraz \& Amat, 2004), as also are local climatic covariates when they influence survival indirectly, e.g. through resource availability (Montevecchi \& Myers, 1997; Sæther, 1997; Durant, Anker-Nilssen \& Stenseth, 2003). To deal with the large uncertainty about which climatic factor was likely to be the most influential on breeding grounds for white stork survival, we included the pre-breeding season (i.e. March through May) and the breeding seasons (i.e. June through August) north Atlantic oscillation (NAO) in the set of candidate covariates. We also included December through March NAO (hereafter referred to as WNAO) because, with its large geographic coverage and its integrative nature, it was likely to reflect the climatic conditions encountered during the return trip from the wintering grounds.

Although interdependency among candidate climatic covariates is to be expected, it is not systematically addressed in ecological studies. It has indeed been investigated in only 19 of the 62 ESR where several climatic covariates have been considered. In more than half of these studies, relationships among covariates have been detected (e.g. Clobert \& Lebreton, 1985; Newton et al., 1992; Catchpole et al., 1999, 2000; Loison, Jullien \& Menaut, 1999; Franklin et al., 2000; Loison et al., 2002; Tavecchia et al., 2002; Grosbois et al., 2006; Jenouvrier, Barbraud \& Weimerskirch, 2006; Kéry et al., 2006; Traylor \& Alisauskas, 2006). In the white stork study case, we detected substantial correlations among rainfall records from the different meteorological stations in the Sahel region [Pearson correlation coefficient $(r)$ : mean for 105 pairs of rainfall time series: 0.34, for 24 out of 105 pairs $r>0.50$ ] suggesting that the mechanisms that drive interannual fluctuations of rainfall operate at large spatial scales. Furthermore, the three factors reflecting climatic conditions during both pre-breeding and breeding periods in the white stork study were intercorrelated (Table 2). Such correlations among distinct local climatic covariates in a same location reflect to some extent the 
occurrence of different types of weather (e.g. in the white stork study: warm, dry and high NAO versus cold, wet and low NAO).

At this stage of the white stork study, we are confronted with a typical situation in empirical studies of climate influences on demography in free-ranging vertebrate populations. Limited knowledge of the system did not allow us to identify a limited set of candidate climatic factors, so we were left with 22 different covariates, some of which were strongly intercorrelated. Using the whole set of candidate covariates cannot be recommended for two reasons. First, the large number of covariates $(J=22)$ raises the classical multiple test problem leading to an inflated probability of detecting spurious correlations (Type I error) (Garcia, 2004; Rice, 1989; Roback \& Askins, 2005). Second, the interdependence among explanatory covariates (hereafter referred to as multi-collinearity) is known to hamper model selection, parameter estimation, and the interpretation of results in regression analyses (Draper \& Smith, 1981, pp. 327-332; Graham, 2003; Neter et al., 1996). Several measures exist to assess the degree to which multi-collinearity affects parameter estimates (Neter et al., 1996), and once the problem has been detected a strategy is required to cope properly with this issue. It is possible to address simultaneously the multiple test and the multi-collinearity issues by building packages combining several intercorrelated climatic variables. Such integrative measures have been used in few of the ESR. However, whenever this has been done, the detection and the quantification of the impacts of climatic fluctuation on survival have been thoroughly achieved (see e.g. Gaillard et al., 1997; Jorgenson et al., 1997; Singer et al., 1997; Loison \& Langvatn, 1998; Loison et al., 1999; Garel et al., 2004; Grosbois et al., 2006; Gunnarsson et al., 2006; Jenouvrier et al., 2006; Kéry et al., 2006; Traylor \& Alisauskas, 2006). For the white stork survival analysis, we combined intercorrelated climatic variables by performing three distinct Principal Component Analyses (PCA), one on the 15 Sahel rainfall time series, one on the three climatic factors for the pre-breeding season and 
one on the three climatic factors for the breeding season. Principal Components (PC) are uncorrelated linear combinations of the original covariates that can be interpreted as synthetic climatic covariates (Draper \& Smith, 1981, pp. 327-332; Graham, 2003). Here, we retained the first and second PCs for Sahel rainfall which accounted for $42 \%$ and $12 \%$ of the variation recorded at the 15 stations, respectively; and the first $\mathrm{PC}$ for the pre-breeding and breeding seasons, which accounted for 66 and $68 \%$ of the variation in the corresponding original climatic covariates. The first Sahel rainfall PC was positively correlated with rainfall for all the stations considered but the two southernmost ones, while the second PC was correlated positively with rainfall in the two southernmost stations (Fig. 2A). Although the second PC accounted for a relatively low fraction of total variation in the Sahel rainfall series, we retained it for rainfall in the two southernmost Sahel stations to be represented in the set of candidate climatic covariates. Indeed, when using PCA-derived indices, variables that could be of biological importance may not be well accounted for by the first component (i.e. the component that contribute the most to total variation). It is thus important to select candidate covariates among PCs not only based on their contribution to total variation but also in such a way that all original covariates are well represented in the set of candidate covariates. The two PCs derived from the analysis of the Sahel rainfall series will hereafter be referred to as CNSRF (central and northern Sahel rainfall) and SSRF (southern Sahel rainfall), respectively. The PCs retained for the pre-breeding season and breeding seasons both correlated positively with temperature and NAO and negatively with rainfall (Fig. 2B, C). These two PCs thus reflected the occurrence in the breeding area of years with warm and dry local conditions associated with high NAO and of years with cold and wet conditions associated with low NAO. They will hereafter be referred to as PBSC (pre-breeding season climate) and BSC (breeding season climate). In this example, PCA applied to a large set of interdependent variables generated few easily interpretable and uncorrelated integrative covariates (Table 2; 
Fig. 2). Non-weighted sums or averages over sets of climatic variables have sometimes been used in ecological studies as synthetic climatic covariates (e.g. Gunnarsson et al., 2006). However, unlike PCA, such procedures do not generate a set of independent (uncorrelated) synthetic covariates. Furthermore, as illustrated with the white stork example, PCA allows combining variables of different nature (here temperature, rainfall and NAO; Fig. 2B, C) that would be difficult to sum or average otherwise. We thus advocate using PCA analyses as a more efficient way of combining climatic variables than simply summing or averaging them.

A last characteristic of climatic variables that deserves caution and that results from natural patterns of variability as well as from greenhouse effect forcing is that they often present marked linear or quadratic temporal trends over time series covering a few decades within the 20th Century (Stenseth et al., 2003). Such trends have been addressed in only 12 out of the 78 ESR and detected in at least four of these (e.g. Kanyamibwa et al., 1990; Grosbois \& Thompson, 2005; Chamaillé-Jammes et al., 2006; Nevoux \& Barbraud, 2006). Within the set of candidate climatic covariates retained as potentially influencing white stork survival, CNSRF showed a marked decreasing trend over the study period (Table 3, Fig. 3).

\section{PROCEDURES FOR ASSESSING THE POTENTIAL IMPACT OF CLIMATIC FACTORS ON SURVIVAL}

Once a set of candidate covariates has been defined, the investigation of temporal variation in survival and of the factors underlying it can be initiated. In a first step, structural models, i.e. models that do not include any external covariate, are explored with the aim of defining one or a few reference models that describe satisfactorily temporal variation in survival without any hypothesis about the factors underlying it. These reference models can be used to quantify temporal variation in survival. Furthermore, the models considered in subsequent steps of the analysis will be evaluated against the reference models. In a second step, ultra- 
structural models where variation in survival is related to climatic drivers are built. Finally, both the structural reference models and the ultra-structural models including covariate effects are used to identify the climatic factors that potentially influence survival and to quantify their potential impact. Two important, complementary criteria are involved in this final step of the analysis: the statistical support for an effect of a climatic factor on survival and the estimated magnitude of this effect (Yoccoz, 1991; Nakagawa \& Cuthill, 2007). Below, we use the white stork survival analysis and a simulation study to describe and evaluate the models, procedures and statistics involved in each of these three steps.

\section{(1) Defining structural reference models}

The first step in investigating variation in survival of white storks involved selecting a structural model as parsimonious as possible and still providing an adequate description of the pattern of temporal variation in survival. The appropriate CMR methods are now well-known (Lebreton et al., 1992; Williams et al., 2002; Sandercock, 2006). Furthermore, these methods are implemented in user-friendly programs such as MARK (White \& Burnham, 1999) and MSURGE (Choquet et al., 2004). As a consequence, methods applied for building CMR models in ecological studies are most often correct (this was the case in 65 of the 73 ESR where CMR data were analysed). We thus provide a minimal description of these methods below and refer readers to Lebreton et al. (1992), Williams et al. (2002), and Sandercock (2006) for more details. Observed numbers of all possible individual histories are assumed to be observations from multinomial distributions with cell probabilities depending on survival and detection parameters (denoted $\phi$ and $p$, respectively). A model is defined that relates, via a link function denoted $f$, the variation in survival and detection parameters to variation in categorical factors and/or continuous covariates. Once a model has been defined, survival and detection parameters are estimated by maximizing the likelihood under the constraints 
imposed by this model. Let us denote this likelihood $L\langle\underset{\sim}{\theta}| I M_{-}$data $\rangle$where $\underset{\sim}{\theta}$ represents the vector of parameters in the model, and $I M \_d a t a$ the individual monitoring data. Reliable inference can be drawn from a model only if a number of assumptions of homogeneity within and among encounter histories are verified (Lebreton et al., 1992). Goodness-of-fit tests (hereafter referred to as GOF tests) implemented in programs such as MARK (White \& Burnham, 1999) and U-CARE (Choquet et al., 2005) allow checking that these assumptions are met. Along with each model comes its relative deviance: $D e v=-2 \log L\langle\underline{\underline{\theta}}| I M_{-}$data $\rangle$; an important statistic that measures the discrepancy between the predictions of the model and the observations. The lower the Dev, the lower the discrepancy. Other useful statistics are the Akaike Information Criterion $(A I C=D e v+2 K$ where $K$ is the number of estimable parameters in the model, and its variants (i.e. AIC c, QAIC and QAICc; Burnham \& Anderson, 2002). AIC is used in the information theoretic approach to quantify the adequacy of a model in terms of an optimal compromise between prediction bias and parameter uncertainty (Burnham \& Anderson, 2002, p. 62; see below). The lower the AIC of a model, the better the compromise. Using the methods briefly presented above, we defined a starting model to describe variation in white stork survival and detection probability that was general enough for the assumptions underlying CMR models to be met (Lebreton et al., 1992). We chose the logit link function because it ensures obtaining survival estimates in the interval $[0 ; 1]$. The Cormack-Jolly-Seber model $\left[\phi\left(F_{t}\right) ; p\left(F_{t}\right)\right.$; see Table 4 for a description] including fully timedependent survival and recapture probabilities (Lebreton et al., 1992) did not significantly depart from the assumptions underlying CMR models $\left(\chi^{2}{ }_{42}=38.2, P=0.64\right)$. This model was thus used as a starting point (Tables 4, 5). Then, using AICc (i.e. the small-sample-corrected version of the $A I C$ ), this starting model was compared to models where recapture probability and/or survival were constant $\left[p\left(F_{c s t}\right)\right.$ or $\left.\phi\left(F_{c s t}\right)\right]$ and to models where survival varied through 
time according to a linear or a quadratic trend [hereafter denoted as $\phi\left(F_{T}\right)$ and $\phi\left(F_{T_{-} q}\right)$; Tables 4,5$]$. The model including constant recapture probability and time-dependent survival had the lowest $A I C c$ (model $\phi\left(F_{t}\right) ; p\left(F_{c s t}\right)$; Table 5, Fig. 1). In all subsequent models recapture probability was therefore kept constant and the model where survival was timedependent (model $F_{t}$ ) was subsequently used as a reference model. Models $\phi\left(F_{T}\right) ; p\left(F_{c s t}\right)$ and $\phi\left(F_{T_{-} q}\right) ; p\left(F_{c s t}\right)$ had relatively large $A I C c$ as compared to that of model $\phi\left(F_{t}\right) ; p\left(F_{c s t}\right)$. This indicates that survival of white storks did not show any clear linear or quadratic trend over time. In the reference model $F_{t}$, time appears as a fixed effect in the sense that a distinct parameter $a_{i}$ is estimated for each time interval. This type of fixed time effect model was the most often employed in the ESR to characterize temporal variation in survival (66 out of 78 studies). Alternatively, in a less often used type of model (12 out of the 78 studies), time was treated as a random effect $\varepsilon_{i}$ (model denoted as $R_{t}$; Table 4), which is assumed to follow a normal distribution on a logit scale with mean 0 and variance $\sigma^{2}$ (e.g. Milner, Elston \& Albon, 1999; Franklin et al., 2000; Loison et al., 2002; Harris et al., 2005; Jenouvrier et al., 2005a, 2006; Sandvik et al., 2005; Schaub et al., 2005). The parameters of interest are now the mean of $f\left(\phi_{i}\right): a$; and the temporal process variance in $f\left(\phi_{i}\right): \sigma^{2}$ (Gould \& Nichols, 1998; Burnham \& White, 2002). The estimates $\hat{a}$ and $\hat{\sigma}^{2}$ can be obtained using procedures for building Generalized Linear Mixed Models (GLMM) in a frequentist framework (McCullagh \& Nelder, 1989; Gould \& Nichols, 1998; Burnham \& White, 2002). Alternatively, estimates can also be derived using a Bayesian framework where survival for a given interval is explicitly considered as a realization of a random process (Barry et al., 2003; Link \& Barker, 2004; Gimenez et al., 2008). None of the ESR used this last option. 


\section{(2) Building models relating survival to climatic factors}

In nine of the $78 \mathrm{ESR}$, survival estimates from structural CMR models such as model $F_{t}$ were treated as quantities known with certainty and used in linear regression models to assess relationships with climatic covariates. Such a procedure, that consists in doing statistics on statistics, is misleading because it fails to account adequately for the sampling variability of the survival estimates (Clobert \& Lebreton, 1985; Link \& Barker, 2004). A better and actually much more often used approach is to build and fit ultrastructural CMR models relating variation in survival to that of climatic or other continuous covariates. Two types of model can be fitted. Fixed-effects models of type $F_{c o}$ (Table 4) are the most often used (68 out of 78 ESR). In such models, $f\left(\phi_{i}\right)$ in the time interval $i$ is related to the value $x_{i}$ of the climatic covariate $x$. Two (or three for quadratic relationships) parameters denoted $a, b$ (and $c$ ) are required in model $F_{c o}$ to describe the relationship between survival and the climatic covariate $x$. In model $F_{c o}$, it is implicitly assumed that survival variation over time is entirely determined by the variation observed in the climatic covariate. In a less often used alternative to model $F_{c o}$ (11 out of 78 ESR), this assumption is relaxed and time variation in $f\left(\phi_{i}\right)$ not accounted for by the fixed effect of the climatic covariate $x$ is accounted for by a random effect $\varepsilon_{i}$ (model $R_{c o}$; Table 4) which follows a normal distribution $N\left(0, \sigma^{2}\right)$ (e.g. Franklin $e t$ al., 2000; Gauthier et al., 2001; Loison et al., 2002; Altwegg et al., 2003, 2006; Schaub et al., 2005; Sandvik et al., 2005). $\sigma^{2}$ is the residual process variance reflecting variation over time in $f\left(\phi_{i}\right)$ that is not accounted for by the relationship with the climatic covariate. As for the random-effects model $R_{t}$, the estimates $\hat{a}, \hat{b}, \hat{c}$ and $\hat{\sigma}^{2}$ can either be approximated using a frequentist framework (Gould \& Nichols, 1998; Mc-Culloch \& Searle, 2001) or derived in a Bayesian framework (Brooks et al., 2002; Barry et al., 2003; Link \& Barker, 2004; Gimenez et al., 2008). However, the Bayesian technique is still underused in ecological studies (none of the 78 ESR). 
In our analysis of white stork survival, we built and fitted all models of type $F_{c o}$ and $R_{c o}$ including only the linear or the quadratic effect of one of the five candidate climatic covariates at a time. Each candidate covariate was standardized so that the mean and variance over its time series were set to 0 and 1 , respectively. We used the program MARK (White $\&$ Burnham, 1999) to fit all models required but the models built in a Bayesian framework, which were implemented using Markov chain Monte Carlo (MCMC) methods with program WinBUGS (Spiegelhalter et al., 2002; see Appendix 2 for details). Note that program MSURGE (Choquet et al., 2004) could also be used. Parameter estimates obtained in the white stork survival analysis for the models introduced above are displayed in Table 6.

\section{(3) Measuring statistical support for the effect of climatic factors}

In studies of climate impacts on vertebrate survival, the identification of factors that might noticeably influence survival is most often undertaken based on various measures of statistical support (i.e. probabilities involving the data in hand and hypotheses). This was the case in 73 of the $78 \mathrm{ESR}$. In the five remaining studies the identification of potentially influential covariates has been undertaken on the grounds of estimated effect sizes. Two inferential approaches have so far been adopted in the ecological literature to assess statistical support: null hypothesis testing (in 40 out of 73 studies) and information theory (in 33 out of 73 studies). Bayesian inference provides a third approach that has great potential but has been applied in none of the 78 ESR. These approaches differ with respect to the probabilities that are considered in order to identify influential climatic covariates. However, irrespective of the chosen approach, the objective pursued is always to maximize the probability of identifying covariates that actually exert a genuine influence on survival (i.e. to maximize statistical power) while minimizing the probability of concluding that a covariate influences survival when it actually has no effect (i.e. minimizing type I error). In what follows we present, for 
each of the three approaches, the underlying conceptual framework and their application. Then we present the results of a simulation study where the performance of these distinct approaches in terms of maximization of the statistical power and minimization of type I error is evaluated.

\section{(a) The null hypothesis testing approach}

(i) Conceptual framework

In the null hypothesis testing approach (hereafter referred to as the NHT approach), a socalled null hypothesis (hereafter referred to as $H_{0}$ ) is first defined. This hypothesis stipulates that the focal climatic covariate has no effect on survival. Then, the value of a test statistic of known distribution under $H_{0}$ is computed for the data in hand. The probability under $H_{0}$ of a data set yielding a value of the test statistic as extreme as or more extreme than the one obtained with the data in hand is computed from the known distribution of the test statistics. This probability corresponds to the probability of the data in hand or of even more extreme events if the null hypothesis is true. It is referred to as the observed $P$-value, and is compared to a predefined threshold (referred to as the $\alpha$-level), usually set at 0.05 . If the observed $P$ value is lower than the $\alpha$-level, the null hypothesis that the focal climatic covariate has no influence on survival is rejected with the probability that this hypothesis is indeed correct being equal to $\alpha$. Although it is conceptually incorrect to do so (e.g. Cohen, 1994; Anderson, Burnham \& Thompson, 2000), this outcome is always interpreted in ecological studies as tacit support for the alternative hypothesis that the focal climatic covariate influences survival. If the observed $P$-value is higher than the $\alpha$-level, no conclusion can be drawn. The pitfalls associated with the application of this procedure have been the subject of extensive discussions and we refer readers to the literature for presentations of these issues [e.g. Yoccoz, 1991; Cohen, 1994; Anderson et al., 2000; Johnson, 2002; Robinson \& Wainer, 
2002; Stephens et al., 2005; Hobbs \& Hilborn, 2006; a list of more than 400 references can also be found at http://warnercnr.colostate.edu/ anderson/thompson1.html (accessed 18 February 2008)].

(ii) Setting the $\alpha$-level

In almost all of the 40 ESR studies using the NHT, no $\alpha$-level was explicitly determined $a$ priori. Most often, observed $P$-values were confronted to a conventional interpretation scale: it was usually considered that $P>0.1$ indicates non significant effects; $0.1>P>0.05$ indicates nearly significant effects; $0.05>P>0.01$ significant effects and $P<0.01$ highly significant effects. This approach stems from the initial conception of the NHT procedure as an exploratory tool (Stephens et al., 2007; Robinson \& Wainer, 2002; Garcia, 2004; Roback \& Askins, 2005). Relying on mere convention for the interpretation of the outcome of a null hypothesis test is not a major drawback as long as one considers that truly solid knowledge comes from repeated confirmation from numerous studies. From this point of view, the objective pursued in the NHT approach is to decide whether or not further experiments intending at falsifying the null hypothesis are worth undertaking. However, as pointed out by many authors (e.g. Yoccoz, 1991; Anderson et al., 2000), the explicit definition of an $\alpha$-level is necessary for a rigorous application of the NHT and deserves careful consideration, even in exploratory contexts. The conclusion of a null hypothesis test is extremely sensitive to the choice of the $\alpha$-level. The decision regarding the value to which it is set is consequently crucial (Field et al., 2004). The probability of a type I error and the statistical power (i.e. the probability of rejecting $H_{0}$ when it is indeed false) are linked by a trade-off. As a consequence, setting $\alpha$ to an extremely low value and thereby insuring an extremely low risk of making type I errors results in decreasing considerably the statistical power for detecting genuine climatic effects. Furthermore, the power for detecting a genuine climatic effect of a 
given magnitude decreases as the size of the sample (usually the number of study years in analyses of climate impact on survival of vertebrates) decreases. Small sample sizes (i.e. low number of study years) should thus motivate researchers to set $\alpha$ to a relatively large value (Yoccoz, 1991; Lebreton et al., 1992; Field et al., 2004). Finally, in exploratory and descriptive studies, achieving a relatively high power should be considered as more important than keeping at a low level the risk of concluding mistakenly that a covariate influences survival. After all, exploratory analyses aim at generating working hypotheses that should anyway be later evaluated, either experimentally or based on the analysis of independent empirical data, for a robust conclusion to be drawn (Robinson \& Wainer, 2002; Roback \& Askins, 2005; Link \& Barker, 2006). So it is not of prime importance that all hypotheses generated in an exploratory analysis get strong statistical support. Given the low sample size in the white stork data set and the exploratory character of the study, we thus set $\alpha$ to 0.20 instead of the conventional level of 0.05 .

(iii) The multiple test issue

In 49 of the 78 ESR, several candidate climatic variables were considered. When a dependent variable such as survival is subjected to a series of null hypothesis tests each of which intends at detecting the effect of a distinct climatic covariate, the probability of erroneously rejecting at least one null hypothesis exceeds the $\alpha$-level and increases as the number of tests increases (Rice, 1989). Although this inflation of type I error and the procedures to prevent it are well known (Moran, 2003; Garcia, 2004; Roback \& Askins, 2005), such procedures have been applied in only two of the 49 ESR considering several candidate covariates (Jenouvrier et al., 2003; Hallet et al., 2004). The issue has been mentioned but not dealt with in an additional six ESR (Clobert et al., 1988; Newton et al., 1992; Catchpole et al., 2000; Jones, Hunter \& Robertson, 2002; Grosbois et al., 2006; Møller \& Szep, 2005). In these studies the authors 
mentioned that due to the absence of correction for multiple tests the climate impacts detected should be considered with caution.

In the analysis of white stork survival we applied the procedure that sets at the $\alpha$-level the expected proportion of erroneously rejected null hypotheses among all the rejected null hypotheses (i.e. it controls the false discovery rate; Benjamini \& Hochberg, 1995). We chose this procedure rather than the well-known sequential Bonferroni approach because it incurs a less dramatic loss of statistical power (Moran, 2003; Garcia, 2004; Roback \& Askins, 2005). As proposed by Wright (1992) we corrected the observed $P$-values and compared these corrected values to 0.20 , the $\alpha$-level we chose.

(iv) Test statistics derived from fixed-effects models

When, as in the white stork survival analysis, model $F_{t}$ satisfactorily fits the data, statistical support for the effect of a covariate can be assessed by comparing deviances among fixedeffects models $F_{c s t}, F_{c o}, F_{t}$ [see Lebreton et al. (1992) for situations where model $F_{t}$ shows lack of fit]. The likelihood ratio test ( $L R T)$ allows assessing the fit of the covariate model relative to that of the time-dependent model:

$$
L R T_{c o / t}=\operatorname{Dev}\left(F_{c o}\right)-\operatorname{Dev}\left(F_{t}\right)
$$

$L R T_{c o / t}$ tests the null hypothesis of absence of variation in survival over time unexplained by the effect of the climatic covariate in $F_{c o}$. It follows asymptotically under $H_{0}$ a chi-squared distribution with $n-J$ degrees of freedom where $n$ is the number of survival estimates obtained from model $F_{t}$ and $J$ the number of parameters required to describe the relationship between survival and the focal climatic covariate. Whatever the covariate and shape considered, residual unexplained variation was detected by $L R T_{c o / t}$ in the white stork survival analysis (Table 7) 
Had the examination of $L R T_{c o / t}$ revealed the absence of residual unexplained variation in a model of type $F_{c o}, L R T$ between that model and the constant model $F_{c s t}$ could have been used to assess the statistical support for the effect of the climatic covariate in $F_{c o}$ (Lebreton $e t$ al., 1992):

$$
L R T_{c s t / c o}=\operatorname{Dev}\left(F_{c s t}\right)-\operatorname{Dev}\left(F_{c o}\right)
$$

$L R T_{c s t / c o}$ tests the null hypothesis $H_{0}$ that the climatic covariate in $F_{c o}$ has no effect on survival. It follows asymptotically under $H_{0}$ a chi-squared distribution with $J$-1 degrees of freedom.

In the analysis of stork survival, the presence of residual unexplained variation in survival after accounting for the effects of climatic covariates prevented us from using this statistic. Instead, the assessment of the fit of the covariate model relative to that of both the constant and the time-dependent models was required (Skalski, Hoffmann \& Smith, 1993; Skalski, 1996). The method used to derive this statistic is referred to as ANODEV by analogy to ANOVA. The statistics Ftest $t_{\text {cst/co/t }}$ :

$$
\text { Ftest } t_{\text {st } / c o / t}=\frac{\left(\frac{\operatorname{Dev}\left(F_{c s t}\right)-\operatorname{Dev}\left(F_{c o}\right)}{J-1}\right)}{\hat{c}}
$$

where $\hat{c}=\frac{\operatorname{Dev}\left(F_{c o}\right)-\operatorname{Dev}\left(F_{t}\right)}{n-J}$ is an estimate of variance inflation in model $F_{c o}$, tests the null hypothesis $H_{0}$ that the climatic covariate in $F_{c o}$ has no effect on survival. It follows under $H_{0}$ a Fisher-Snedecor distribution with $J-1$ and $n$ - $J$ degrees of freedom. Using the statistics Ftest $_{c s t / c o / t}$ in the white stork survival analysis and applying the procedure proposed by Benjamini \& Hochberg (1995) for dealing with the multiple tests issue, none of the null hypotheses could be rejected at the false discovery rate of $20 \%$ (Table 7).

In 16 of the 40 ESR using the NHT approach, no residual temporal variation in survival was detected, so that $L R T_{c s t / c o}$ or Ftest $t_{c s t / c o / t}$ could indifferently be used to assess the 
statistical support for the covariates in model $F_{c o}$. In the 24 other studies, residual variation was either detected (five instances) or not investigated (19 instances) so that Ftest $t_{c s t / c o / t}$ would have been required to assess the statistical support for the covariates in model $F_{c o}$. In five of these 24 studies, $L R T_{\text {cst/co }}$ was used instead, which can lead to a high probability of selecting spurious effects (Skalski et al., 1993; Skalski, 1996).

(v) Test statistics derived from mixed-effects models

Although it is uncommon to do so (this option was adopted in only one out of the 78 ESR; Milner et al. 1999), the statistical support for the linear effect of a climatic covariate can be assessed using the mixed-effects model of type $R_{c o}: \hat{b}$, the normally distributed estimator of the slope of the relationship with the climatic covariate and, $\sigma(\hat{b})$, its estimated standard error can be used to build a test statistic under Wald's procedure (Mc-Culloch \& Searle, 2001, p. 24). The statistic:

$$
W\left(R_{c o}\right)=\left(\frac{b}{\hat{\sigma}(b)}\right)^{2}
$$

tests the null hypothesis $H_{0}: b=0$. It follows under $H_{0}$ a Fisher-Snedecor distribution with 1 and $n$-2 degrees of freedom (Mc-Culloch \& Searle, 2001, p. 24). Note that the square root of $W\left(R_{c o}\right)$ follows under $H_{0}$ a Student's t-distribution with $n$ - 2 degrees of freedom. Using the statistics $W\left(R_{c o}\right)$ and applying the Benjamini \& Hochberg's procedure, none of the null hypotheses of absence of linear relationships could be rejected at the false discovery rate of $20 \%$ in the white stork survival analysis (Table 7). Unfortunately, we could not apply the same procedure for quadratic relationships because a statistical tool is lacking to assess the statistical support for a quadratic relationship between survival and a climatic covariate from a mixed-effects model of type $R_{c o}$. 


\section{(b) Information-theoretic approach}

\section{(i) Conceptual framework}

While the NHT approach focuses on the evaluation of dichotomous hypotheses, the information-theoretic approach (hereafter referred to as the IT approach) allows simultaneous comparisons of a multitude of models within an a priori defined candidate set (Burnham \& Anderson, 2002). Several criteria are available for ranking models in the IT approach (Link \& Barker, 2006; Buckland, Burnham \& Augustin, 1997). The Akaike Information Criterion $(A I C=D e v+2 K$ where $K$ is the number of estimable parameters in the model, see Burnham \& Anderson, 2002) assumes that 'truth' is high-dimensional and thus impossible to depict with a mathematical model (Anderson \& Burnham, 2002), which is pertinent in the context of demographic studies in free-ranging vertebrate populations. Indeed, AIC has been used in all of the 33 ESR using the IT approach. AIC allows ranking competing models by measuring the quality of a model in terms of an optimal compromise between prediction bias and parameter uncertainty, or, equivalently, between underfitting and overfitting (Burnham \& Anderson, 2002, p. 62). The lower the $A I C$ of a model is, the closer to optimality is this compromise, and the better is the approximation provided by the model of the high-dimensional reality (Burnham \& Anderson, 2002, p. 62). Differences in AIC among models are usually used as criteria for model selection. Accordingly, these statistics have been used to identify potentially influential climatic covariates in 30 out of the 33 ESR using the IT approach. A simple and widely used rule of thumb has been proposed by Burnham \& Anderson (2002, pp. 70-72) and allows interpreting the difference in $A I C$ between two models in terms of relative support in the data for each of these two models. If two models differ by less than two AIC points, they can be considered as getting roughly identical support from the data. On the other hand, the lower AIC model can be considered as clearly better supported by the data when the AIC difference is greater than two points. Although this rule of thumb is somewhat arbitrary, 
it has been shown to perform satisfactorily for model and covariate selection (Richards, 2005) and it has been used in most of the ESR using AIC differences (20 out of 30 ESR; the 10 other studies used minimum $A I C$ as a covariate selection criterion). We thus applied this criterion for the identification of potentially influential climatic covariates in the white stork survival analysis (see below).

Another useful statistic derived from AIC, introduced by Buckland et al. (1997) and evaluated by Richards (2005) and Link \& Barker (2006) is the AIC weight of a model (see also Burnham \& Anderson, 2002, p. 75). It quantifies the strength of evidence in the data for that model relatively to that of all the other models in the candidate set (i.e. the sum of weights over a set of candidate models is 1 ). It is proportional to the probability of the model given the data. It is consequently considered as useful, especially for producing multi-model inferences that account for model selection uncertainty. It can also been used to evaluate the evidence ratio of two alternative models. Although AIC weights were provided for illustrative purposes in some of the studies we reviewed, they have so far rarely been used as a decisive criterion for the identification of potentially influential climatic covariates in studies of survival in vertebrate populations (only three out of the 33 ESR using the IT approach; Piper, 2002; Barbraud \& Weimerskirch, 2003; Traylor \& Alisauskas, 2006). Furthermore their performances for model selection are in need of evaluation (e.g. Richards, 2005; Link \& Barker, 2006). We thus did not use $A I C$ weights as decisive criteria for the identification of potentially influential climatic covariates in the white stork survival analysis. However, we computed the evidence ratio relative to the constant survival model $F_{c s t}$ for each candidate covariate model considered.

(ii) Criteria for identifying influential climatic factors 
As in most of the ESR using the IT approach, we considered the effect of a focal climatic covariate on white stork survival as statistically supported when the model $F_{c o}$ was at least as well supported as the general model $F_{t}$ and better supported than the baseline model $F_{c s t}$ (Anderson \& Burnham, 2002; Burnham \& Anderson, 2002; Guthery et al., 2005). Assuming that two models can be considered as differently supported by the data when their AIC differs by more than two points (see above), we considered that the effect of the climatic covariate included in the model $F_{c o}$ was statistically supported if $\Delta_{c o / c s t}<-2$ and $\Delta_{c o / t} \leq 2$ where $\Delta_{c o / c s t}=$ $\operatorname{AIC} c\left(F_{c o}\right)-\operatorname{AICc}\left(F_{c s t}\right)$ and $\Delta_{c o / t}=A I C c\left(F_{c o}\right)-A I C c\left(F_{t}\right)$. Furthermore, we considered that quadratic effects were statistically supported when the inclusion of the quadratic term to a model including the linear term for the same candidate covariate resulted in a drop in AICc of at least two points. Applying these criteria in the white stork example resulted in concluding that the linear effect of CNSRF and the quadratic effect of PBSC were statistically supported (Table 7).

(c)Bayesian approach

(i) Conceptual framework

While the classical approach assumes that the parameters are fixed and have unknown values to be estimated, Bayesian inference relies on the a posteriori distribution of the parameters. This distribution is obtained via the Bayes' theorem, through a process updating the a priori distribution of the parameters, using the information in the data, which is summarized by the likelihood. The prior distribution captures the expert's knowledge about the system before collecting data. If there is no strong prior information on the parameters, vague priors are usually assigned to the parameters, such as uniform distributions between 0 and 1 for probabilities. Because mark-recapture models often have many parameters, the joint posterior distribution is high-dimensional and cannot be easily displayed. Therefore we need to 
summarize this information under the form of interpretable point estimates (posterior means or medians) and uncertainty intervals (credibility intervals). This process involves calculating multi-dimensional integrals, which is circumvented by using Markov chain Monte Carlo (MCMC) simulations. This class of algorithms is based on building a Markov chain with stationary distribution equal to the posterior distribution of interest. Once the chain has converged, its realisations can be regarded as a dependent sample from the posterior distribution, and standard Monte Carlo integration can be carried out to obtain numerical summaries of focal parameters.

The development of the MCMC machinery along with the availability of powerful personal computers has led to an increasing number of Bayesian applications in ecology (Ellison, 2004; Clark, 2005; McCarthy, 2007), the analysis of mark-recapture data making no exception (Link \& Barker, 2004; Gimenez et al., 2008). Besides, flexible and reliable software applications are now available allowing relatively easy implementation of complex models. Here we use the program WinBUGS (Spiegelhalter et al., 2002), which implements up-to-date and powerful MCMC algorithms. It is freely available at http://www.mrcbsu.cam.ac.uk/bugs/.

(ii) Criteria for identifying influential climatic factors

The issue of model selection in a Bayesian framework is not easy to deal with. There is a myriad of procedures, and none of them seems to be as consensual as NHT and IT are in the population ecology literature. Several methods produce a value for each candidate model to be compared among a set of pre-selected models [Bayes factor - Kass \& Raftery, 1995; mean square predictive error - e.g. Ghosh \& Norris, 2005; deviance information criterion (DIC) Spiegelhalter et al., 2002; Bayesian information criterion (BIC) - e.g. Link \& Barker, 2006]. These methods are popular but are sometimes difficult to implement due to theoretical and 
computational difficulties (Gelman et al., 2003). Recently, extensions of standard MCMC algorithms have been developed, which perform an automatic exploration of the model space (Gibbs variable selection - George \& McCulloch, 1993; Reversible Jump MCMC - Green, 1995). One may feel uneasy about exploring hundreds of potential models as it might look like data dredging, but in the case of variable selection, we have found that Reversible Jump MCMC in particular is relevant to determine the best combination of covariates (Gimenez et al., 2008). Interestingly, these methods can all be implemented in WinBUGS, pending some effort though.

Given so many procedures, the issue of choosing the right method is of particular concern for the user, e.g. the biologist (Gimenez, 2008). This open question would deserve a proper treatment in itself and is therefore beyond the scope of this paper. Besides, none of the ESR has used a Bayesian model selection method. For the white stork survival analysis, we based our conclusions on the statistical support for climatic covariate effects on the examination of the $95 \%$ credible interval of the parameters involved. Note that Bayesian credible intervals and frequentist confidence intervals are inherently different and may lead to contrasting conclusions (McCarthy, 2007). A 95\% credible interval provides a 0.95 probability that the true value of the parameter is within that interval, whereas a $95 \%$ confidence interval gives, if the sampling is repeated many times, a proportion equal to 0.95 of confidence intervals built from each sample that contain the true value of the parameter. We considered a linear effect of a climatic covariate upon white stork survival as statistically supported when 0 was outside the $95 \%$ credible interval of the posterior mean of the slope of the relationship. We considered the quadratic effect as statistically supported when the $95 \%$ credible region of posterior means of the slopes of linear and quadratic terms did not include $[0 ; 0]$. Using these criteria resulted in concluding that the linear effect of CNSRF and the quadratic effect of PBSC were statistically supported (Table 7; Fig. 4). 


\section{(d) Detecting influential climatic factors in the presence of temporal trends}

The situation where survival time series show a trend over time deserves further comment. In order to address linear or quadratic trends in survival time series, it is necessary to build models of the type $F_{T}$ or $F_{T_{-} q}$, respectively (Table 4). Investigation of trends can then be undertaken with the statistics introduced above to assess the statistical support for the effect of a covariate (e.g. Ftests or AIC differences). As already mentioned in Section IV.1, neither a linear nor a quadratic trend were detected in the white stork survival time series (the $P$-values associated with $F t e s t_{c s t / T / t}$ and $F t e s t_{c s t / T_{-} q / t}$ were 0.59 and 0.33 , respectively, and, $\Delta_{T / t}$ and $\Delta_{T_{-} q / t}$ were equal to 7.64 and 6.03, respectively; see also Table 5). Furthermore, it is difficult to evaluate how often survival time series of vertebrates show temporal trends because these are not systematically addressed (only 17 out of the 78 ESR). Let us nonetheless consider a situation where, for instance, a linear trend is detected (see e.g. Newton et al., 1992; Grosbois \& Thompson, 2005; Kéry et al., 2006). In such a situation a relationship between survival and a climatic covariate can be detected only because this covariate also exhibits a linear trend over time. Such a relationship, that results solely from the co-occurrence of a trend, is particularly likely spurious for two reasons. First, the trend in the time series of survival can be an artefact resulting from the presence of heterogeneity in the survival and/or the detection parameters (Carothers, 1973, 1979; Buckland, 1982; Pledger et al., 2003; Devineau et al., 2006). Second, assuming that the survival time series shows a genuine trend, it is difficult to rule out the possibility that this trend results from a relationship with some overlooked causal factor that would also exhibit a trend, rather than from a causal relationship with the focal climatic covariate (see Coulson, 2001, for an example on density dependence). Our advice, when the survival time series and the focal climatic covariate both show a trend is to test whether the climatic covariate considered accounts for a significant fraction of the variation in 
survival about the trend. This can be done using the residual regression technique (Graham, 2003). The first step is to remove the temporal trend from the climate covariate $x$. Let us refer to this de-trended covariate as $x_{d}$. The value of $x_{d}$ at each date $i$ can be worked out as $x_{d, i}=x_{i}-\left(\hat{\alpha}+\hat{\beta} T_{i}\right)$; where $\hat{\alpha}$ and $\hat{\beta}$ are the estimates, obtained from a linear regression model, of the parameters of the relationship between the climatic covariate $x_{i}$ and a linear trend $T_{i}$. In a second step the following model is built:

$$
f\left(\phi_{i}\right)=a+b_{1} T_{i}+b_{2} x_{d, i}: \text { model } F_{T+d c o}
$$

Ftest $_{T / T+d c o / t}$ allows testing the null hypothesis $H_{0}: b_{2}=0$. This null hypothesis states that there is no relationship between the variation in survival about a trend and the variation in the climatic covariate about a trend. Under an IT approach, the evidence for such a relationship should be obtained by examining $\Delta_{T+d c o / T}$ and $\Delta_{T+d c o l t}$.

Exploration of the relationship between the variation in survival and the variation of a climatic covariate in presence of a trend has been undertaken in only three of the ESR (Newton et al., 1992; Grosbois \& Thompson, 2005; Kéry et al., 2006). In two of these studies, the authors concluded that the effect of a time-varying covariate could not be differentiated from that of a simple trend (Newton et al., 1992; Grosbois \& Thompson, 2005). Because in most ESR the presence of temporal trends in the survival and climatic covariates was simply not addressed, it is difficult to assess how often effects of climatic factors could have been detected because of the co-occurrence of trends in survival and in the candidate climatic covariates. We believe that this issue should be examined on a more systematic basis in the future.

(4) Performances of distinct statistical approaches for detecting potentially influential climatic factors from statistical support: a simulation study 
Different conclusions as to which climatic covariates influenced white stork survival were reached when different statistical procedures were used. Such a discrepancy could be expected for at least two reasons. First, in only one of the statistical approaches (i.e. the NHT) was a procedure for controlling the false discovery rate applied. Not surprisingly, because procedures that control type I error incur a decrease of statistical power (Moran, 2003; Garcia, 2004; Roback \& Askins, 2005), none of the candidate climatic covariates could be considered as potentially influential according to the NHT procedure. By contrast, two climatic covariates were detected as potentially influential when the IT or the Bayesian approaches were adopted. However, with the latter approaches, the risk of type I error was not controlled and might be high when large numbers of candidate covariates are considered (Burnham \& Anderson, 2002, pp. 37-43, 244-248; Stephens et al. 2005). Second, as stated above, the concepts underlying statistical support differed among the procedures used (Stephens et al., 2005; Hobbs \& Hilborn, 2006; Stephens et al., 2007). In the NHT, influential climatic covariates are identified based on the probability of the data or of more extreme data if the null hypothesis of no climatic influence on survival is true. In the Bayesian approach, influential climatic covariates are identified by examination of the posterior distribution of the parameters describing the relationship between survival and climatic covariates. With the IT approach, influential climatic covariates are detected based on an evaluation of the relative quality of the approximation of the complex reality provided by models. Although these conceptual differences are understood, no clear guideline has yet emerged about which paradigm is better adapted to a given case study. Below, we present the results of a simulation study where the performance of these distinct approaches is evaluated in terms of maximization of the statistical power and minimization of type I error. In order to rule out the multiple test issue, the influence of only one virtual climatic covariate was included in this simulation study. 


\section{(a) Methods}

We addressed two characteristics of statistical criteria introduced above for detecting potentially influential covariates. These characteristics were the probability of considering as statistically supported an effect that does not exist (test level or type I error in the NHT approach), and the probability of considering as statistically supported an effect that does exist (test power in the NHT approach; it is also the complement to one of type II error). For each of 36 possible scenarios of variation in survival over years, we simulated $500 \mathrm{CMR}$ data sets with 17 capture occasions and 50 newly marked individuals released at each occasion (these features were comparable to those of the white stork data). The scenarios differed with respect to the slope, $b$, of the linear relationship between survival (on a logit scale) and a virtual climatic covariate in which values over the 16 time intervals were drawn from a normal distribution with a mean of 0 and a variance of 1 (a distinct set of values was drawn for each simulated data set). Six values of $b$ were considered ranging from 0 (no influence of the covariate) to 0.5 . This range was centred on the estimate of $b$ obtained in the white stork example for the linear effect of CNSRF $(\approx 0.25)$. Translated in terms of the size of the effect, the maximum value considered for the slope $(b=0.5)$ generated, for a decrease in the virtual climatic covariate by one and two standard deviation units, a reduction in survival odd ratio of about $40 \%$ and $60 \%$, respectively. The scenarios also differed with respect to the residual process temporal variance in survival ( $\sigma^{2}$ of model $R_{c o}$ ) that ranged from 0 (no residual process variance) to 0.3 . This range was similar to that used by Burnham \& White (2002) introducing random-effects models for the analysis of survival and included the estimate of $\sigma^{2}$ obtained in the white stork survival analysis $(\approx 0.1)$. Furthermore, it covered the range of process temporal variance of adult and juvenile survival reported for birds (Sæther \& Bakke, 2000) and for large mammals (Gaillard \& Yoccoz, 2003). The data sets were generated under the hypothesis of constant recapture probability ( $p=0.9$ as estimated in the white stork 
analysis). The computation of survival used to simulate a data set was performed in two steps: the 16 survival values given by the linear relationship with the virtual climatic covariate were first computed; random numbers drawn from a normal distribution with a mean of 0 and a variance $\sigma^{2}$ were then added to each of these 16 survival values. For each of the $500 \mathrm{CMR}$ data sets generated, models $F_{c s t}, F_{c o}, F_{t}$ were fitted by maximum likelihood and $R_{c o}$ was fitted using the method of moments (Burnham \& White, 2002) and a Bayesian approach. Although the maximum likelihood method (Lebreton et al., 1992) and the method of moments (Burnham \& White, 2002) are available on standard softwares such as MARK, we implemented them in Matlab® to allow looping over the 500 simulated data sets. Coherence between estimates obtained using Matlab® with those obtained using MARK was checked for the white stork data set. We used the software WinBUGS (Spiegelhalter et al., 2002) to implement the Bayesian approach (MCMC method) for building model $R_{c o}$ (see Appendix 2 for details) by calling it from software R through the package R2WinBUGS (Sturtz, Ligges \& Gelman, 2005). Priors and likelihood are specified within WinBUGS, while managing the simulated data, setting initial values, and post-processing the results appears easier in practice using R. The results obtained on the 500 simulated data with fixed-, random- and mixedeffects models were then used to estimate the distribution of the various statistics used to assess the statistical support for an effect of a virtual climatic covariate for each of the 36 scenarios. For tests, the $\alpha$-level was set at 0.05 , the most commonly used value in the ecological literature

\section{(b) Results}

Using either Ftest $t_{c s t / c o / t}$ or $L R T_{c s t / c o}$ according to whether significant residual variation was detected or not, the probability of detecting spurious effects of climatic covariates was close to the $\alpha$-level $(=0.05)$ for most levels of residual process variance, $\sigma^{2}$, although it slightly 
exceeded it for intermediate levels $\left(P=0.08,0.07\right.$ and 0.06 for $\sigma^{2}=0.03,0.05$ and 0.1 , respectively; line in Table 8A with $b=0$ ). In this respect, the systematic use of Ftest $t_{c s t / c o / t}$ instead of using it only when residual process variance was detected ensured that the probability of detecting spurious effects of climatic covariates never exceeded the $\alpha$-level (line in Table 8B with $b=0$ ). However, the probabilities of detecting genuine effects of climatic covariates were slightly higher when the procedure involving the use of either Ftest $t_{c s t / c o / t}$ or $L R T_{\text {cst/co }}$ was preferred over the systematic use of Ftest $t_{c s t / c o / t .}$

The statistical performance of $W\left(R_{c o}\right)$ derived from estimates obtained from a mixedeffects model built using the method of moments were very similar to those of Ftest cst/co/t $_{\text {t }}$ (Table 8C).

The Bayesian procedure presented the advantage that probabilities of detecting genuine effects of climatic covariates were high relative to that achieved with other approaches. However an important drawback was that probabilities of detecting spurious effects were high especially for high process variance (Table 8D where $b=0$ and $\sigma^{2}>0.01$ ).

The IT approach was best adapted to situations where the level of residual process variance was low. In these situations, the probabilities of detecting spurious and genuine effects of climatic covariates were relatively low and high, respectively (columns in Table 8E where $\left.\sigma^{2}<0.03\right)$. However, the IT approach performed poorly when the residual process variance was high: the probabilities of detecting spurious and genuine effects were then relatively high and low, respectively (columns in Table $8 \mathrm{E}$ where $\sigma^{2}>0.01$ ).

\section{(c) Conclusions}

The simulation study has shown that all procedures perform well (i.e. incur low probabilities of retaining spurious effects and provide relatively high probabilities of detecting genuine effects) in situations where the unexplained process variance $\sigma^{2}$ is low. Such situations are 
likely to occur when variation in survival is low and/or when prior knowledge on the study population is good enough for defining models including climatic factors that account for most of the temporal variation observed in survival. However, as in the white stork example, data are usually collected in wild populations in which survival is most likely influenced by multiple factors (Burnham \& Anderson, 2002; Schwarz, 2002). In this context, relatively large variation in survival is expected, and the definition of a model accounting for most of the temporal variation in survival through relationships with climatic or other covariates cannot always be achieved. For instance, residual variation in survival after the effect of climatic covariates had been accounted for was detected in 15 of the 53 ESR in which it was addressed. The results of the simulation study showed that in such situations the NHT approach provides statistics such as Ftest $t_{c s t / c o / t}$ and $W\left(R_{c o}\right)$ that allow testing effects of climatic covariates with reasonable statistical power and limited risks of retaining spurious effects. Such statistics were used in four of the 15 studies mentioned above while in 10 other studies, the IT approach was used to assess the statistical support for climatic covariates. The results of our simulation study suggest that comparison among fixed-effects models using the IT procedure is inefficient in such situations. In our understanding this poor performance of the IT approach makes sense. When variation in survival is large and prior knowledge on the study population is limited, there is a risk that among the set of candidate models that relate variation in survival to variation in climatic factors none describes the data satisfactorily (Burnham \& Anderson, 2002, p. 62, pp. 310-317; Guthery et al., 2005; Stephens et al., 2005; Hobbs \& Hilborn, 2006). In such situations the only candidate model describing satisfactorily survival variation will often be a structural model with many parameters, such as model $F_{t}$, that brings little insight into the ecological factors underlying survival variation (Burnham \& Anderson, 2002, pp. 328-330). Still, according to model selection criteria such as AIC, $F_{t}$ will often outperform models including effects of climatic factors that account for a fraction of the 
observed variation in survival, but that fail to account for most of it. In such situations AIC comparison among fixed-effects models is thus not an efficient procedure for identifying effects of climatic covariates (Anderson \& Burnham, 2002; Burnham \& Anderson, 2002, pp. 328-330; Stephens et al., 2005).

With a relatively large estimate of the unexplained process variance, $\sigma^{2}$, around 0.1 , the white stork example perfectly illustrates the situation in which the hypothesis testing approach was best adapted and the statistics Ftest $t_{c s t / c o / t}$ or $W\left(R_{c o}\right)$ should be used. Using these statistics and applying the correction for multiple tests, none of the relationships considered was statistically supported (Table 7).

\section{(5) Measuring the magnitude of the effects of climatic factors}

To our knowledge, no survey of statistical power in demographic studies of vertebrate populations has so far been undertaken. However, this has been done in the field of behavioural ecology by Jennions \& Møller (2003) who concluded that statistical power was low in a large majority of studies. Because empirical studies of climate impacts on vertebrate survival, as illustrated by the analysis of white stork survival, are almost always characterized by low sample sizes, poor prior knowledge of the underlying processes, and high variability, we can confidently claim that the statistical power to detect effects of climatic factors should often be dramatically low. This is especially true when, as in the application of the NHT paradigm on the white stork survival analysis, one applies procedures that control the risk of type I error. For this reason, we suggest that in the context of exploratory analyses the estimated magnitude of an effect could be used as the decisive criterion for identifying within a set of candidate climatic factors those that might influence survival (Yoccoz, 1991; Nakagawa \& Cuthill, 2007; Stephens et al., 2007). Statistical support should nonetheless be provided along with estimated magnitude as an indication of the confidence in the effect of 
the covariate being genuine, but not as a decisive criterion. Conversely, when, as is almost always the case in ecological studies, statistical support is used as a decisive criterion to identify potentially influential covariates, the magnitude of their potential effect should always be estimated and presented because it is the proper measure of their potential biological importance (Yoccoz, 1991; Nakagawa \& Cuthill, 2007).

When measuring such a magnitude, one has to keep in mind that climate impacts on survival in a given species should ideally be addressed at large spatial scales in order to document its potential geographic variation (Newton et al., 1992; Gaillard et al., 1997; Loison et al., 1999; Tavecchia et al., 2002; Parmesan \& Yohe, 2003; Altwegg et al., 2005; Harris et al., 2005; Schaub et al., 2005; Grosbois et al., 2006). It could also be useful to conduct analyses of climate impacts across species in order to identify specific characteristics (life history, habitat type, diet type, etc.....) that modulate the magnitude of climate impacts on survival (see e.g. Jenouvrier et al., 2005a; Sandvik et al., 2005). In these respects, metaanalyses combining results obtained in specific studies of one population of a single species are extremely valuable (Arnqvist \& Wooster, 1995; Parmesan \& Yohe, 2003; Sæther et al., 2003, 2006; Both et al., 2004). This approach is more efficient if standardization of the measures of climate impacts on ecological processes is achieved across specific studies (Parmesan \& Yohe, 2003. Nakagawa \& Cuthill, 2007). It is thus important to choose measures of the impacts of climatic factors that can be compared across studies. Below we present several types of statistics that reflect to some extent the magnitude of the impact of climatic factors and discuss their usefulness for studies extended at the multi-population or inter-specific scale.

(a) Fraction of temporal variation accounted for by climatic factors 
The most common way of characterizing the impact of a covariate in linear regressions is the fraction of the dependent variable accounted for by its effect (Nakagawa \& Cuthill, 2007). It quantifies the relative importance of the focal covariate as compared to other drivers in generating variation in the dependent variable. This type of standardised effect size measure was used for evaluating the impact of climatic covariates on survival in roughly half of the ESR (i.e. 41 out of 78). Procedures to derive this type of statistic from CMR models have been developed. The most often used statistic is derived from fixed-effects models (Skalski, 1996):

$$
R_{-}^{2} \operatorname{Dev}=\frac{\operatorname{Dev}\left(F_{c s t}\right)-\operatorname{Dev}\left(F_{c o}\right)}{\operatorname{Dev}\left(F_{c s t}\right)-\operatorname{Dev}\left(F_{t}\right)} .
$$

A much less often used statistic can be derived from models $R_{c o}$ and $R_{t}$ that contain random effects (but see e.g. Franklin et al., 2000; Gauthier et al., 2001; Loison et al., 2002; Altwegg et al., 2003, 2006; Schaub et al., 2005; Sandvik et al., 2005):

$$
R_{-}^{2} \operatorname{Var}=\frac{\hat{\sigma}^{2}\left(R_{t}\right)-\hat{\sigma}^{2}\left(R_{\mathrm{cov}}\right)}{\hat{\sigma}^{2}\left(R_{t}\right)} .
$$

$R^{2} \_$Dev and $R^{2}$ Var can be viewed as equivalents of the coefficient of determination, i.e. the proportion of deviance and variance explained, respectively. Using these statistics as a covariate selection criterion in the white stork survival data, we considered that covariates for which $R^{2} \_$Dev or $R^{2}$ Var exceeded 0.20 , implying that these were likely to account for more than $20 \%$ of temporal variation in survival, could be considered as potentially influential. We computed the statistics $R_{-}^{2}$ Dev and $R_{-}^{2}$ Var for the linear and quadratic relationships between white stork survival and the five candidate climatic covariates (Fig. 5). The linear and quadratic effects of CNSRF and the quadratic effect of PBSC accounted for more than $20 \%$ of the variation according to both statistics and were thus considered as influential (Fig. 5). However, the inclusion of the quadratic term for the effect of CNSRF did not result in a substantial increase of the fraction of temporal variation accounted for as compared to a linear 
effect only (Fig. 5). Accordingly we considered the linear relationship with CNSRF and the quadratic relationship with PBSC as the only supported effects. This conclusion had to be attenuated because the risk of type I error exceeded $20 \%$ for both relationships (see above; and Table 7). Examination of the figures obtained for the ten relationships considered revealed that $R^{2} \_$Dev was lower than $R^{2}$ Var for relationships accounting for a large fraction of the variation (Fig. 5). This was expected because $R^{2} \_$Dev expresses the amount of temporal process variance in survival accounted for by the relationship with the climatic covariate relative to a variance quantity that includes sampling variance in addition to total temporal process variance. In this respect, it is better to use $R^{2}$ Var because it expresses the amount of temporal process variance in survival accounted for by the relationship with the climatic covariate relative to the total temporal process variance only. However, $R^{2}$ Var was lower than $R^{2} \_$Dev, and was actually often negative for relationships accounting for a small fraction of the variation (Fig. 5). As already noticed by e.g. Altwegg et al. (2003), $R^{2}$ _Var evaluated from models built with the method of the moments was not a satisfactory measure of magnitude for small effects. Although the method of the moments is well founded (McCullagh \& Nelder, 1989; Gould \& Nichols, 1998; Burnham \& White, 2002), its performance in the analysis of empirical data is still debated. For the time being, we believe that it is preferable to use $R^{2} \_$Dev especially for evaluating the magnitude of small effects.

It is not clear whether coefficients of determination can or cannot be compared safely among case studies considering different populations of a species or even populations of different species (Nakagawa \& Cuthill, 2007). Actually, coefficients of determination often suffer from substantial biases, especially when they are obtained from multiple regression models with many predictors. Although unbiased estimates have been developed for linear regressions (Nakagawa \& Cuthill, 2007), no equivalent statistics has to our knowledge yet been proposed in the context of CMR models. Furthermore, one drawback of coefficients of 
determination is that no method has so far been proposed to determine their standard error in the context of CMR models. No confidence interval can thus be obtained for them. For this reason, whenever the size of an effect is evaluated with $R^{2} \_$Var or $R^{2} \_e v$, a measure of the statistical support for the existence of this effect should also be provided.

\section{(b) Slopes}

Estimates of the parameters describing the relationship between survival and climatic factors can be considered as un-standardised effect size statistics. They allow assessing differences in survival between extreme values of climatic factors, and are thus useful measures of the absolute magnitude of their effects. This type of effect size measure was provided in almost all the ESR. Parameter estimates for the logit-linear and-quadratic relationship between white stork survival and CNSRF and PBSC, respectively, are displayed in Table 6. Note that we included in Table 6 only the relationships that were statistically supported. It could be preferable to provide parameter estimates for all the relationships examined in the analysis (i.e. ten relationships in the white stork survival example). Actually, in the perspective of undertaking robust meta-analyses, parameter estimates of relationships that are weakly supported on the grounds of statistical significance should ideally be provided in tables of results (Jennions \& Møller, 2002).

In the white stork example, the point estimates of the parameters describing the relationship between survival and climatic factors (the intercepts: $\hat{a}$; and the slopes $\hat{b}$ and $\hat{c}$ for the linear and quadratic terms, respectively) did not differ according to the type of model used ( $F_{c o}$ or $R_{c o}$; Table 6 ). However, the confidence intervals for the parameter estimates obtained from the model $F_{c o}$ were narrow as compared to those obtained from model $R_{c o}$ (Table 6). Indeed, the standard errors of the slope estimates obtained from the fixed-effects model $F_{c o}$ are underestimated when a large residual temporal variation remains (i.e. when the 
model $F_{c o}$ shows a lack of fit). In these situations the standard errors of the slope estimates should be multiplied by the scale parameter estimate $\sqrt{\hat{c}}=\sqrt{\frac{\operatorname{Dev}\left(F_{c o}\right)-\operatorname{Dev}\left(F_{t}\right)}{n-J}}$, and confidence intervals should be based on a student distribution with $n-J$ degrees of freedom rather than on the normal distribution (Lebreton et al., 1992). Accordingly the discrepancy among slope estimate standard errors vanished after correction by the scale parameter $\sqrt{\hat{c}}$ (Table 6). If appropriate scaling is applied to the standard errors of estimates obtained from fixed-effects models when needed (i.e. when there is residual unexplained variation), these then compare well with the estimates of slopes and associated standard errors obtained from mixed-effects models (Breslow, 1990). However, appropriate correction of standard errors was applied in only two of the 15 ESR where residual temporal variation was detected (Julliard et al., 1999; Milner et al., 1999).

The estimates of the parameters describing the relationship between survival and climatic factors can differ widely according to the link function chosen for the survival and to the possible transformations that can be applied to the focal climatic covariate before entering it in the regression model. The choice of the link function conditions the shape of the modelled response of survival to variation in the climatic covariate (Lebreton et al., 1992; Skalski et al., 1993). In order to figure out clearly the type of relationship modelled with different link functions one has to determine how a change of $\delta$ units in the climatic covariate translates into survival variation. With the identity function, a $\delta$ units change in the climatic covariate has an additive effect equal to $b \delta$ on survival (Draper $\&$ Smith, 1981). Using a logit scale for survival, a $\delta$ units change in the climatic covariate has a multiplicative effect equal to the $\exp (b \delta)$ on the odds ratio of survival (Hosmer \& Lemeshow, 1989). Using the log-log link function, so that survival is expressed as instantaneous mortality rate, a $\delta$ units change in the climatic covariate has an additive effect equal to the $\exp (b \delta)$ on the instantaneous mortality 
rate (Cox \& Oakes, 1984). Finally with the log link function, often used in CMR data when the length of time intervals vary, a $\delta$ units change in the climatic covariate has a multiplicative effect equal to $\exp (b \delta)$ on survival (McCullagh \& Nelder, 1989). Whatever the practical or biological reasons involved in the choice of a link function, it is thus clear that slope estimates obtained with different link functions cannot be easily compared.

The value obtained for the slope of the relationship between survival and a climatic covariate is also sensitive to possible transformations that can be applied to the climatic covariate before including it in the regression model. The climatic covariate can be included in the regression model as such. The slope then expresses the change in $f(\phi)$ expected when the climatic covariate changes by one unit. In that case the interpretation of the slope is straightforward. The climatic covariate can also be centred and standardized, as was done in the white stork survival analysis. The variation in the climatic covariate is then expressed in terms of anomaly relative to the pattern of variability observed in the time series and the slope of the relationship with $f(\phi)$, sometimes referred to as the standardized slope, expresses the change in $f(\phi)$ expected when the climatic covariate changes by one standard deviation unit. Provided that the same link function $f$ is used, the slope of the relationship expressed in terms of variation in $f(\phi)$ per standard deviation unit of the climatic covariate presents the important advantage of allowing comparisons of the magnitude of the impact of distinct climatic factors such as temperature and precipitation on survival. It can also be useful to compare the magnitude of the impact of climatic factors across case studies. However, such comparisons can be drawn only within a type of relationship. For instance, although CNSRF and PBSC have been standardized, comparing the slope of the linear relationship between survival and CNSRF with the slope for the linear term of the quadratic relationship between survival and PBSC makes no sense. It would then often be difficult to compare slope estimates obtained from distinct study cases. 


\section{(c) Measures of magnitude for comparative studies}

In an outstanding review of effect size statistics, Nakagawa \& Cuthill (2007) argue that standardized effect size statistics or the information necessary to derive such statistics should be provided in any biological study because meta-analyses are needed in order to test many ecological and/or evolutionary theories as well as to evaluate the generality of findings from small-scale studies (Arnqvist \& Wooster, 1995). Nakagawa \& Cuthill (2007) point out that the correlation coefficient, that measures the strength of association between two variables, is the standardized effect size used in the standard statistical models for meta-analyses when the dependent and independent variables are continuous. Indeed, the correlation coefficient seems to be a more robust standardized effect size statistic than the coefficient of determination or the standardised slope. It is striking that attempts at obtaining estimates of the correlation coefficient in the context of CMR models could be found in none of the papers from the ecological or the biostatistical literature that we reviewed. We believe that this is a major gap in CMR modelling techniques. However, Nakagawa \& Cuthill (2007) also provide a comprehensive overview of the links existing among the various effect size measures and list the equations that allow converting one measure of effect size into another. It is not yet clear to us whether or not these equations apply in the context of CMR models. However we believe that published empirical studies of climatic impact on the survival of vertebrates should systematically report slope estimates with standard errors that account for all the sources of over-dispersion (see above), variances in the time series of the covariates, estimates of the process temporal variance in survival probability (with their standard errors and/or confidence or credible intervals), and estimates of the coefficients of determination, so that proper standardized effect size statistics for meta-analyses could be easily derived $a$ posteriori. 


\section{(6) Impact of climatic factors on white stork survival: conclusions}

The exploratory analysis of white stork survival has generated two hypotheses on the influence of climatic factors. The correlation pattern examined suggests that BadenWürtemberg white storks could be sensitive to rainfall in their wintering ground and to climatic conditions in their breeding grounds from their arrival there back from wintering to the onset of the breeding period. White storks may survive poorly in years when rainfall is low in the Sahel region (Fig. 6) and in years when extreme climatic conditions (either, high NAO, high temperature and low rainfall, or, low NAO, low temperature and high rainfall) occur in the breeding area during the pre-breeding season (Fig. 6). Furthermore, assuming that these climatic factors exert a genuine influence on survival, the magnitude of their impact is likely to be large. Each could account for up to $30 \%$ of the temporal variation in survival (Fig. 5). However the risk of these preliminary conclusions being false exceeded $20 \%$ (Table 7), a high level as compared to the standard of 5\% usually retained in ecological studies. This situation of detection of potentially strong effects associated with low confidence for these effects being genuine was a consequence of the high number of candidate climatic factors initially considered as potentially influential which, in turn, stemmed from poor prior knowledge of the study system. The next step in the investigation of the impact of climatic factors on Baden-Würtemberg white storks would be to challenge these hypotheses. So additional CMR data covering a different time window have to be gathered and used for evaluating hypotheses. Initiating longitudinal monitoring of physiological and/or behavioural traits and of the abundance of important food resources would also be necessary in order to uncover the mechanisms through which Sahel rainfall and climatic conditions in the breeding grounds affect survival of white stork. 


\section{DISCUSSION}

In Table 9 we summarize the points developed in earlier sections of this paper. We listed the specificities of climatic covariates and survival estimates derived from analyses of long-term data collected at the individual scale. We also listed the implications of these specificities for the analysis of the impact of climate on survival, advice for avoiding the resulting pitfalls, and the frequency with which these pitfalls were poorly dealt with in the ESR. Although we presented procedures to attenuate some of the problems identified (Table 9 and see Section III), we believe that these problems are partly inherent to the observational nature of the studies we focus on. Below we first point out the limits of observational studies. We then provide recommendations and point to future research directions that could produce stronger inference from empirical studies on climatic impacts on vertebrate survival. Robustness improvement in most of the ESR undoubtedly implies an increase in the number of statistical units and/or a reduction in the number of candidate climatic covariates (Table 9.B). This can be achieved mainly at three stages of a study: field protocol design, selection of the data sets used for documenting survival variations and selection of the climatic covariates. Furthermore better exploitation of existing statistical tools would result in stronger inference.

\section{(1) The limits of observational studies of impacts of climatic factors on vertebrate Survival}

The most rigorous conception for acquiring scientific knowledge is the strong inference procedure (Quinn \& Dunham, 1983). This procedure first implies that a theory concerning the processes that generate a particular pattern in natural systems has to be evaluated. One or several experiments should be designed, with possible outcomes that allow users to exclude unequivocally one or several of the stipulated hypotheses. The experiment should then be carried out. The statistical procedure used in order to evaluate the outcome of the experiment 
is the NHT, which allows falsifying a hypothesis of interest. Application of the strong inference procedure brings about deductive inference that can be considered as true.

The strong inference procedure can usually not be applied in the context of the studies reviewed here, and more generally of ecological studies (Quinn \& Dunham, 1983; Guthery et al., 2005). First, alternatives regarding which climatic factor should influence survival and what impacts they are expected to exert do not stem from sound ecological theory. Instead, empirical observations and basic knowledge from research fields such as physiology or ethology strongly suggest that climatic factors are amongst the numerous factors (e.g. density dependence, resource availability, biotic interactions with competitors and predators) that influence survival in free-ranging populations. Second, experiments allowing the rejection of the hypothesis that a given climatic factor influences survival in a population are often unfeasible. Third, the data used in the type of studies we reviewed were most often not collected for the specific purpose of studying the processes through which climatic factors influence survival. These are often survey data that are primarily collected for the purpose of documenting variation in survival and that serve secondarily for exploring the relative importance of a series of putative factors in generating this variation. Finally, the strong inference approach hardly applies in studies of biological systems because these systems are so complex that the putative processes structuring them and driving their dynamics cannot be reduced to a series of dichotomous mutually exclusive alternatives.

Observational studies of climate impacts on survival can thus only bring about inductive inference. Inductive inference produces more or less strong support for processes that presumably influence the focal ecological phenomenon, but is never sufficient to validate or invalidate them (Quinn \& Dunham, 1983; Robinson \& Wainer, 2002; Roback \& Askins, 2005; Link \& Barker, 2006). For instance, in the correlative studies considered herein, the detection of a relationship between a climatic factor and survival cannot be considered as a 
demonstration of a direct influence of this climatic factor on demography. It can indeed reflect an indirect influence of the climatic factor implying a chain of causation, or even the direct or indirect influence of a confounding factor (especially, as mentioned above, in situations where a detected relationship results solely from the co-occurrence of trends in the survival and climatic factor time series). Although this type of study constitutes a major step towards reaching the ultimate goals of identifying the processes through which climate influences survival, it does not allow doing so as such.

The strength of the conclusions obtained in an investigation of a scientific question through inductive inference depends to a large extent on the number of competing hypotheses that are necessary to represent the whole range of putative processes (Burnham \& Anderson 2002; Johnson \& Omland, 2004; Hobbs \& Hilborn, 2006; Stephens et al., 2007) and on the number of parameters that are necessary to depict each of these competing hypotheses with a mathematical model (Ginzburg \& Jensen, 2004). These characteristics depend in turn to a large extent on the quantity and quality of prior knowledge about the focal ecological system. When prior knowledge of the system is good, the number of competing hypotheses and the main drivers of the focal ecological phenomenon under each of the competing hypotheses are well identified a priori. The IT procedure can then be used to obtain relatively strong but still inductive inference about processes (Anderson \& Burnham, 2002; Burnham \& Anderson, 2002; Ginzburg \& Jensen, 2004; Johnson \& Omland, 2004; Hobbs \& Hilborn, 2006; Stephens et al., 2007). When prior knowledge is poor, too many hypotheses are necessary in order to cover the full range of competing putative processes (Anderson \& Burnham, 2002; Robinson \& Wainer, 2002; Guthery et al. 2005; Stephens et al., 2005, 2007), some of which imply far too many possible drivers for the focal ecological phenomenon (Ginzburg \& Jensen, 2004). We believe that this was the case in most of the empirical studies of impacts of climatic 
factors on vertebrate survival we reviewed (Table 9.B; 9.D) as well as in our investigation of variation in white stork survival.

In such situations, it is necessary to admit that the study aims at generating hypotheses regarding the climatic covariates that potentially have an impact on survival and that further evaluation of these hypotheses would imply either experiments specifically designed or analyses of independent data sets (Robinson \& Wainer, 2002; Roback \& Askins, 2005; Link \& Barker, 2006). The IT approach seems at first sight well adapted for such exploratory studies because it relies on probabilities that the hypotheses of interest are true given the data in hand. However, Burnham \& Anderson (2002) and our simulation study suggest that the IT approach entails high and uncontrolled risks of spurious findings in exploratory situations (Table 9.D). On the other hand, many authors consider that the NHT approach suffers from severe flaws that severely limit its potential for producing strong inductive inference (e.g. Yoccoz, 1991; Cohen, 1994; Johnson, 2002; Robinson \& Wainer, 2002; Hobbs \& Hilborn, 2006; Stephens et al., 2007) With the NHT approach, the actual hypothesis of interest that a focal climatic covariate influences survival, is accepted in the sense that its complement (the null hypothesis) is rejected. This approach thus does not focus explicitly on the hypothesis of interest. Furthermore, what is evaluated is the probability with which the data in hand or more extreme data could have been obtained if the null hypothesis were true, rather than the probability that the null hypothesis is true given the data in hand. However, the results of our simulation study suggest that hypothesis testing can be useful in exploratory analyses (Guthery et al. 2005; Robinson \& Wainer, 2002; Stephens et al., 2005), especially if effect size statistics are provided along with measures of statistical significance (Yoccoz, 1991). 


\section{(2) Improvement of the balance between the number of statistical units and the number}

\section{of candidate climatic factors}

(a) Field protocol design

In 63 of the 78 ESR, CMR protocols consisted of one session per year taking place during the breeding season of the focal species. The inter-annual time scale is a natural one, especially in the highly seasonal environments of temperate zones where most long-term demographic monitoring programs are maintained, because one time unit matches the complete seasonal cycle that constrains the pace of vital activities of any organism. However, the inter-annual time scale does not allow to infer directly from survival estimates the time of year when most mortality occurs and, as a consequence, when environmental conditions (including climatic conditions) are particularly critical. In the few ESR where several sessions per year have been carried out (Singer et al., 1997; Julliard et al., 1999; Hoyle, Pople \& Toop, 2001; Conroy et al., 2002; Piper, 2002; Tavecchia et al., 2002; Barbraud \& Weimerskirch, 2003; Garel et al., 2004; Hallet et al., 2004; Schaefer et al., 2006), a scale was added to the characterization of temporal variation in survival. The first advantage was an increase in the number of statistical units available for documenting temporal variation in survival. A second advantage was that critical periods within a year could be identified more precisely and the number of candidate climatic covariates could be considerably reduced.

\section{(b) Selection of data sets used for documenting survival variation}

CMR protocols most often focus on a single population or even a single sub-population of the focal species. In only eight ESR were CMR data from several populations analysed simultaneously (Newton et al., 1992; Gaillard et al., 1997; Loison et al., 1999; Tavecchia et al., 2002; Altwegg et al., 2005; Harris et al., 2005; Schaub et al., 2005; Grosbois et al., 2006). 
Addressing the impact of climatic factors on survival with such multi-population data sets is particularly valuable for two reasons. First, the number of statistical units available for documenting temporal variation in survival is increased: indeed, the detection of correlations of survival with the same climatic factor in several populations of a given species is very convincing evidence that this factor has an impact on survival (e.g. Newton et al., 1992; Gaillard et al., 1997; Tavecchia et al., 2002; Harris et al., 2005; Schaub et al., 2005; Grosbois et al., 2006). Second, using multi-population data sets allows investigators to document geographic variation in influences of climatic factors and to make predictions about the impact of various climate change scenarios in terms of changes in species abundance over the entire distribution range. Although logistic problems usually prevent one research team from simultaneously monitoring several populations of the same species in distant locations, there is undoubtedly a large number of seabirds, passerines, small mammals and large herbivores for which multi-population CMR data sets could be assembled through collaborations among researchers. Such collaborations have already been established for landbirds (Sæther et al., 2003, 2006; Both et al., 2004; Schaub et al., 2005; Grosbois et al., 2006), and seabirds (Harris et al., 2005), and the results obtained illustrate the potential of such approaches for documenting geographical variation in the impact of climatic factors. This type of approach will hopefully develop in the near future. Moreover, the analysis of multiple population data sets allows investigators to assess both the magnitude of co-variation (i.e. of synchrony over time) in survival of different populations and the role of climatic factors in generating covariation in survival among populations (Schaub et al., 2005; Sæther et al., 2006). The most direct way to get estimates of the process covariance among survival estimates from several populations involves variants of mixed-effects models which are currently being developed. 


\section{(c) Selection of a set of climatic factors}

The definition of a relatively small set of non-redundant candidate climatic covariates is probably the most problematic issue (Table 9.B; 9C). The number of candidate covariates depends to a large extent on the level of uncertainty with which the mechanisms through which climate influences survival are known. In some rare instances, eco-physiological and/or behavioural studies have provided sufficient information on these mechanisms so this uncertainty is low (e.g. in large herbivore species: Sæther, 1997; Gaillard, Festa-Bianchet \& Yoccoz, 1998). However, the investigator often has to deal with a poor knowledge of such mechanisms. In these situations defining a small set of potentially relevant candidate climatic covariates can be extremely difficult for several reasons. As mentioned previously, monitoring programs at the individual level are most often carried out at the inter-annual time scale so that critical times of the year cannot be determined directly. Furthermore, climatic covariates can influence survival with time lags. For example, the effect of climatic conditions experienced in early stages of life can persist for many years (Albon, CluttonBrock \& Guinness, 1987; Gaillard et al., 1997). In the case of resident populations of lowmobility species, the geographic area where the potentially critical climatic covariates have to be measured is most often restricted and well defined. However, in other instances, the definition of this geographic area is less straightforward. Examples include long-distance migratory species (Sillett, Holmes \& Sherry, 2000; Møller \& Szep, 2005; Stokke et al., 2005; Sæther et al., 2006), and highly mobile species such as pelagic seabirds relying on resources that are themselves highly mobile (Barbraud \& Weimerskirch, 2005; Grosbois \& Thompson, 2005; Crespin et al., 2006; Nevoux \& Barbraud, 2006; Votier et al., 2005). Finally, local climate can influence survival indirectly through variation in abundance of food (Frederiksen et al., 2004; Sandvik et al., 2005). The complexity of climate influences on survival in such 
cases generally hampers identification of a small set of potentially relevant climatic covariates.

Selecting all local climatic covariates that are potentially relevant when uncertainty about the mechanisms is important often results in too large a set of candidate covariates. When this option is nonetheless preferred, we strongly advise against the inclusion of several highly correlated covariates in the set of candidate covariates. We believe that using local weather packages (obtained for instance from multivariate analyses such as PCA) is a powerful way of achieving a reasonable balance between relevance and parsimony during the stage of selection of candidate climatic covariates (Loison et al., 1999; Grosbois et al., 2006; Jenouvrier et al., 2006; Kéry et al., 2006; Traylor \& Alisauskas, 2006 among the papers reviewed here and Moss, Oswald \& Baines, 2001; Sirabella et al., 2001; Beaugrand \& Reid, 2003; Forsman \& Mönkkönen, 2003; for other types of demographic studies). Collaborations with climatologists could facilitate defining such local weather packages.

Another way to deal with high levels of uncertainty about which local climatic covariates could influence survival involves using large-scale teleconnection indices such as NAO or the southern oscillation index (Holmgren et al., 2001; Ottersen et al., 2001; Stenseth et al., 2003). However, large-scale teleconnection indices are likely to influence survival through a complex causal pathway. The teleconnection index is then just a surrogate or proxy for an unknown variable that is supposed to influence survival directly (Almaraz \& Amat, 2004) and the detection of a relationship between it and survival brings about little information on the mechanisms through which climatic factors influence demography.

\section{(3) Better exploitation of statistical tools}

(a) A priori power analyses 
In the ESR the power to detect effects of climatic factors was not assessed before the investigation of potentially influential factors. Yet, the procedures for evaluating a priori statistical power in CMR analyses have been described and applied in few studies (Lebreton et al., 1992; Devineau et al., 2006). We believe that a priori power evaluation would provide important information for setting the $\alpha$-level when the NHT procedure is used and for defining a reasonable size for the set of candidate covariates (i.e. a size with which covariate effects can be evaluated with reasonable power when corrections for multiple tests are applied). However, one important change in current practice is required before power analyses can be undertaken. In none of the ESR were precise alternative hypotheses explicitly formulated. Instead, it was implicitly assumed that the alternative hypotheses were just the counterpart of the null hypotheses (the parameters of the relationships between survival and the focal climate covariate are different from zero or, equivalently, the fraction of the temporal variation in adult survival accounted for by the effect of the focal climate covariate is more than zero). We believe that the formulation of precise alternative hypotheses would contribute to obtaining more robust analyses. It would allow evaluation of statistical power and more meaningful conclusions (Field et al., 2004; Devineau et al., 2006).

\section{(b) Integrated modelling}

Combining several sources of information on survival can greatly reduce estimation uncertainties and thereby increase statistical power for detecting climatic effects. Integrated modelling tools are currently being developed to draw inferences based on the simultaneous analysis of different types of data. Attempts at evaluating the influence of climatic factors on survival using integrated modelling of live recaptures and dead recoveries have already been performed (Catchpole et al., 2000; Blums et al., 2002; Altwegg et al., 2003; Schaub et al., 2005). In its most elaborate version such integrated modelling could combine monitoring data 
at the population and individual levels for building statistical models with a structure that includes explicit descriptions of the link between demographic parameters and population dynamics. Such integrated models certainly have a great potential for investigating the influence of climate change on population dynamics (Besbeas, Freeman \& Morgan, 2005). They are currently being developed but have seldom been used so far for evaluating the influence of climatic factors on survival and population dynamics (but see Besbeas et al., 2002).

\section{(c) Cross validation}

Two important components need to be evaluated for assessing the validity of a statistical model. Internal validity is the ability of the model to describe the variation in the focal dependent variable in the population where, and over the time period when, the data used to build the model have been collected. External validity is the ability to predict variation in the dependent variable in other populations and/or over other time periods where and when the same processes are supposedly acting.

An important risk incurred when exploring the potential influence on survival of many climatic factors by analysing short time series is that of coming up with a model performing well in terms of internal validity but poorly in terms of external validity. This risk further increases when the multiple test issue is ignored. For these reasons, we believe that although the statistical models produced in many of the ESR represent valuable hypotheses, their external validity still needs to be evaluated before they can be used for the ultimate aim of predicting survival under future climatic conditions.

In our opinion, the best approach to evaluate the external validity of a model obtained from the analysis of data collected in a given population over a given time period, is to assess its predictive performance on a data set collected in a different population and over a distinct 
time period. We thus believe that undertaking multi-population and multi-species investigations is the best approach to produce predictive models with high external validity. However, generating hypotheses and evaluating their external validity simultaneously on a single data set is to a certain extent possible with cross-validation procedures. Such procedures, where the data set is iteratively split into a fitting and a validation subset, have been used in investigations of climatic impacts in time series of abundance (e.g. Turchin, 2003; Corani \& Gatto, 2007) and for producing predictive models of species distribution ranges through the analysis of climatic niches (e.g. Broennimann et al., 2007, Dormann et al., 2008). Although it has to our knowledge never been applied in empirical studies of impacts of climatic factors on survival of vertebrate populations, cross validation would clearly improve the robustness of the results obtained in such studies.

\section{(d) Tools for addressing complex causal pathways}

While the regression models presented here are efficient tools for detecting correlations, they hardly provide information on the type (direct or indirect) of the relationships detected, nor account for relationships among explanatory covariates. Modelling tools have recently been introduced in the field of ecology (e.g. structural equation modelling; Bollen, 1989) to state explicitly through flow charts the existence of relationships among explanatory environmental covariates and the type (direct or indirect) of relationship linking survival to the explanatory environmental covariates (Graham, 2003; see Almaraz \& Amat, 2004 for an application in the field of population biology). Adaptation of this type of modelling tool to the analysis of temporal variation in survival is desirable. It could be used to infer complex causal pathways linking survival to several inter-related climatic and biotic covariates. This type of complex pathway is suspected to underlie relationships between survival of pelagic seabirds and fluctuation of large-scale climatic indices (Jenouvrier et al., 2005b; Sandvik et al., 2005). 
Furthermore, from a methodological point of view, the application of this type of modelling tool would to some extent tackle the multi-collinearity issue (Graham, 2003).

Complex causal pathways also imply that a candidate climatic covariate may not be the actual causal factor but may nonetheless reflect imperfectly temporal variation in this causal factor because it is causally connected to it. This is obvious when large-scale integrative climatic indices such as the NAO are considered in the set of covariates. In this context, regression models that integrate explicitly measurement errors in predictors could be useful. Such models have already been used in the field of population biology (e.g. Solow, 1998; Almaraz \& Amat, 2004) and in the CMR context to study density-dependence (Barker, Fletcher \& Scofield, 2002). To our knowledge they have never been applied in the context of investigation of the relationship between climate and survival.

Lastly, causal pathways can generate non-linear relationships among climate indices (Mysterud et al., 2001; Lima et al., 2002). The recent development of non-parametric models in a statistical framework adapted to the analysis of monitoring data at the individual level now allows investigators to model with maximum flexibility such non-linear relationships (Gimenez et al., 2006).

\section{(e) Multi-model inference}

In the ESR, the IT procedure was often chosen as a statistical framework. However, it was used as a tool for identifying among a set of climatic factors those that might noticeably influence survival. As discussed above, we believe that the IT procedure is not superior to the NHT procedure when used for such exploratory investigations. On the other hand, when prior knowledge of the system is good enough for building a limited number of relevant models, the IT procedure offers interesting possibilities. In particular, AIC weights can be used to draw inductive inference, such as the estimation of the impact of a climatic factor, from 
several models (Buckland et al., 1997). Such multi-model inference is extremely valuable because it accounts for uncertainty in model selection. However, the possibility offered by the IT procedure to draw multi-model inference has been exploited in only two of the 78 ESR (Beauplet et al., 2005; Traylor \& Alisauskas, 2006; see also Hartley et al., 2006; Dormann et $a l ., 2008$ for the inclusion of model selection uncertainty in inferences on biodiversity and species ranges).

\section{f) IT selection criterion for models including random effects}

Our evaluation of the performances of statistical procedures for identifying influential climatic factors suggests that the IT procedure does not perform well in situations where prior knowledge of the system is poor. In our opinion such a poor performance arises from the impossibility of defining a model that explains most of the temporal variation in survival through relationships with biologically relevant predictors. We suggest that introducing in the set of candidate models mixed effect models of the type of $R_{t}$ and $R_{c o}$ that account parsimoniously for unexplained process variation would most likely improve the statistical performance of the IT approach when prior knowledge is poor (Burnham \& Anderson, 2002, pp. 310-317). Although methods for deriving AIC for CMR models including random effects have been proposed (Burnham \& White, 2002; Vaida \& Blanchard, 2005), their efficiency has so far received little evaluation and they have to our knowledge never been applied in analyses of field CMR data. Procedures based on AIC comparisons within sets of candidate models including fixed- and mixed-effects models have undoubtedly great potential for addressing the impact of climatic factors on survival.

(g) Incorporation of prior knowledge 
In a CMR context, the possibility of incorporating prior knowledge of the system in the analysis has rarely been exploited (but see McCarthy \& Masters, 2005), and never with the aim to demonstrate the impact of climatic factors on demographic parameters. In the white stork example, the positive effect on survival of rainfall at wintering sites was demonstrated several times in the literature, whereas that of climatic conditions at breeding sites was unknown prior to this study. One way of incorporating this prior information would be to assign a positive distribution to the regression parameter representing the impact of rainfall on survival, and a vague prior such as a normal distribution with large variance for the parameter standing for the impact of climatic conditions at breeding sites which was poorly documented prior to this analysis. By doing so, the use of information in the data will be focused on investigating a potential effect of climatic conditions at breeding sites.

\section{CONCLUSIONS}

(1) Although a noticeably large number of ecological studies have detected impacts of climatic factors on survival in populations of vertebrates, many of these results should be considered with caution.

(2) We identified three statistical problems that were often quite poorly dealt with in the 78 case studies we reviewed (Table 9). First, the evidence for impact of climatic factors on survival has been obtained from analyses where multiple correlated climatic covariates were considered without tackling the multiple test and multi-collinearity problems (Table 9.B; 9.C). Second, in the studies where large variation in survival was observed, and where climatic and other time-varying covariates did not account for most of this variation, statistical support for the effect of climatic covariates was often assessed using statistics that poorly accounted for unexplained variation (Table 9.D). Finally most of the studies we reviewed did not address the potential co-occurrence of temporal trends in the survival and climatic covariates despite 
such co-occurrence easily resulting in spurious detections of climate effects (Table 9.E). We suggest that the two last issues are relatively easy to deal with because data can simply be reanalysed using more robust statistical methods such as those reviewed here.

(3) In our opinion, the most problematic issue is the low ratio between the number of statistical units available for documenting time variation in survival and the number of climatic covariates considered as potentially influential (Table 9.B). Indeed, we believe that this issue is inherent to observational studies where prior knowledge of the system is too poor for a limited set of potential drivers of survival to be defined. More robust results could be obtained by improving procedures used at early stages of investigations (e.g. field protocol design allowing investigations at infra-annual scales and selection of multi-population data sets) as well as at the final stage of data analysis (i.e. better exploitation of the possibilities offered by existing statistical tools).

(4) We are convinced that major findings regarding the influence of climatic factors on demographic processes, on the dynamics of distribution ranges or on the structure of communities can be expected from investigations at multi-population and multi-specific levels.

(5) We urge population ecologists to consider our recommendations because results obtained in investigations of demographic processes in single populations and species can be integrated in meta-analyses or used as pieces of prior knowledge for other investigations only if they are obtained with robust and standardized statistical methods.

\section{ACKNOWLEDGEMENTS}

The authors would like to thank Jean-Dominique Lebreton for his conceptual contribution to this paper. We also thank Marc Kéry, and Charles G. M. Paxton for their comments on early drafts of the manuscript. We are grateful to Tim Coulson and Nigel Yoccoz for having 
reviewed the paper. This project and V. G.'s research were supported by grants from the Centre National de la Recherche Scientifique (ACI CLIM-POP), the Ministère de l'Ecologie et du Développement Durable and the Institut Français de la Biodiversité (program GICC and GICC2). O. G.'s research was supported by a Marie-Curie Intra-European Fellowship within the Sixth European Community Framework Programme. 


\section{APPENDICES}

(1) Case studies where climate impacts on survival of vertebrates have been addressed using capture-mark-recapture data (papers from 1985 to 2006 from journals referenced in Current Contents). $F_{c s t}, F_{t}, F_{c o}, F_{t}, F_{T}, F_{T_{-}}, R_{t}, R_{c o}$ are different types of CMR models for describing survival

(Table 4). $L R T_{x / y}, \Delta_{x / y}$, Ftest $_{x / y / z}, W\left(R_{c o}\right)$ are statistics to assess statistical support (Table 7 and Sections IV.1-IV.3). $R^{2} \_D e v, R_{-}^{2} V a r$ are effect size statistics (Sections IV.5). GOF: Goodness of fit test. CI: confidence interval.

\begin{tabular}{|c|c|c|c|c|c|c|c|c|c|c|c|c|c|}
\hline 苞 & 苞 & 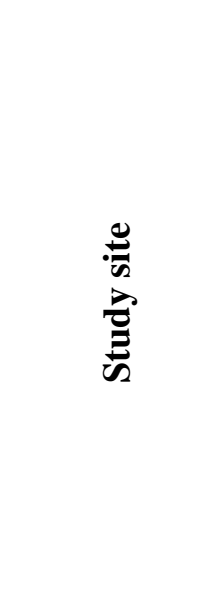 &  & 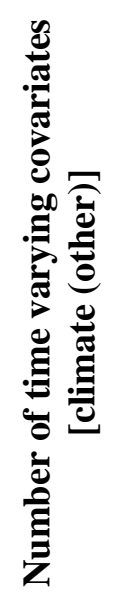 & 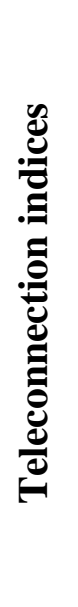 & 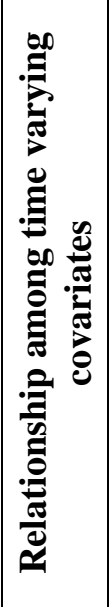 & 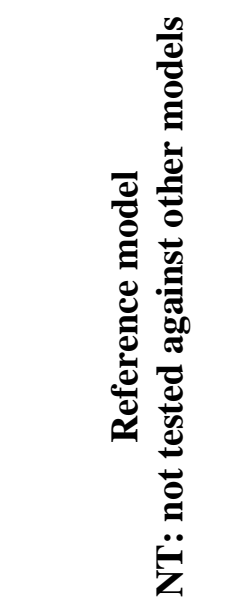 &  & 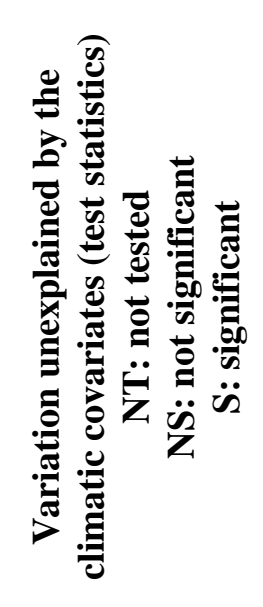 & 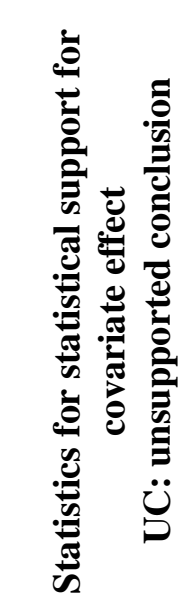 & 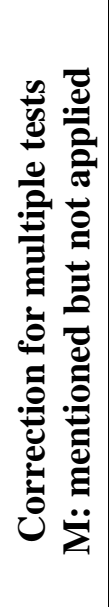 & 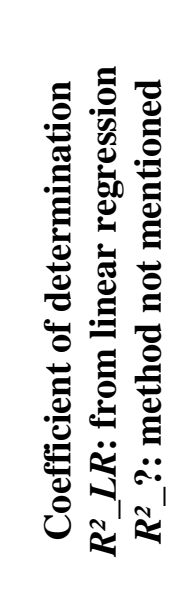 &  \\
\hline 1 & $\begin{array}{l}\text { Tundra vole } \\
\text { Microtus } \\
\text { oeconomus }\end{array}$ & Norway & $4 y$ & 1 & & & $F_{t}(\mathrm{NT})$ & $\begin{array}{l}\text { LR on survival } \\
\text { estimates derived } \\
\text { from a LGR }\end{array}$ & NT & $F$-LR & & $\begin{array}{l}\text { Pearson } \\
\text { correlation } \\
\text { coefficient }\end{array}$ & \\
\hline 2 & $\begin{array}{l}\text { Red deer } \\
\text { Cervus elaphus }\end{array}$ & $\begin{array}{l}\text { Isle of Rum } \\
\text { Scotland }\end{array}$ & $10 \mathrm{y}$ & $\begin{array}{l}\geq 2 \\
(1)\end{array}$ & & $\mathrm{N}$ & $\begin{array}{l}F_{t} \text { or } F_{c s t} \\
\text { depending on } \\
\text { sex and age } \\
\left(L R T_{c s t / t}\right)\end{array}$ & $\begin{array}{l}\text { LR on the rate of } \\
\text { number known } \\
\text { alive at } t+1 \text { among } \\
\text { those seen at } t \text {. }\end{array}$ & NT & $F$-LR & $\mathrm{N}$ & & \\
\hline
\end{tabular}




\begin{tabular}{|c|c|c|c|c|c|c|c|c|c|c|c|c|}
\hline 3 & $\begin{array}{l}\text { Asp viper } \\
\text { Vipera aspis }\end{array}$ & Switzerland & $14 \mathrm{y}$ & 3 & & $\mathrm{Y}$ & $F_{c s t}\left(\Delta_{c s t / t}\right)$ & CMR & $\operatorname{NS}\left(\Delta_{c s t / t}\right)$ & $\Delta_{c s t / c o}$ & $\mathrm{~N}$ & \\
\hline 4 & $\begin{array}{l}\text { Barn owl Tito } \\
\text { alba }\end{array}$ & Switzerland & $12 \mathrm{y}$ & $3(1)$ & & $\mathrm{N}$ & $F_{t}\left(\Delta_{c s t / t}\right)$ & CMR & $\mathrm{S}\left(\Delta_{c o / t}\right)$ & \begin{tabular}{|l|}
$\Delta_{c o / t}$ \\
$\Delta_{c s t / c o}$ \\
UC (based \\
on $R^{2}$ ) \\
\end{tabular} & $\mathrm{N}$ & $\begin{array}{l}R^{2} \text { Dev } \\
R^{2} \text { Var }\end{array}$ \\
\hline 5 & $\begin{array}{l}\text { Barn owl Tito } \\
\text { alba }\end{array}$ & Switzerland & $68 \mathrm{y}$ & 1 & & & $F_{t}\left(\Delta_{c s t / t}\right)$ & CMR & $\mathrm{S}\left(\Delta_{c o / t}\right)$ & Ftest cst/co/t $_{\text {t }}$ & & $R^{2}$ VVar \\
\hline 6 & $\begin{array}{l}\text { Emperor } \\
\text { penguin } \\
\text { Aptenodytes } \\
\text { forsteri }\end{array}$ & $\begin{array}{l}\text { Terre Adélie } \\
\text { (Antarctica) }\end{array}$ & $19 \mathrm{y}$ & 3 & & $\mathrm{~N}$ & $F_{t}\left(L R T_{c s t / t}\right)$ & CMR & $\mathrm{NS}\left(L R T_{c o / t}\right)$ & $L R T_{c o / t}$ & $\mathrm{~N}$ & $R^{2} \_$Var \\
\hline 7 & $\begin{array}{l}\text { Blue petrel } \\
\text { Halobaena } \\
\text { caerulea }\end{array}$ & $\begin{array}{l}\text { Kerguelen } \\
\text { archipelago }\end{array}$ & $12 \mathrm{y}$ & $2(1)$ & $\mathrm{Y}$ & $\mathrm{Y}$ & $F_{t}\left(\Delta_{c s t / t}\right)$ & CMR & $\mathrm{NS}\left(\Delta_{c o / t}\right)$ & $\begin{array}{l}A I C \text { weights } \\
\Delta_{c s t / c o}\end{array}$ & $\mathrm{~N}$ & $\begin{array}{l}R^{2} \_ \text {Dev } \\
R_{\text {_ }}^{2} \text { Var }\end{array}$ \\
\hline 8 & $\begin{array}{l}\text { Blue petrel } \\
\text { Halobaena } \\
\text { caerulea }\end{array}$ & $\begin{array}{l}\text { Kerguelen } \\
\text { archipelago }\end{array}$ & $10 y$ & $1(1)$ & & $\mathrm{N}$ & $F_{t}\left(\Delta_{c s t / t}\right)$ & CMR & $\mathrm{NS}\left(\Delta_{c o / t}\right)$ & $\begin{array}{l}\Delta_{c o / t} \\
\Delta_{c s t / c o}\end{array}$ & $\mathrm{~N}$ & $R^{2} \_$Dev \\
\hline 9 & $\begin{array}{l}\text { Snow petrel } \\
\text { Pagodroma } \\
\text { nivea }\end{array}$ & Terre Adélie & $16 \mathrm{y}$ & 24 & & $\mathrm{~N}$ & $F_{t}\left(L R T_{c s t / t}\right)$ & CMR & $\mathrm{NS}\left(L R T_{c o / t}\right)$ & $L R T_{c s t / c o}$ & $\mathrm{~N}$ & $R^{2} \_D e v$ \\
\hline 10 & $\begin{array}{l}\text { Subantarctic fur } \\
\text { seal } \\
\text { Arctocephalus } \\
\text { tropicalis }\end{array}$ & $\begin{array}{l}\text { Amsterdam } \\
\text { island }\end{array}$ & $6 y$ & 1 & & & $\begin{array}{l}F_{c s t}\left(\Delta_{c s t / t}\right) \text { or } F_{t} \\
(\mathrm{NT}) \text { depending } \\
\text { on age }\end{array}$ & $\begin{array}{l}\text { Depending on age, } \\
\text { CMR or Spearman } \\
\text { rank correlation on } \\
\text { estimates derived } \\
\text { from age class size } \\
\text { and survival } \\
\text { estimates }\end{array}$ & $\begin{array}{l}\text { NS }\left(\Delta_{c s t / t}\right) \text { or } \\
\text { NT depending } \\
\text { on age }\end{array}$ & $\begin{array}{l}\text { Spearman } \\
\text { rank } \\
\text { correlation } \\
\text { test }\end{array}$ & & $\begin{array}{l}\text { Spearman } \\
\text { rank } \\
\text { correlation } \\
\text { coefficient }\end{array}$ \\
\hline 11 & $\begin{array}{l}\text { Cassin's auklet } \\
\text { Ptychoramphus } \\
\text { aleuticus }\end{array}$ & $\begin{array}{l}\text { Triangle and } \\
\text { Frederick's } \\
\text { islands } \\
\text { (British } \\
\text { Columbia) }\end{array}$ & $5 y$ & 1 & $\mathrm{Y}$ & & $F_{c s t}\left(\Delta_{c s t / t}\right)$ & CMR & $\operatorname{NS}\left(\Delta_{c s t / t}\right)$ & $\Delta_{c s t / c o}$ & & \\
\hline 12 & $\begin{array}{l}\text { Three duck } \\
\text { species }\end{array}$ & Latvia & $17-21 \mathrm{y}$ & 1 & & & $\begin{array}{l}F_{c s t} \text { or } F_{t} \\
\text { depending on }\end{array}$ & CMR & $\mathrm{NS}\left(\Delta_{c o / t}\right)$ & $\begin{array}{l}\Delta_{c s t / c o} \\
\Delta_{c o / t}\end{array}$ & & \\
\hline
\end{tabular}




\begin{tabular}{|c|c|c|c|c|c|c|c|c|c|c|c|c|c|}
\hline & & & & & & & species $\left(\Delta_{c s t / t}\right)$ & & & $\begin{array}{l}\text { UC in one } \\
\text { species } \\
\left(\Delta_{c s t / c o}=-\right. \\
0.72)\end{array}$ & & & \\
\hline 13 & $\begin{array}{l}\text { Northern red- } \\
\text { backed vole } \\
\text { Clethrionomys } \\
\text { rutilus }\end{array}$ & $\begin{array}{l}\text { Yukon } \\
\text { (Canada) }\end{array}$ & $10 \mathrm{y}$ & $\begin{array}{l}>1(> \\
1)\end{array}$ & & $\mathrm{N}$ & $F_{t}(\mathrm{NT})$ & $\begin{array}{l}\text { LR on survival } \\
\text { estimates derived } \\
\text { from population } \\
\text { size estimates }\end{array}$ & NT & $F$-LR & $\mathrm{N}$ & $R_{-}^{2} \mathrm{LR}$ & \\
\hline 14 & $\begin{array}{l}\text { Seychelles } \\
\text { warbler } \\
\text { Acrocephalus } \\
\text { sechellensis }\end{array}$ & $\begin{array}{l}\text { Cousin } \\
\text { Island } \\
\text { (Seychelles) }\end{array}$ & $18 \mathrm{y}$ & $5(1)$ & & $\mathrm{N}$ & $F_{t}\left(\Delta_{c s t / t}\right)$ & CMR & $\mathrm{S}\left(\Delta_{c o / t}\right)$ & $\begin{array}{l}\Delta_{c s t / c o} \\
\Delta_{c o / t}\end{array}$ & $\mathrm{~N}$ & & $\mathrm{C}$ \\
\hline 15 & $\begin{array}{l}\text { Common lizard } \\
\text { Lacerta } \\
\text { vivipara }\end{array}$ & France & $13 \mathrm{y}$ & 3 & & $\mathrm{Y}$ & $\begin{array}{l}F_{t} \text { or } F_{c s t}\left(\Delta_{c s t / t}\right) \\
\text { depending on } \\
\text { sex }\end{array}$ & CMR & $\mathrm{NS}\left(\Delta_{c o / t}\right)$ & $\begin{array}{l}\Delta_{c s t / c o} \\
\Delta_{c o / t}\end{array}$ & $\mathrm{~N}$ & & $\begin{array}{l}\mathrm{S} \\
\mathrm{C}\end{array}$ \\
\hline 16 & $\begin{array}{l}\text { Soay sheep } \\
\text { Ovis aries }\end{array}$ & $\begin{array}{l}\text { St Kilda } \\
\text { (Scotland) }\end{array}$ & $10 \mathrm{y}$ & $4(1)$ & $\mathrm{Y}$ & $\mathrm{Y}$ & $F_{t}\left(\Delta_{c s t / t}\right)$ & CMR & $\mathrm{S}\left(\Delta_{c o / t}\right)$ & $\begin{array}{l}\Delta_{c o / t} \\
\Delta_{c s t / c o} \\
\text { UC (based } \\
\text { on } \\
\text { uncorrected } \\
\text { CI) }\end{array}$ & $\mathrm{M}$ & & \\
\hline 17 & $\begin{array}{l}\text { Lapwing } \\
\text { Vanellus } \\
\text { vanellus }\end{array}$ & UK & $29 y$ & 13 & & $\mathrm{Y}$ & $F_{c s t}\left(\Delta_{c s t / t}\right)$ & CMR & $\operatorname{NS}\left(\Delta_{c s t / t}\right)$ & $\begin{array}{l}\Delta_{c o / t} \\
\Delta_{c s t / c o}\end{array}$ & $\mathrm{~N}$ & & $\begin{array}{l}\mathrm{S} \\
\mathrm{C}\end{array}$ \\
\hline 18 & $\begin{array}{l}\text { Coot Fulica } \\
\text { atra }\end{array}$ & Netherlands & $15 \mathrm{y}$ & $1(1)$ & & $\mathrm{N}$ & $F_{t}(\mathrm{NT})$ & $\begin{array}{l}\text { LR on } F_{t} \text { estimates } \\
\text { (log transformed) }\end{array}$ & NT & $F$-LR & $\mathrm{N}$ & & \\
\hline 19 & $\begin{array}{l}\text { Starling } \\
\text { Sturnus } \\
\text { vulgaris }\end{array}$ & Belgium & $6 y$ & 1 & & & $F_{t}\left(L R T_{c s t / t}\right)$ & CMR & $\mathrm{NS}\left(L R T_{c o / t}\right)$ & $L R T_{\text {cst/co }}$ & & & \\
\hline 20 & $\begin{array}{l}\text { Great tit Parus } \\
\text { major }\end{array}$ & England & $20 y$ & $5(6)$ & & $\mathrm{Y}$ & $F_{t}\left(L R T_{c s t / t}\right)$ & CMR & $\mathrm{NS}\left(\mathrm{GOF} F_{c o}\right)$ & $L R T_{c s t / c o}$ & $\mathrm{M}$ & & \\
\hline 21 & $\begin{array}{l}\text { Serin Serinus } \\
\text { serinus }\end{array}$ & Spain & $15 y * 2 s$ & $3(1)$ & & $\mathrm{N}$ & $F_{t}\left(\Delta_{c s t / t}\right)$ & CMR & $\mathrm{S}\left(\Delta_{c o / t}\right)$ & $\begin{array}{l}\Delta_{c o / t} \\
\Delta_{c s t / c o}\end{array}$ & $\mathrm{~N}$ & & \\
\hline
\end{tabular}




\begin{tabular}{|c|c|c|c|c|c|c|c|c|c|c|c|c|c|}
\hline 22 & $\begin{array}{l}\text { Sand martin } \\
\text { Riparia riparia }\end{array}$ & $\begin{array}{l}\text { Breeding in } \\
\text { Nottinghams } \\
\text { hire (UK) } \\
\text { wintering in } \\
\text { West Africa }\end{array}$ & $23 \mathrm{y}$ & 3 & & $\mathrm{~N}$ & $F_{t}\left(\Delta_{c s t / t}\right)$ & CMR & $\mathrm{S}\left(\Delta_{c o / t}\right)$ & Ftest $t_{c s t / c o / t}$ & $\mathrm{~N}$ & & $\mathrm{~S}$ \\
\hline 23 & $\begin{array}{l}\text { Common } \\
\text { guillemot } \\
\text { Cepphus grylle }\end{array}$ & $\begin{array}{l}\text { Isle of May } \\
\text { (Scotland) }\end{array}$ & $10 y$ & 4 & $\mathrm{Y}$ & $\mathrm{N}$ & $F_{t}\left(\Delta_{c s t / t}\right)$ & CMR & $\mathrm{S}\left(\Delta_{c o / t}\right)$ & Ftest $t_{c s t / c o / t}$ & $\mathrm{~N}$ & $R^{2} \_$Dev & \\
\hline 24 & $\begin{array}{l}\text { Four resident } \\
\text { forest bird } \\
\text { species: } \\
\text { Baeolophus } \\
\text { bicolor, } \\
\text { Picoides } \\
\text { pubescens, } \\
\text { Poecile } \\
\text { carolinensis, } \\
\text { Sita } \\
\text { carolinensis }\end{array}$ & Ohio (USA) & $5 y$ & 1 & & & $F_{c s t}\left(\Delta_{c s t / t}\right)$ & CMR & $\mathrm{NS}\left(\Delta_{c s t / t}\right)$ & $L R T_{c s t / c o}$ & & & \\
\hline 25 & $\begin{array}{l}\text { Soay sheep } \\
\text { Ovis aries }\end{array}$ & $\begin{array}{l}\text { St Kilda } \\
\text { (Scotland) }\end{array}$ & $13 \mathrm{y}$ & $1(1)$ & $\mathrm{Y}$ & $\mathrm{N}$ & $F_{t}\left(L R T_{c s t / t}\right)$ & $\begin{array}{l}\text { LGR (no detection } \\
\text { parameter) }\end{array}$ & NT & $L R T_{\text {cst } / c o}$ & $\mathrm{~N}$ & $R_{-}^{2}$ Dev & \\
\hline 26 & $\begin{array}{l}\text { Northern } \\
\text { spotted owl } \\
\text { Strix } \\
\text { occidentalis }\end{array}$ & $\begin{array}{l}\text { California } \\
\text { (USA) }\end{array}$ & $9 y$ & 10 & & $\mathrm{~N}$ & $F_{t}\left(\Delta_{c s t / t}\right)$ & CMR & $\operatorname{NS}\left(\Delta_{c o / t}\right)$ & $\begin{array}{l}\Delta_{c o / t} \\
\Delta_{c s t / c o}\end{array}$ & $\mathrm{~N}$ & $R^{2}$ Var & \\
\hline 27 & $\begin{array}{l}\text { Black-legged } \\
\text { kittiwake Rissa } \\
\text { tridactyla }\end{array}$ & $\begin{array}{l}\text { Isle of May } \\
\text { (Scotland) }\end{array}$ & $16 \mathrm{y}$ & $4(2)$ & $\mathrm{Y}$ & $\mathrm{N}$ & $\begin{array}{l}F_{T_{-} q}>F_{c s t}>F_{t} \\
\left(\Delta_{c s t / t} ; \Delta_{c s t / T_{-} q} ;\right. \\
\left.\Delta_{T_{-} q / t}\right)_{2}\end{array}$ & CMR & $\mathrm{NS}\left(\Delta_{c s t / t}\right)$ & $L R T_{\text {cst } / c o}$ & $\mathrm{~N}$ & $R^{2}$ Var & $\mathrm{S}$ \\
\hline 28 & $\begin{array}{l}\text { Desert tortoise } \\
\text { Gopherus } \\
\text { agassizii }\end{array}$ & $\begin{array}{l}\text { California } \\
\text { (USA) }\end{array}$ & $5 y$ & 1 & & & $F_{t}\left(\Delta_{c s t / t}\right)$ & CMR & $\mathrm{NS}\left(\Delta_{c o / t}\right)$ & $\begin{array}{l}\Delta_{c o / t} \\
\Delta_{c s t / c o}\end{array}$ & & & \\
\hline 29 & $\begin{array}{l}\text { Roe deer } \\
\text { Capreolus } \\
\text { capreolus }\end{array}$ & France & $10 y$ & $2(2)$ & & $\mathrm{N}$ & $F_{t}\left(L R T_{c s t / t}\right)$ & CMR & $\mathrm{NS}\left(L R T_{c o / t}\right)$ & $L R T_{c s t / c o}$ & $\mathrm{~N}$ & $R^{2} \_$Dev & \\
\hline 30 & Mouflon Ovis & Southern & 9 biw & 12 & & $\mathrm{~N}$ & $F_{t}\left(\Delta_{c s t / t}\right)$ & CMR & $\mathrm{NS}\left(\Delta_{c o / t}\right)$ & $\Delta_{c o / t}$ & $\mathrm{~N}$ & & \\
\hline
\end{tabular}




\begin{tabular}{|c|c|c|c|c|c|c|c|c|c|c|c|c|c|}
\hline & aries & France & & & & & & & & $\Delta_{c s t / c o}$ & & & \\
\hline 31 & \begin{tabular}{|l|} 
Blue tit \\
Cyanistes \\
caeruleus
\end{tabular} & \begin{tabular}{|l} 
France \\
(mainland \\
and Corsica)
\end{tabular} & $6-13 y$ & 9 & $\mathrm{Y}$ & $\bar{Y}$ & $F_{t}\left(\Delta_{c s t / t}\right)$ & CMR & NT & Ftest cst/co/t $_{\text {t }}$ & $\mathrm{M}$ & $R^{2} \_D e v$ & \\
\hline 32 & $\begin{array}{l}\text { Northern } \\
\text { fulmar } \\
\text { Fulmarus } \\
\text { glacialis }\end{array}$ & $\begin{array}{l}\text { Orkneys } \\
\text { (Scotland) }\end{array}$ & $34 \mathrm{y}$ & $2(1)$ & $\mathrm{Y}$ & $\mathrm{Y}$ & $\begin{array}{l}F_{T}>F_{c s t}>F_{t} \\
F_{c s t}>F_{T}>F_{t} \\
\text { depending on } \\
\operatorname{sex}\left(\Delta_{c s t h} ; \Delta_{c s t} ;\right. \\
\left.\Delta_{T / t}\right)\end{array}$ & CMR & $\mathrm{NS}\left(\Delta_{c s t / t}\right)$ & $\begin{array}{l}L R T_{\text {cst } / c o} \\
L R T_{T / c o+T}\end{array}$ & $\mathrm{~N}$ & $R^{2} \_D e v$ & $\begin{array}{l}\mathrm{S} \\
\mathrm{C}\end{array}$ \\
\hline 33 & $\begin{array}{l}\text { Mallard Anas } \\
\text { platyrhynchos }\end{array}$ & Sweden & $2 \mathrm{y} * 16$ & 1 & & & $F_{c s t}$ & KF & NT & $\Delta_{c s t / c o}$ & & & $\mathrm{~S}$ \\
\hline 34 & $\begin{array}{l}\text { Soay sheep } \\
\text { Ovis aries }\end{array}$ & \begin{tabular}{|l|} 
St Kilda \\
(Scotland)
\end{tabular} & $8 y * 18 w$ & 9 & & $\mathrm{~N}$ & $F_{t}(\mathrm{NT})$ & $\begin{array}{l}\text { LR on number of } \\
\text { deaths }\end{array}$ & NT & $F$-LR & $\mathrm{Y}$ & $R^{2}$ Dev & \\
\hline 35 & $\begin{array}{l}\text { Atlantic puffin } \\
\text { Fratercula } \\
\text { arctica }\end{array}$ & $\begin{array}{l}\text { North eastern } \\
\text { Atlantic }\end{array}$ & $11-17 \mathrm{y}$ & 6 & $\mathrm{Y}$ & $\mathrm{Y}$ & $\begin{array}{l}F_{t} \text { or } F_{c s t} \\
\text { depending on } \\
\text { colony }\left(\Delta_{c s t / t}\right)\end{array}$ & CMR & NT & Ftest $t_{\text {cst } / c o / t}$ & $\mathrm{~N}$ & $R^{2} \_D e v$ & \\
\hline 36 & $\begin{array}{l}\text { Atlantic puffin } \\
\text { Fratercula } \\
\text { arctica }\end{array}$ & Scotland & $21 \mathrm{y}$ & $4(7)$ & & $\mathrm{N}$ & $F_{t}\left(L R T_{c s t / t}\right)$ & LR on $F_{t}$ estimates & $\mathrm{NS}\left(L R T_{c o / t}\right)$ & $F$-LR & $\mathrm{N}$ & & $\mathrm{S}$ \\
\hline 37 & \begin{tabular}{|l} 
Ghost bat \\
Macroderma \\
gigas
\end{tabular} & Australia & $5 y * 4 s$ & 4 & & $\mathrm{~N}$ & $F_{t}\left(\Delta_{c s t / t}\right)$ & CMR & $\mathrm{NS}\left(\Delta_{c o / t}\right)$ & $\begin{array}{l}\Delta_{c o / t} \\
\Delta_{c s t / c o}\end{array}$ & $\mathrm{~N}$ & & \\
\hline 38 & $\begin{array}{l}\text { Southern } \\
\text { fulmar } \\
\text { Fulmarus } \\
\text { glacialoides }\end{array}$ & Terre Adélie & $38 \mathrm{y}$ & 12 & & $\mathrm{~N}$ & $F_{c s t}\left(\Delta_{c s t / t}\right)$ & CMR & $\mathrm{NS}\left(\Delta_{c s t / t}\right)$ & $\begin{array}{l}\Delta_{c o / t} \\
\Delta_{c s t / c o} \\
\text { UC (based } \\
\text { on } \Delta_{c s t / c o}=- \\
0.39 \text { ) }\end{array}$ & $\mathrm{Y}$ & $R_{-}^{2}$ Dev & \\
\hline 39 & \begin{tabular}{|l|} 
Emperor \\
penguin \\
Aptenodytes \\
forsteri, snow \\
petrel \\
Pagodroma \\
nivea
\end{tabular} & Terre Adélie & $31-34 y$ & 13 & $\mathrm{Y}$ & $\mathrm{N}$ & $\begin{array}{l}F_{c s t} \text { or } F_{t} \\
\text { depending on } \\
\text { sex and species } \\
\left(\Delta_{c s t / t}\right)\end{array}$ & CMR & $\begin{array}{l}\text { NS or S } \\
\text { depending on } \\
\text { sex and species } \\
\left(\Delta_{c o / t}\right)\end{array}$ & $\begin{array}{l}\Delta_{c o / t} \\
\Delta_{c s t / c o}\end{array}$ & $\mathrm{~N}$ & $R_{-}^{2} D e v$ & \\
\hline
\end{tabular}




\begin{tabular}{|c|c|c|c|c|c|c|c|c|c|c|c|c|c|}
\hline 40 & $\begin{array}{l}\text { Adélie } \\
\text { penguins } \\
\text { Pygoscelis } \\
\text { adeliae }\end{array}$ & Terre Adélie & $8 y$ & 7 & $\mathrm{Y}$ & $\mathrm{Y}$ & $F_{t}\left(\Delta_{c s t / t}\right)$ & CMR & $\mathrm{NS}\left(\Delta_{c o / t}\right)$ & $\begin{array}{l}\Delta_{c o / t} \\
\Delta_{c s t / c o}\end{array}$ & $\mathrm{~N}$ & $R^{2} \_D e v$ & \\
\hline 41 & $\begin{array}{l}\text { Least auklet } \\
\text { Aethia pusilla }\end{array}$ & North Pacific & $10 \mathrm{y}$ & 3 & $\mathrm{Y}$ & $\mathrm{N}$ & $F_{c s t}\left(\Delta_{c s t / t}\right)$ & CMR & $\operatorname{NS}\left(\Delta_{c s t / t}\right)$ & $\Delta_{\text {cst } / c o}$ & $\mathrm{M}$ & & \\
\hline 42 & $\begin{array}{l}\text { Bighorn sheep } \\
\text { Ovis } \\
\text { canadensis }\end{array}$ & $\begin{array}{l}\text { Alberta, } \\
\text { (Canada) }\end{array}$ & $18 \mathrm{y}$ & $1(1)$ & & $\mathrm{N}$ & $F_{c s t}\left(\Delta_{c s t / t}\right)$ & CMR & $\operatorname{NS}\left(\Delta_{c s t / t}\right)$ & $\Delta_{c s t / c o}$ & $\mathrm{~N}$ & & \\
\hline 43 & $\begin{array}{l}\text { African } \\
\text { multimammate } \\
\text { rat Mastomys } \\
\text { natalensis }\end{array}$ & Tanzania & $24 \mathrm{~m}$ & $2(1)$ & & $\mathrm{Y}$ & $F_{t}\left(L R T_{c s t / t}\right)$ & CMR & NT & Ftest cst/co/t $_{\text {t }}$ & $\mathrm{N}$ & $R_{-}^{2} D e v$ & \\
\hline 44 & $\begin{array}{l}\text { White stork } \\
\text { Ciconia ciconia }\end{array}$ & \begin{tabular}{|l|} 
Alsace \\
(breeding) \\
\end{tabular} & $20 y$ & 7 & & $\mathrm{~N}$ & $F_{c s t}\left(L R T_{c s t / t}\right)$ & CMR & $\mathrm{NS}\left(L R T_{c s t / t}\right)$ & $L R T_{c s t / c o}$ & $\mathrm{~N}$ & & $\mathrm{C}$ \\
\hline 45 & $\begin{array}{l}\text { Svalbard pink- } \\
\text { footed goose } \\
\text { Anser } \\
\text { brachyrhynchus }\end{array}$ & $\begin{array}{l}\text { Svalbard } \\
\text { (arctic) in } \\
\text { summer, } \\
\text { Denmark and } \\
\text { Netherlands } \\
\text { in winter }\end{array}$ & $13 \mathrm{y}$ & $2(3)$ & $\mathrm{Y}$ & $\mathrm{Y}$ & $F_{t}\left(\Delta_{c s t / t}\right)$ & CMR & $\mathrm{S}\left(L R T_{c o / t}\right)$ & Ftest cst/co/t $_{\text {t }}$ & $\mathrm{N}$ & $R^{2} \_D e v$ & $\begin{array}{l}\mathrm{S} \\
\mathrm{C}\end{array}$ \\
\hline 46 & $\begin{array}{l}\text { Willow tit } \\
\text { Poecile } \\
\text { montana }\end{array}$ & Finland & $3 y * 9 m$ & 2 & & $\mathrm{~N}$ & $\begin{array}{l}F_{t} \text { or } F_{c s t} \text { for } \\
\text { seasonal } \\
\text { variation, } \\
\text { depending on } \\
\text { year }\left(L R T_{c s t / t}\right)\end{array}$ & LR on $F_{t}$ estimates & NT & $F$-LR & $\mathrm{N}$ & $R^{2} \_\mathrm{LR}$ & \\
\hline 47 & $\begin{array}{l}\text { Manatee } \\
\text { Trichechus } \\
\text { manatus }\end{array}$ & $\begin{array}{l}\text { Florida } \\
\text { (USA) }\end{array}$ & $15 \mathrm{y}$ & 1 & & & $F_{t}\left(\Delta_{c s t / t}\right)$ & CMR & NT & Ftest $t_{c s t / c o / t}$ & & $R^{2} \_D e v$ & \\
\hline 48 & $\begin{array}{l}\text { Leaf-eared } \\
\text { mice Phyllotis } \\
\text { darwini }\end{array}$ & Central Chile & $12 \mathrm{y} * 4 \mathrm{~s}$ & $2(3)$ & $\mathrm{Y}$ & $\mathrm{N}$ & $F_{t}\left(\Delta_{c s t / t}\right)$ & CMR & $\mathrm{S}\left(\Delta_{c o / t}\right)$ & $\begin{array}{l}\Delta_{c o / t} \\
\Delta_{c s t / c o}\end{array}$ & $\mathrm{~N}$ & $R^{2} \_D e v$ & \\
\hline 49 & $\begin{array}{l}\text { Short-tailed } \\
\text { shrew Blarina } \\
\text { brevicauda }\end{array}$ & $\begin{array}{l}\text { Pennsylvania } \\
\text { (USA) }\end{array}$ & $\begin{array}{l}20 \mathrm{y}^{*} \\
12 \mathrm{~m}\end{array}$ & $3(1)$ & $\mathrm{Y}$ & $\mathrm{N}$ & $F_{t}\left(L R T_{c s t / t}\right)$ & CMR & $\begin{array}{l}\text { NS and S } \\
\text { depending on } \\
\text { age }\left(\Delta_{c o / t}\right)\end{array}$ & $\begin{array}{l}\Delta_{c o / t} \\
\Delta_{c s t / c o}\end{array}$ & $\mathrm{~N}$ & $R^{2} \_D e v$ & \\
\hline
\end{tabular}




\begin{tabular}{|c|c|c|c|c|c|c|c|c|c|c|c|c|c|}
\hline 50 & $\begin{array}{l}\text { Chamois, isard } \\
\text { Rupicapra } \\
\text { rupicapra }\end{array}$ & $\begin{array}{l}\text { French Alps } \\
\text { and Pyrenees }\end{array}$ & $12 \mathrm{y}$ & 15 & $\mathrm{Y}$ & $\mathrm{Y}$ & $F_{t}\left(\Delta_{c s t / t}\right)$ & CMR & $\begin{array}{l}\text { NS and S } \\
\text { depending on } \\
\text { population }\end{array}$ & $L R T_{c s t / c o}$ & $\mathrm{~N}$ & $R^{2} \_D e v$ & \\
\hline 51 & $\begin{array}{l}\text { Red deer } \\
\text { Cervus elaphus }\end{array}$ & Norway & $19 y$ & 2 & & $\mathrm{Y}$ & $\begin{array}{l}F_{t} \text { or } F_{c s t} \\
\text { depending on } \\
\text { age }\left(\Delta_{c s t / t}\right)\end{array}$ & CMR & NT & $L R T_{c s t / c o}$ & $\mathrm{~N}$ & & $\begin{array}{l}\mathrm{S} \\
\mathrm{C}\end{array}$ \\
\hline 52 & $\begin{array}{l}\text { European } \\
\text { dipper Cinclus } \\
\text { cinclus }\end{array}$ & Norway & $18 \mathrm{y}$ & $3(1)$ & $\mathrm{Y}$ & $\mathrm{Y}$ & $F_{t}\left(\Delta_{c s t / t}\right)$ & CMR & $\begin{array}{l}\text { NS and S } \\
\text { depending on } \\
\text { age }\left(\Delta_{c o / t}\right)\end{array}$ & $\begin{array}{l}\Delta_{c o / t} \\
\Delta_{c s t / c o} \\
\mathrm{UC} \text { (based } \\
\text { on } R^{2} \text { ) }\end{array}$ & $\mathrm{N}$ & $\begin{array}{l}R^{2} \text { Dev } \\
R^{2} \text { Var }\end{array}$ & \\
\hline 53 & $\begin{array}{l}\text { Soay sheep } \\
\text { Ovis aries }\end{array}$ & $\begin{array}{l}\text { St Kilda } \\
\text { (Scotland) }\end{array}$ & $9 y$ & $1(1)$ & $\mathrm{Y}$ & $\mathrm{N}$ & $R_{t}(\mathrm{NT})$ & $\begin{array}{l}\text { Mixed LGR (no } \\
\text { detection } \\
\text { parameter) }\end{array}$ & NT & $\begin{array}{l}W\left(R_{c o}\right) \text { and } \\
\text { Ftest } t_{c s t / c o / t}\end{array}$ & $\mathrm{~N}$ & & \\
\hline 54 & $\begin{array}{l}\text { Moose Alces } \\
\text { alces }\end{array}$ & Alaska & $11 y^{*} 3 \mathrm{~s}$ & 1 & & & $\begin{array}{l}F_{t} ; \text { homogeneity } \\
\text { test }\end{array}$ & KM & $\begin{array}{l}\text { NS; } \\
\text { homogeneity } \\
\text { test among } \\
\text { normal snow } \\
\text { years }\end{array}$ & $\begin{array}{l}\text { Homogeneit } \\
\text { y test } \\
\text { between } \\
\text { years with } \\
\text { different } \\
\text { climatic } \\
\text { conditions }\end{array}$ & & & \\
\hline 55 & $\begin{array}{l}\text { Barn swallow } \\
\text { Hirundo rustica }\end{array}$ & $\begin{array}{l}\text { Denmark } \\
\text { (breeding) }\end{array}$ & $18 \mathrm{y}$ & 7 & & $\mathrm{~N}$ & $F_{t}\left(\Delta_{c s t / t}\right)$ & CMR & $\mathrm{NS}\left(\Delta_{c o / t}\right)$ & Ftest $t_{c s t / c o / t}$ & $\mathrm{M}$ & $R_{-}^{2} ?$ & \\
\hline 56 & $\begin{array}{l}\text { Sparrowhawk } \\
\text { Accipiter nisus }\end{array}$ & UK & $9-15 y$ & $\begin{array}{l}\geq 15 \\
(1)\end{array}$ & & $\mathrm{N}$ & $\begin{array}{l}F_{t} \text { or } F_{c s t} \\
\text { depending on } \\
\text { site }\left(L R T_{c s t / t}\right)\end{array}$ & CMR & NT & $L R T_{c s t / c o}$ & $\mathrm{M}$ & & $\begin{array}{l}\mathrm{S} \\
\mathrm{C}\end{array}$ \\
\hline 57 & $\begin{array}{l}\text { Thin-billed } \\
\text { prion } \\
\text { Pachyptila } \\
\text { belcheri }\end{array}$ & $\begin{array}{l}\text { Kerguelen } \\
\text { Islands }\end{array}$ & $14 \mathrm{y}$ & $>500$ & $\mathrm{Y}$ & $\mathrm{N}$ & $F_{c s t}\left(\Delta_{c s t / t}\right)$ & CMR & $\mathrm{NS}\left(\Delta_{c s t / t}\right)$ & $\Delta_{c s t / c o}$ & $\mathrm{~N}$ & & $\begin{array}{l}\mathrm{S} \\
\mathrm{C}\end{array}$ \\
\hline 58 & $\begin{array}{l}\text { Mauritius } \\
\text { kestrel Falco } \\
\text { punctatus }\end{array}$ & $\begin{array}{l}\text { Mauritius } \\
\text { island } \\
\text { (Indian } \\
\text { ocean) }\end{array}$ & $15 y$ & $2(2)$ & & $\mathrm{N}$ & $\begin{array}{l}F_{t} \text { or } F_{c s t} \\
\text { depending on } \\
\text { age }\left(\Delta_{c s t / t}\right)\end{array}$ & CMR & $\mathrm{NS}\left(\Delta_{c o / t}\right)$ & $\begin{array}{l}\Delta_{c o / t} \\
\Delta_{c s t / c o}\end{array}$ & $\mathrm{~N}$ & $R^{2} \_D e v$ & \\
\hline 59 & $\begin{array}{l}\text { Kudu } \\
\text { Tragelaphus }\end{array}$ & $\begin{array}{l}\text { Kruger Park } \\
\text { (South }\end{array}$ & $11 y$ & $2(1)$ & & $\mathrm{N}$ & $F_{t}(\mathrm{NT})$ & $\begin{array}{l}\text { LR on number alive } \\
\text { at } i+1 \text { among those }\end{array}$ & NT & $F$-LR & $\mathrm{N}$ & $R^{2} \_\mathrm{LR}$ & $\mathrm{C}$ \\
\hline
\end{tabular}




\begin{tabular}{|c|c|c|c|c|c|c|c|c|c|c|c|c|c|}
\hline & strepsiceros & Atrica) & & & & & & seen at $i$ & & & & & \\
\hline 60 & $\begin{array}{l}\text { Sedge warbler } \\
\text { Acrocephalus } \\
\text { schoenobaenus }\end{array}$ & Britain & $16 y$ & 1 & & & $F_{t}\left(L R T_{c s t / t}\right)$ & CMR & $\mathrm{NS}\left(L R T_{c o / t}\right)$ & $L R T_{c s t / c o}$ & & $R^{2}$ VVar & $\begin{array}{l}\mathrm{S} \\
\mathrm{C}\end{array}$ \\
\hline 61 & $\begin{array}{l}\text { Reed bunting } \\
\text { Emberiza } \\
\text { schoeniclus }\end{array}$ & England & $28 y$ & 1 & & & $F_{t}\left(L R T_{c s t / t}\right)$ & CMR & NT & $L R T_{c s t / c o}$ & & & $\begin{array}{l}\mathrm{S} \\
\mathrm{C}\end{array}$ \\
\hline 62 & $\begin{array}{l}\text { Lapwing } \\
\text { Vanellus } \\
\text { vanellus }\end{array}$ & Great Britain & $20-50 y$ & 35 & & $\mathrm{Y}$ & $\begin{array}{l}F_{t}\left(\mathrm{GOF} \text { of } F_{t}\right. \\
\left.\text { and } F_{c s t}\right)\end{array}$ & LR on $F_{t}$ estimates & NT & $F$-LR & $\mathrm{N}$ & $R^{2} \_$Var & \\
\hline 63 & $\begin{array}{l}\text { Great tit Parus } \\
\text { major }\end{array}$ & Netherlands & $35 y$ & $1(3)$ & & $\mathrm{N}$ & $F_{t}(\mathrm{NT})$ & $\begin{array}{l}\text { LR on } F_{t} \text { estimates } \\
\text { (arcsine } \\
\text { transformed) }\end{array}$ & NT & $F$-LR & $\mathrm{N}$ & $R_{-}^{2} \mathrm{LR}$ & \\
\hline 64 & $\begin{array}{l}\text { Longtailed } \\
\text { wagtail } \\
\text { Motacilla clara }\end{array}$ & South Africa & $20 y * 4 s$ & $6(2)$ & & $\mathrm{N}$ & $F_{t}\left(\Delta_{c s t / t}\right)$ & CMR & $\mathrm{S}\left(\Delta_{c o / t}\right)$ & $A I C$ weights & $\mathrm{N}$ & & $\mathrm{S}$ \\
\hline 65 & $\begin{array}{l}\text { New Zealand } \\
\text { long-tailed bats } \\
\text { Chalinolobus } \\
\text { tuberculatus }\end{array}$ & New Zealand & $9 y$ & $1(1)$ & & $\mathrm{N}$ & $F_{c s t}\left(\Delta_{c s t / t}\right)$ & CMR & $\operatorname{NS}\left(\Delta_{c s t / t}\right)$ & $L R T_{c s t / c o}$ & $\mathrm{~N}$ & & \\
\hline 66 & $\begin{array}{l}\text { Song thrush } \\
\text { Turdus } \\
\text { philomelos }\end{array}$ & Britain & $32 y$ & 2 & & $\mathrm{~N}$ & $F_{c s t}\left(\Delta_{c s t / t}\right)$ & CMR & $\mathrm{NS}\left(\Delta_{c s t / t}\right)$ & $L R T_{c s t / c o}$ & $\mathrm{~N}$ & & \\
\hline 67 & $\begin{array}{l}5 \text { seabird } \\
\text { species:Uria } \\
\text { aalge, Uria } \\
\text { lomvia, Alca } \\
\text { torda, } \\
\text { Fratercula } \\
\text { arctica, Rissa } \\
\text { tridactyla }\end{array}$ & Barents Sea & $14 \mathrm{y}$ & $\begin{array}{l}16 \\
(3)\end{array}$ & $\mathrm{Y}$ & $\mathrm{N}$ & $\begin{array}{l}F_{c s t}, F_{T} \text { or } F_{t} \\
\text { depending on } \\
\text { species }\left(\Delta_{c s t / t},\right. \\
\left.\Delta_{c s t / T} \Delta_{T / t}\right)\end{array}$ & CMR & $\begin{array}{l}\text { NS or } \mathrm{S} \\
\text { depending on } \\
\text { species }\left(\Delta_{c o / t}\right)\end{array}$ & $\begin{array}{l}\Delta_{c o t} \\
\Delta_{c s t / c o} \\
\mathrm{UC} \text { in two } \\
\text { species } \\
\left(\Delta_{c s t / c o}=-\right. \\
0.73 \text { and } \\
\left.\Delta_{c s t / c o}=1.22\right)\end{array}$ & $\mathrm{N}$ & $R^{2} \_D e v$ & $\mathrm{~S}$ \\
\hline 68 & $\begin{array}{l}\text { Guanaco Lama } \\
\text { guanicoe }\end{array}$ & Chile & $5 y$ & $1(1)$ & & $\mathrm{Y}$ & $\begin{array}{l}F_{t} ; \text { homogeneity } \\
\text { test Kaplan- } \\
\text { Meyer model }\end{array}$ & CR & NT & Wald & $\mathrm{N}$ & & \\
\hline 69 & Two African & Kenya & $22 \mathrm{~m}$ & 8 & & $\mathrm{~N}$ & $F_{c s t}\left(\Delta_{c s t / t}\right)$ & CMR & $\mathrm{NS}\left(\Delta_{c o / t}\right)$ & $\Delta_{c s t / c o}$ & $\mathrm{~N}$ & & \\
\hline
\end{tabular}




\begin{tabular}{|c|c|c|c|c|c|c|c|c|c|c|c|c|}
\hline & $\begin{array}{l}\text { warbler species } \\
\text { Sylvia Boehmi, } \\
\text { Sylvia lugens }\end{array}$ & & & & & & & & & & & \\
\hline 70 & $\begin{array}{l}\text { White stork } \\
\text { Ciconia ciconia }\end{array}$ & $\begin{array}{l}\text { Germany, } \\
\text { Poland } \\
\text { (breeding) }\end{array}$ & $19 \mathrm{y}$ & $1(3)$ & & $\mathrm{Y}$ & $\begin{array}{l}F_{t}\left(\Delta_{c s t / t}\right) \text { and } \\
\text { quantified from } \\
R_{t}\end{array}$ & CMR & $\begin{array}{l}\text { NT but } \\
\text { Quantified } \\
\text { from } R_{c o}\end{array}$ & Not assessed & $\mathrm{N}$ & $R^{2}$ Var \\
\hline 71 & $\begin{array}{l}\text { Pipistrelle bat } \\
\text { Pipistrellus } \\
\text { pipistrellus }\end{array}$ & $\begin{array}{l}\text { Hesse } \\
\text { (Germany) }\end{array}$ & $3 y * 2 s$ & 2 & & $\mathrm{~N}$ & $F_{t}\left(\Delta_{c s t / t}\right)$ & CMR & $\mathrm{S}\left(\Delta_{c o / t}\right)$ & $\begin{array}{l}\Delta_{c o / t} \\
\Delta_{c s t / c o}\end{array}$ & $\mathrm{~N}$ & \\
\hline 72 & $\begin{array}{l}\text { Black-throated } \\
\text { blue warbler } \\
\text { Dendroica } \\
\text { caerulescens }\end{array}$ & $\begin{array}{l}\text { New } \\
\text { Hampshire } \\
\text { (USA) }\end{array}$ & $11 y$ & 1 & $\mathrm{Y}$ & & $\begin{array}{l}F_{t} \text { or } F_{c s t} \\
\text { depending on } \\
\text { site }\left(\Delta_{c s t / t}\right)\end{array}$ & CMR & $\mathrm{NS}\left(\Delta_{c o / t}\right)$ & $\begin{array}{l}\Delta_{c o / t} \\
\Delta_{c s t / c o}\end{array}$ & & \\
\hline 73 & $\begin{array}{l}\text { Elk Cervus } \\
\text { elaphus }\end{array}$ & $\begin{array}{l}\text { Yellowstone } \\
\text { (USA) }\end{array}$ & $3 y$ & 4 & & $\mathrm{~N}$ & $F_{t}(\mathrm{NT})$ & LGR & NT & $L R T_{\text {cst } / c o}$ & $\mathrm{~N}$ & $R^{2} \_D e v$ \\
\hline 74 & $\begin{array}{l}\text { Common house } \\
\text { martin } \\
\text { Delichon } \\
\text { urbicum }\end{array}$ & Germany & $8 \mathrm{y}$ & 10 & & $\mathrm{~N}$ & $F_{t}\left(\Delta_{c s t / t}\right)$ & CMR & $\mathrm{S}\left(\Delta_{c o / t}\right)$ & Not assessed & $\mathrm{N}$ & $R^{2}$ Var \\
\hline 75 & $\begin{array}{l}\text { Eurasian } \\
\text { woodcock } \\
\text { Scolopax } \\
\text { rusticola }\end{array}$ & France & $7-14 y$ & 2 & & $\mathrm{Y}$ & $\begin{array}{l}F_{t} \text { or } F_{c s t} \\
\text { depending on } \\
\text { area }\left(\Delta_{c s t / t}\right)\end{array}$ & CMR & $\begin{array}{l}\text { NS or } \mathrm{S} \\
\text { depending on } \\
\text { area }\left(\Delta_{c o / t}\right)\end{array}$ & $\begin{array}{l}\Delta_{c o / t} \\
\Delta_{c s t / c o} \\
\mathrm{UC} \text { in one } \\
\text { area out of } \\
\text { three }\end{array}$ & $\mathrm{N}$ & $R^{2} \_$Dev \\
\hline 76 & $\begin{array}{l}\text { White-winged } \\
\text { scoter } \\
\text { Melanitta fusca }\end{array}$ & Canada & $\begin{array}{l}15 \text { bidaily } \\
\text { intervals }\end{array}$ & 1 & & & $F_{c s t}(\mathrm{NT})$ & CMR & NT & $A I C$ weights & & \\
\hline 77 & $\begin{array}{l}\text { Common } \\
\text { guillemot } \\
\text { Cepphus grylle }\end{array}$ & $\begin{array}{l}\text { Skomer } \\
\text { Island (UK) }\end{array}$ & $18 \mathrm{y}$ & $2(2)$ & $\mathrm{Y}$ & $\mathrm{Y}$ & $F_{c s t}\left(\Delta_{c s t / t}\right)$ & CMR & $\mathrm{NS}\left(\Delta_{c s t / t}\right)$ & $\Delta_{c s t / c o}$ & $\mathrm{~N}$ & $R^{2} \_D e v$ \\
\hline 78 & $\begin{array}{l}\text { Northern } \\
\text { Goshawk } \\
\text { Accipiter } \\
\text { gentilis } \\
\end{array}$ & $\begin{array}{l}\text { Arizona } \\
\text { (USA) }\end{array}$ & $4 y$ & $1(1)$ & & $\mathrm{N}$ & $F_{t}\left(\Delta_{c s t / t}\right)$ & $\mathrm{KF}$ & $\mathrm{NS}\left(\Delta_{c o / t}\right)$ & Ftest $t_{c s t / c o / t}$ & $\mathrm{~N}$ & $R^{2} \_$Dev \\
\hline
\end{tabular}


1, Aars \& Ims (2002); 2, Albon et al. (1987); 3, Altwegg et al. (2005); 4. Altwegg et al. (2003); 5, Altwegg et al. (2006); 6, Barbraud \& Weimerskirch (2001); 7, Barbraud \& Weimerskirch (2003); 8. Barbraud \& Weimerskirch (2005); 9, Barbraud et al. (2000); 10, Beauplet et al. (2005); 11, Bertram et al. (2005); 12, Blums et al. (2002); 13, Boonstra \& Krebs (2006); 14, Brouwer et al. (2006); 15, Chamaillé-Jammes et al. (2006); 16, Catchpole et al. (2000); 17, Catchpole et al. (1999); 18, Cavé \& Visser (1985); 19, Clobert \& Lebreton (1985); 20, Clobert et al. (1988); 21, Conroy et al. (2002); 22, Cowley \& Siriwardena (2005); 23, Crespin et al. (2006); 24, Doherty \& Grubb (2002); 25, Forchhammer et al. (2001); 26, Franklin et al. (2000); 27, Frederiksen et al. (2004); 28, Freilich et al. (2000); 29, Gaillard et al. (1997); 30, Garel et al. (2004); 31, Grosbois et al. (2006); 32, Grosbois \& Thompson (2005); 33, Gunnarsson et al. (2006); 34, Hallet et al. (2004); 35. Harris et al. (2005); 36, Harris et al. (1997); 37, Hoyle et al. (2001); 38, Jenouvrier et al. (2003); 39, Jenouvrier et al. (2005); 40, Jenouvrier et al. (2006); 41, Jones et al. (2002); 42, Jorgenson et al. (1997); 43, Julliard et al. (1999); 44, Kanyamibwa et al. (1990); 45, Kery et al. (2006); 46. Lahti et al. (1998); 47, Langtimm \& Beck (2003); 48, Lima et al. (2001); 49, Lima et al. (2002); 50, Loison et al. (1999); 51, Loison \& Langvatn (1998); 52, Loison et al. (2002); 53, Milner et al. (1999); 54, Modafferi \& Becker (1997); 55, Møller \& Szep (2005); 56, Newton et al. (1992); 57, Nevoux \& Barbraud (2006); 58, Nicoll, Jones \& Norris (2003); 59, Owen-Smith (1990); 60, Peach et al. (1991); 61, Peach et al. (1999); 62, Peach et al. (1994); 63, Perdeck et al. (2000); 64, Piper (2002); 65, Pryde et al. (2005); 66, Robinson et al. (2004); 67, Sandvik et al. (2005); 68. Sarno et al. (1999); 69, Schaefer et al. (2006); 70, Schaub et al. (2005); 71, Sendor \& Simon (2003); 72, Sillet et al. (2000); 73, Singer et al. (1997); 74, Stokke et al. (2005); Tavecchia et al. (2002); 76, Traylor \& Alisauskas (2006); 77, Voitier et al. (2005); 78, Wiens et al. (2006). 


\section{(2) Bayesian modelling}

To specify the Bayesian model $R_{c o}$ for the analysis of the white stork and 500 simulated data sets, all priors were selected as sufficiently vague in order to induce little prior knowledge. Generally, if the data are sufficiently informative, the likelihood dominates the noninformative priors and the posterior summaries using MCMC samples are close to the results of a frequentist analysis. Specifically, we chose uniform distributions on $[0,1]$ for the detection probabilities, normal distributions with mean 0 and variances $1,000,000$ for the $b$ 's, and an inverse-gamma with both parameters equal to 0.001 for $\sigma^{2}$. We used software WinBUGS (Spiegelhalter et al., 2002) to implement our approach. For applications of this program in wildlife (Link et al., 2002) and for fisheries see Meyer \& Millar (1999). We generated three chains of length 15,000, discarding the first 5,000 as burn-in. These simulations lasted a few seconds on a PC (512Mo RAM, 2.6GHz CPU). Convergence was assessed using the Gelman and Rubin statistic, also called the potential scale reduction, which compares the within to the between variability of chains started at different initial values (Gelman, Meng \& Stern, 1996). Note that the covariate was first standardized in order to avoid numerical instabilities and to improve MCMC mixing. We found that the Markov chains exhibit moderate autocorrelation and good mixing regarding all parameters. In order to check for the robustness of our results, we ran our model using different priors during a sensitivity analysis, and in all cases there were only minimal changes. The codes used for fitting random- and fixed-effects models in a Bayesian framework for the analysis of white stork survival can be obtained from the first author on request. 


\section{REFERENCES}

AARS, J. \& IMS, R. A. (2002). Intrinsic and climatic determinants of population demography: the winter dynamics of tundra voles. Ecology 83, 3449-3456.

Albon, S. D., Clutton-Brock, T. H. \& Guinness, F. E. (1987). Early development and population dynamics in red deer. II. Density independent effects and cohort variation. Journal of Animal Ecology 56, 69-81.

Almaraz, P. \& Amat, J., A. (2004). Complex structural effects of two hemispheric climatic oscillators on the regional spatio-temporal expansion of a threatened bird. Ecology Letters 7, 547-556.

AltwegG, R., Dummermuth, S., Anholt, B. R. \& Flatt, T. (2005). Winter weather affects asp viper Vipera aspis population dynamics through susceptible juveniles. Oikos 110, $55-66$.

AltwegG, R., Roulin, A., Kestengolz, M. \& Jenni, L. (2003). Variation and covariation in survival, dispersal, and population size in barn owls Tyto alba. Journal of Animal Ecology 72, 391-399.

Altwegg, R., Roulin, A., Kestengolz, M. \& Jenni, L. (2006). Demographic effects of extreme winter weather in the barn owl. Oecologia 149, 44-51

ANDERSON, D. R. \& BuRnhAM, K. R. (2002). Avoiding pitfalls when using informationtheoretic methods. Journal of Wildlife Management 66, 912-918.

Anderson, D. R., BurnhaM, K. P. \& ThOMPSON, W. L. (2000). Null hypothesis testing: Problems, prevalence, and an alternative. Journal of Wildlife Management 64, 912-923. ARNASON, A. N. (1973). The estimation of population size, migration rates and survival in a stratified population. Researches on Population Ecology 15, 1-8.

ARNQVist, G., WoOster, D. (1995). Meta-analysis: synthesizing research findings in ecology and evolution. Trends in Ecology \& Evolution 10, 236-240. 
1 BAlmford, A., GreEn, R. E. \& Jenkins, M. (2003). Measuring the changing state of nature. Trends in Ecology and Evolution 18, 326-330.

Barbraud, C., Barbraud, J. C. \& Barbraud, M. (1999). Population dynamics of the white stork Ciconia ciconia in western France. Ibis 141, 469-479.

BARBRAUd, C. \& WEIMERSKIRCH, H. (2001). Emperor penguins and climate change. Nature 411, 183-186. a marine top predator. Proceedings of The Royal Society of London B. 270, 2111-2116.

BARBRAUD, C. \& WEIMERSKIRCH, H. (2005). Environmental conditions and breeding experience affect costs of reproduction in blue petrels. Ecology 86, 682-692.

Barbraud, C., Weimerskirch, H., Guinet, C. \& Jouventin, P. (2000). Effect of sea-ice extent on adult survival of an Antarctic top predator: the snow petrel Pagodroma nivea.

BARBRAUD, C. \& WEIMERSKIRCH, H. (2003).Climate and density shape population dynamics of Oecologia 125, 483-488.

BARKER, R., FletChER, D. \& SCOFIELD, P. (2002). Measuring density dependence in survival from mark-recapture data. Journal of Applied Statistics 29, 305-313.

Barry, S. C., Brooks, S. P., Catchpole, E. A. \& Morgan, B. J. T. (2003). The analysis of ring-recovery data using random effects. Biometrics 59, 54-65.

BEAUgRAnd, G. \& REID, P. C. (2003). Long-term changes in phytoplankton, zooplankton and salmon related to climate. Global Change Biology 9, 801-817.

Beauplet, G., Barbraud, C., Chambellant, M. \& Guinet, C. (2005). Interannual variation in the post-weaning and juvenile survival of subantarctic fur seals: influence of pup sex, growth rate and oceanographic conditions. Journal of Animal Ecology 74, 1160-1172.

BenjAmini, Y. \& HochBerg, Y. (1995). Controlling the false discovery rate - a practical and powerful approach to multiple testing. Journal of the Royal Statistical Society Series BMethodological 57, 289-300. 
Bertram, D. F., HARFEnist, A. \& SMith, B. D. (2005). Ocean climate and El Nino impacts on survival of Cassin's auklets from upwelling and downwelling domains of British Columbia. Canadian Journal of Fisheries and Aquatic Sciences 62, 2841-2853.

Besbeas, P., Freeman, S. N. \& Morgan, B. J. T. (2005). The potential of integrated population modelling Australian \& New Zealand Journal of Statistics 47, 35-48.

Besbeas, P., Freeman, S. N., Morgan, B. J. T. \& Catchpole, E. A. (2002). Integrating markrecapture-recovery and census data to estimate animal abundance and demographic parameters. Biometrics 58, 540-547.

Blums, P., Nichols, J. D., Hines, J. E. \& MEDNIS, A. (2002). Sources of variation in survival and breeding site fidelity in three species of European ducks. Journal of Animal Ecology 71, 438-450.

BÖHNING-GAESE, K. \& LEMOINE, N. (2004). Importance of climate change for the ranges, communities and conservation of birds. Advances in Ecological Research 35, 211-236.

BolLEN, K. A. (1989). Structural equations with latent covariates. John Wiley and Sons, New York, NY.

BoOnstra, R. \& Krebs, C. J. (2006). Population limitation of the northern red-backed vole in the boreal forests of northern Canada. Journal of Animal Ecology 75, 1269-1284.

Both, C., Artemyev, A. V., BlaAuw, B., Cowie, R. J., Dekhuijzen, A. J., Eeva, T., Enemar, A., Gustafsson, L., Ivankina, E. V., Jarvinen, A., Metcalfe, N. B., Nyholm, N. E. I., Potti, J., Ravussin, P. A., Sanz, J. J., Silverin, B., Slater, F. M., Sokolov, L. V., TÖRÖK, J., WinKEL, W., Wright, J., ZANG, H. \& VISSER, M. E. (2004). Large-scale geographical variation confirms that climate change causes birds to lay earlier. Proceedings of the Royal Society of London B 271, 1657-1662.

BRESLOW, N. (1990). Tests of hypotheses in overdispersed Poisson regression and other quasilikelihood models. Journal of the American Statistical Association 85, 565-571. 
Broennimann, O., Treier, U. A., Müller-Schärer, H., Thuiller, W., Peterson, A. T. \& GuISAN, A. (2007). Evidence of climatic niche shift during biological invasion. Ecology Letters 10, 701-709

Brooks, S. P., CATChPole, E. A., Morgan, B. J. T. \& Harris, M. P. (2002). Bayesian methods for analysing ringing data. Journal of Applied Statistics 29, 187-206.

Brouwer, L., Richardson, D. S., EikenaAR, C. \& Komdeur, J. (2006). The role of group size and environmental factors on survival in a cooperatively breeding tropical passerine. Journal of Animal Ecology 75, 1321-1329.

Brownie, C., Anderson, D., Burnham, K. P. \& Robson, D. S. (1985). Statistical inference from band recovery data - a handbook. Second edition. United States Department of the Interior Fish and Wildlife Service., Washington, D.C.

Brownie, C., Hines, J. E., Nichols, J. D., Pollock, K. H. \& Hestbeck, J. B. (1993). Capturerecapture studies for multiple strata including non-Markovian transitions. Biometrics 49, $1173-1187$.

BuCKLAND, S. T. (1982). A mark-recapture survival analysis. Journal of Animal Ecology 51, 833-847.

Buckland, S. T., Burnham, K. P. \& Augustin, N. H. (1997). Model selection: An integral part of inference. Biometrics 53, 603-618.

BurnhAM, K. P. \& ANDERSON, D. R. (2002). Model selection and Multi-Model Inference, a practical information-theoretic approach. Second edition. Springer, New York, NY.

BuRnhAM, K. P. \& White, G. C. (2002). Evaluation of some random effects methodology applicable to bird ringing data. Journal of applied statistics 29, 245-264.

CAM, E., Hines, J. E., Monnat, J.-Y., Nichols, J. D. \& Danchin, E. (1998). Are adult nonbreeders prudent parents? The kittiwake model. Ecology 79, 2917-2930.

CAROTHERs, A. D. (1973). Effects of unequal catchability on Jolly-Seber estimates. Biometrics 
29, 79-100.

2 CARothers, A. D. (1979). Quantifying unequal catchability and its effect on survival estimates in an actual population. Journal of Animal Ecology 48, 863-869. covariates. Bird Study 46, S5-S13.

CAvÉ, A. J. (1983). Purple heron survival and drought in tropical West-Africa. Ardea 71, 217224.

CAVÉ, A. J. \& VISSER, J. (1985). Winter severity and breeding bird numbers in a coot population. Ardea 73, 129-138.

Factors influencing Soay sheep survival. Applied Statistics 49, 453-472.

Catchpole, E. A., Morgan, B. J. T., Freeman, S. N. \& Peach, W. J. (1999). Modelling the survival of British lapwings Vanellus vanellus using ring-recovery data and weather

$$
\text { population. Ardea 73, 129-138. }
$$

Chamaillé-J Ammes, S., Massot, M., Aragon, P. \& Clobert, J. (2006). Global warming and positive fitness response in mountain populations of common lizards Lacerta vivipara. Global Change Biology 12, 392-402.

Choquet, R., Reboulet, A.-M., Pradel, R., Gimenez, O. \& Lebreton, J.-D. (2004). MSURGE: new software specifically designed for multistate capture-recapture models. Animal Biodiversity and Conservation 27, 207-215.

Choquet, R., Reboulet, A.-M, Lebreton, J.-D.,. Gimenez, O. \& Pradel, R (2005). UCARE user's guide, Version 2.2. CEFE/CNRS, Montpellier (ftp://ftp.cefe.cnrs.fr/biom/Soft-CR)

Chuine, I. \& BeAubien, E. G. (2001). Phenology is a major determinant of tree species range. Ecology Letters 4, 500-510.

ClARK, J. S. (2005). Why environmental scientists are becoming Bayesians. Ecology Letters 8 , $2-14$. 
Clark, J. S., Carpenter, S. R., Barber, M., Collins, S., Dobson, A., Foley, J. A., Lodge, D., Pascual, M., Pielke, R. J., Pizer, W., Pringle, C., Reid, W. V., Rose, K. A., SAla, O., Schlesinger, W. H., WALl, D. H. \& WeAR, D. (2001). Ecological forecasts: an emerging imperative. Science 293, 657-660.

Clobert, J. \& Lebreton, J. -D. (1985). Dépendance de facteurs de milieu dans les estimations de taux de survie par capture-recapture. Biometrics 41, 1031-1037.

Clobert J., Lebreton, J. D. \& Allaine, D. (1987). A general approach to survival rate estimation by recaptures or resightings of marked birds. Ardea 75, 133-142.

Clobert J., Lebreton, J. D. \& Allaine, D., \& Gaillard, J. M. (1994). The estimation of age- specific breeding probabilities from recaptures or resightings in vertebrate populations. 2. Longitudinal models. Biometrics 50, 375-387.

Clobert, J., Perrins, C. M., MC-Cleery, R. H. \& Gosler, G. (1988). Survival rate in the great tit Parus major in relation to sex, age and immigration status. Journal of Animal Ecology 57, 287-306.

CoHEN, J. (1994). The earth is round ( $\mathrm{P}<0.05)$. American Psychologist 49, 997-1003.

Conroy, M. J., Senar, J. C. \& DomÈnech, J. (2002). Analysis of individual- and time-specific covariate effects on survival of Serinus serinus in north-eastern Spain. Journal of Applied Statistics 29, 125-142.

CORANI, G. \& GATTO, M. (2007). Structural risk minimization : a robust method for densitydependence detection and model selection. Ecography. 30, 400-416.

Coulson, J. C. (2001). Does density-dependent mortality occur in wintering Eurasian Oystercatchers Haematopus ostralegus and breeding adult Black-legged Kittiwakes Rissa tridactyla? Ibis 143, 500-502. 
Coulson, T., Catchrole, E. A., Albon, S. D., Morgan, B. J. T., Pemberton, J. M., Clutton-Brock, T. H., Crawley, M. J. \& Grenfell, B. T. (2001). Age, sex, density, winter weather, and population crashes in Soay sheep. Science 292, 1528-1531.

Cowley, E. \& Siriwardena, G. M. (2005). Long-term variation in survival rates of Sand Martins Riparia riparia: dependence on breeding and wintering ground weather, age and sex, and their population consequences. Bird Study 52, 237-251.

Cox, D. R. \& OAKES, D. (1984). Analysis of survival data. Chapman and Hall, London, U.K..

Crespin, L., Harris, M. P., Lebreton, J. -D., Frederiksen, M. \& Wanless, S. (2006). Recruitment to a seabird population depends on environmental factors and on population size. Journal of Animal Ecology 75, 228-238.

Devineau, O., Choquet, R. \& LeBreton, J. D. (2006). Planning capture-recapture studies: Straightforward precision, bias, and power calculations. Wildlife Society Bulletin 34, 1028-1035.

DOHERTY, P. F. \& GRUBB, T. C. (2002). Survivorship of permanent-resident birds in a fragmented forested landscape. Ecology 83, 844-857.

Doran, P. T., Priscu, J. C., Berry Lyons, W., Walsh, J. E., Fountain, A. G., Mc-Knight, D. M., Moorhead, D. L., Virginia, R. A., Wall, D. H., Clow, G. D., Fritsen, C. H., MC-KAY, C. P. \& PARSONS, A. N. (2002). Antarctic climate cooling and terrestrial ecosystem response. Nature 415, 517-520.

Dormann, C. F., Schweiger, O., Arens, P., Augenstein, I., Aviron, S., Bailey, D., Baudry, J., Billeter, R., Bugter, R., Bukacek, R., Burel, F., Cerny, M., De Cock, R., De Blust, G., DeFilipPi, R., Diekotter, T., Dirksen, J., Durka, W., Edwards, P. J., FrenZel, M., Hamersky, R., HendrickX, F., Herzog, F., Klotz, S., KoOlstra, B., Lausch, A., Le Ceeur, D., LiRA, J., Maelfait, J.P., Opdam, P., Roubalova, M., SchermanNLegionnet, A., Schermann, N., Schmidt, T., Smulders, M. J. M., Speelmans, M., 
Simova, P., Verboom, J., Van Wingerden, W. \& Zobel, M. (2008). Prediction uncertainty of environmental change effects on temperate European biodiversity. Ecology Letters 11, 235-244.

DRAPER, N. R. \& SMith, H. (1981a). Applied regression analysis, Second Edition. John Wiley \& Sons, Inc., New York, NY.

DunN, P. (2004). Breeding dates and reproductive performance. Advances in Ecological Research 35, 69-87.

DurAnt, J., ANKER-NiLSSEN, T. \& STENSETH, N. C. (2003). Trophic interactions under climate fluctuations: the Atlantic puffin as an example. Proceedings of the Royal Society of London B 270, 1461-1466.

Easterling, D. R., Meehl, G. A., Parmesan, C., Changnon, S. A., Karl, T. R. \& Mearns, L. O. (2000). Climate extremes: observations, modelling, and impacts. Science 289, 2068-2074.

ElLISON, A. M. (2004). Bayesian inference in ecology. Ecology Letters 7, 509-520.

Field, S. A., Tyre, A. J., Jonzen, N., Rhodes, J. R. \& Possingham, H. P. (2004). Minimizing the cost of environmental management decisions by optimizing statistical thresholds. Ecology Letters 7, 669-675.

Forchhammer, M. C., Clutton-Brock, T. H., Lindström, J. \& Albon, S. D. (2001). Climate and population density induce long-term cohort variation in a northern ungulate. Journal of Animal Ecology 70, 721-729.

Forsman, J. T. \& MÖNKKÖNEN, M. (2003). The role of climate in limiting European resident bird populations. Journal of Biogeography 30, 55-70.

Franklin, A. B., Anderson, D. R., Gutiérrez, R. J. \& Burnham, K. P. (2000). Climate, habitat quality, and fitness in northern spotted owl populations in northwestern California. Ecological Monographs 70, 539-590. 
1 Frederiksen, M., WANLESS, S., Rothery, P. \& Wilson, L. J. (2004). The role of industrial fisheries and oceanographic change in the decline of North Sea black-legged kittiwakes. Journal of Applied Ecology 41, 1129-1139.

Freilich, J. E., Burnham, K. P., Collins, C. M. \& GARry, C. A. (2000). Factors affecting population assessments of desert tortoises. Conservation Biology 14, 1479-1489.

Gaillard, J.-M., Boutin, J.-M., Delorme, D., Van Laere, G., Duncan, P. \& Lebreton, J. D. (1997). Early survival in roe deer: causes ans consequences of cohort variation in two contrasted populations. Oecologia 112, 502-513.

Gaillard, J.-M., Festa-Bianchet, M. \& Yoccoz, N. G. (1998). Population dynamics of large herbivores: covariate recruitment with constant adult survival. Trends in Ecology and Evolution 13, 58-63.

Gaillard, J. M. \& Yoccoz, N. G. (2003). Temporal variation in survival of mammals: A case of environmental canalization? Ecology 84, 3294-3306.

GARCIA, L. V. (2004). Escaping the Bonferroni iron claw in ecological studies. Oikos 105, 657663.

Garel, M., Loison, A., Gaillard, J. -M., Cugnasse, J. M. \& Maillard, D. (2004). The effects of a severe drought on mouflon lamb survival. Proceedings of the Royal Society of London B 271, S471-S473.

Gauthier, G., Pradel, R., Menu, S. \& Lebreton, J. -D. (2001). Seasonal survival of greater snow geese and effect of hunting under dependence in sighting probability. Ecology 82, 3105-3119.

Gelman, A., Carlin, J. B., Stern, H. S. \& Rubin, D. B. (2003). Bayesian Data Analysis, Second Edition. Chapman \& Hall. London.

Gelman, A., Meng, X. L. \& Stern, H. (1996). Posterior predictive assessment of model fitness via realized discrepancies. Statistica Sinica 6, 733-760. 
1 George, E. I. \& McCulloch, R. E. (1993). Variable Selection via Gibbs Sampling. Journal of the American Statistical Association 88, 881-889.

GHOSH, S. K. \& NORRIS, J. L. (2005). Bayesian capture-recapture analysis and model selection allowing for heterogeneity and behavioral effects. Journal of Agricultural, Biological, and Environmental Statistics 10, 35-49.

Gimenez, O., Crainiceanu, C., Barbraud, C., Jenouvrier, S. \& Morgan, B. J. T. (2006). Semiparametric regression in capture-recapture modelling. Biometrics 62, 691-698.

GinZBURG, L. R. \& JENSEN, C. X. J. (2004). Rules of thumb for judging ecological theories. Trends in Ecology \& Evolution 19, 121-126.

GoulD, W. R. \& NichOLS, J. D. (1998). Estimation of temporal variability of survival in animal populations. Ecology 79, 2531-2538.

GRAHAM, M. H. (2003). Confronting multicollinearity in ecological multiple regression. Ecology 84, 2809-2815.

GreEN, P. (1995). Reversible Jump Markov Chain Monte Carlo Computation and Bayesian Model Determination. Biometrika 82, 711-732.

GRIST, J. P. \& NiCHOLSON, S. E. (2001). A study of the dynamic factors influencing the rainfall variability in the West African Sahel. Journal of Climate 14, 1337-1359. 
1 Grosbois, V., Henry, P.-Y., Blondel, J., Perret, P., Lebreton, J.-D., Thomas, D. W. \& LAMBRECHTS, M. M. (2006). Climate impacts on Mediterranean blue tit survival: an inverstigation across seasons and spatial scales. Global Change Biology 12, 2235-2249.

Grosbois, V. \& ThOMPson, P. M. (2005). North Atlantic climate variation influences survival in adult fulmars. Oikos 109, 273-290.

GuISAN, A. \& THUILLER, W. (2005). Predicting species distribution: offering more than simple habitat models. Ecology Letters 8, 993-1009.

Gunnarson, G., Elmberg, J., SJÖBerg, K., PÖysÄ, H. \& Nummi, P. (2006). Experimental evidence for density-dependent survival in mallard (Anas platyrhynchos) ducklings. Oecologia 149, 203-213.

Guthery, F. S., Brennan, L. A., Peterson, M. J. \& Lusk, J. J. (2005). Information theory in wildlife science: Critique and viewpoint. Journal of Wildlife Management 69, 457-465.

Hallet, T. B., Coulson, T., Pilkington, J. G., Clutton-Brock, T. H., Pemberton, J. M. \& GrENFELL, B. T. (2004). Why large-scale climate indices seem to predict ecological processes better than local weather. Nature 430, 71-75.

HARrington, R., WoIWOD, I. \& SPARKS, T. (1999). Climate change and trophic interactions. Trends in Ecology and Evolution 14, 146-150.

HARris, M. P., ANKer-Nilssen, T., MC-CleERy, R. H., ERIKSTAD, K. E., ShAW, D. N. \& GROSBOIS, V. (2005). Effect of wintering area and climate on the survival of adult Atlantic puffins Fratercula arctica in the eastern Atlantic. Marine Ecology Progress Series 297, 283-296.

Harris, M. P., Freeman, S. N., Wanless, S., Morgan, B. J. T. \& Wernham, C. V. (1997). Factors influencing the survival of Puffins Fratercula arctica at a North Sea colony over a 20-year period. Journal of Avian Biology 28, 287-295.

HARTLEy, S., HARRIS, R. \& LESTER, P. J. (2006). Quantifying uncertainty in the potential 
distribution of an invasive species: climate and the Argentine ant. Ecology Letters $\mathbf{9}$, 1068-1079.

HAYs, G. C., RichaRdSON, A. J. \& RoBinson, C. (2005). Climate change and marine plankton. Trends in Ecology \& Evolution 20, 337-344.

HobBs, N. T. \& HiLbORn, R. (2006). Alternatives to statistical hypothesis testing in ecology: a guide to self teaching. Ecological Applications 16, 5-19.

Holmgren, M., Scheffer, M., Ezcurra, E., Gutierrez, J. R. \& Mohren, G. M. J. (2001). El Niño effects on the dynamics of terrestrial ecosystems. Trends in Ecology \& Evolution 16, 89-94.

Hosmer, D. W. \& LeMESHOw, S. (1989). Applied logistic regression. Wiley, New York, NY.

Hoyle, S. D., Pople, A. R. \& ToOP, G. J. (2001). Mark-recapture may reveal more about ecology than about population trends: demography of a threatened ghost bat (Macroderma gigas) population. Austral Ecology 26, 80-92.

Hulme, P. E. (2005). Adapting to climate change: is there scope for ecological management in

IPCC (2007). Climate Change 2007: synthesis report. Contribution of working groups I, II and III to the fourth assessment report of the Intergovernmental Panel on Climate Change. IPCC, Geneva, Switzerland

JENNIONS, M. D. \& MøLLER, A.P. (2003). A survey of the statistical power of research in 
JENOUVRIER, S., BARBRAUd, C. \& WEIMERSKIRCH, H. (2003). Effects of climate variability on the temporal population dynamics of southern fulmars. Journal of Animal Ecology 72, $576-587$.

JENOUVRIER, S., BARBRAUd, C. \& WEIMERSKIRCH, H. (2005). Long-term contrasted responses to climate of two antarctic seabird species. Ecology 86, 2889-2903.

JenOuVRIER, S., BARBRAUd, C. \& WeIMERSKIRCH, H. (2006). Sea ice affects the population dynamics of Adélie penguins in Terre Adélie. Polar Biology 29, 413-423.

Jenouvrier, S., Weimerskirch, H., Barbraud, C., PARK, Y. H. \& CAZElles, B. (2005). Evidence of a shift in the cyclicity of Antarctic seabird dynamics linked to climate. Proceedings of the Royal Society B 272, 887-895.

JeTZ, W., Wilcove, D. S. \& Dobson, A.P. (2007). Projected impacts of climate and land-use change on the global diversity of birds. Plos Biology 5, 1211-1219.

JOHNSON, D. H. (2002). The role of hypothesis testing in wildlife science. Journal of Wildlife Management 66, 272-276.

JoHnson, J. B. \& OMLAND, K. S. (2004). Model selection in ecology and evolution. Trends in Ecology \& Evolution 19, 101-108.

Jones, I. L., Hunter, F. M. \& Robertson, G. J. (2002). Annual adult survival of least auklets (Aves, Alcidae) varies with large-scale climatic conditions of the North Pacific Ocean. Oecologia 133, 38-44.

Jorgenson, J. T., Festa-Bianchet, M., Gaillard, J. -M. \& Wishart, W. D. (1997). Effects of age, sex, disease, and density on survival of bighorn sheep. Ecology 78, 1019-1032.

Julliard, R., Leirs, H., Stenseth, N. C., Yoccoz, N. G., Prévot-Julliard, A. C., VERHAGEN, R. \& VERHEYEN, W. (1999). Survival-variation within and between functional categories of the African multimammate rat. Journal of Animal Ecology 68, $550-561$. 
KASS, R. E. \& RAFTERY, A. E. (1995). Bayes factor. Journal of the American Statistical Association 90, 773-795.

Kanyamibwa, S., Schierer, A., Pradel, R. \& Lebreton, J. -D. (1990). Changes in adult survival rates in a western European population of the white strok Ciconia ciconia. Ibis 132, 27-35.

Kéry, M., Madsen, J. \& Lebreton, J. -D. (2006). Survival of Svalbard pink-footed geese Anser brachyrhynchus in relation to winter climate, density and land-use. Journal of Animal Ecology 75, 1172-1181.

KING, D. (2005). Climate change: the science and the policy. Journal of Applied Ecology 42, 779-783.

KLEIDON, A. \& MoONEY, H. A. (2000). A global distribution of biodiversity inferred from climatic constraints: results from a process-based modelling study. Global Change Biology 6, 507-523.

LAhti, K., Orell, M., RytKönen, S. \& Koivula, K. (1998). Time and food dependence in willow tit winter survival. Ecology 79, 2904-2916.

LANGTimm, C. A. \& BECK, C. A. (2003). Lower survival probabilities for adult florida manatees in years with intense coastal storms. Ecological Applications 13, 257-268.

Lebreton, J.-D., Burnham, K. P., Clobert, J. \& Anderson, D. R. (1992). Modelling survival and testing biological hypothesis using marked animals: a unified approach with case studies. Ecological Monographs 62, 67-118.

Lima, M., Julliard, R., Stenseth, N. C. \& JaKsiC, F. M. (2001). Demographic dynamics of a Neotropical small rodent (Phyllotis darwini): feedback structure, predation and climatic factors. Journal of Animal Ecology 70, 761-775. 
1 Lima, M., Merrit, J., F. \& BozinOviC, F. (2002). Numerical fluctuations in the northern shorttailed shrew: evidence of non-linear feedback signatures on population dynamics and demography. Journal of Animal Ecology 71, 159-172.

LINK, W. A. \& BARKER, R. J. (2004). Hierarchical mark-recapture models: a framework for inference about demographic processes. Animal Biodiversity and Conservation 27, 441449.

LINK, W. A. \& BARKER, R. J. (2006). Model weights and the foundations of multimodel inference. Ecology 87, 2626-2635.

Link, W. A., CAM, E., Nichols, J. D. \& COOCH, E. G. (2002). Of BUGS and birds: Markov chain Monte Carlo for hierarchical modeling in wildlife research. Journal of Wildlife Management 66, 277-291.

Loison, A., Jullien, J. -M. \& MENAUt, P. (1999). Relationship between chamois and isard survival and variation in global and local climate regimes: contrasting examples from the Alps and Pyrenees. Ecological Bulletins 47, 126-136.

LOISON, A. \& LANGVATn, R. (1998). Short- and long-term effects of winter and spring weather on growth and survival of red deer in Norway. Oecologia 116, 489-500.

Loison, A., SÆther, B.-E., JerstaD, K. \& RøStaD, O. W. (2002). Disentangling the sources of variation in the survival of the European dipper. Journal of Applied Statistics 29, 289-304.

Ludwig, G. X., Alatalo, R. V., Helle, P., Linden, H., Lindstrom, J. \& Sittari, H. (2006). Short- and long-term population dynamical consequences of asymmetric climate change in black grouse. Proceedings of the Royal Society B-Biological Sciences 273, 2009-2016.

McCARThy, M. A. \& MAsters, P. (2005). Profiting from prior information in Bayesian analyses of ecological data. Journal of Applied Ecology 42, 1012--1019. 
1 MCCARThy, M. A. (2007). Bayesian methods for ecology. Cambridge University Press. Cambridge.

McCullagh, P. \& Nelder, J. A. (1989). Generalized linear models. Chapman and Hall, London, U. K.

MC-Culloch, C. E. \& SEARle, S. R. (2001). Generalized, linear, and mixed models. John Wiley \& Sons, Inc., New York, NY.

MeYER, R. \& MillaR, R. B. (1999). BUGS in Bayesian stock assessments. Canadian Journal of Fisheries and Aquatic Sciences 56, 1078-1087.

Milner, J. M., Elston, D. A. \& Albon, S. D. (1999). Estimating the contribution of population density and climatic fluctuations to interannual variation in survival of Soay sheep. Journal of Animal Ecology 68, 1235-1247.

Mitchell-OldS, T. \& SHAW, R. G. (1987). Regression analysis of natural selection statistical inference and biological interpretation. Evolution 41, 1149-1161.

MODAFFERI, R. D. \& BECKER, E. F. (1997). Survival of radiocollared adult moose in lower Susitna River Valley, southcentral Alaska. Journal of Wildlife Management 61, 540-

MøLler, A. P. \& MERILÄ, J. (2004). Analysis and interpretation of long-term studies investigating responses to climate change. Advances in Ecological Research 35, 111130.

MøLLER, A. P. \& SZEP, T. (2005). Rapid evolutionary change in a secondary sexual character linked to climatic change. Journal of Evolutionary Biology 18, 481-495.

Montevecchi, W. A. \& Myers, R. A. (1997). Centurial and decadal oceanographic influences on changes in northern gannet populations and diets in the north-west Atlantic: implications for climate change. ICES Journal of Marine Science 54, 608-614. 
Ecology \& Evolution 21, 400-407.

2 Moran, M., R. (2003). Arguments for rejecting the sequential Bonferroni in ecological studies. Oikos 100, 403-405.

Moss, R., OswaLD, J. \& BAINES, D. (2001). Climate change and breeding success: decline of the capercaillie in Scotland. Journal of Animal Ecology 70, 47-61.

MuRRAY, D. L. (2006). On improving telemetry-based survival estimation. Journal of Wildlife Management 70, 1530-1543.

Mysterud, A., Stenseth, N. C., Yoccoz, N. G., Langvatn, R. \& Steinheim, G. (2001). Nonlinear effects of large-scale climatic variability on wild and domestic herbivores. Nature 410, 1096-1099.

NAKAGAWA, S. \& CuTHILl, I. C. (2007). Effect size, confidence interval and statistical significance: a practical guide for biologists. Biological Reviews 82, 591-605.

Neter, J., Kutner, M. H., NAchtsheim, C. J. \& Wasserman, W. (1996). Applied linear statistical models. Irwin, Chicago, Illinois, USA.

Nevoux, M. \& BARbraud, C. (2006). Relationships between sea ice concentration, sea surface temperature and demographic traits of thin-billed prions. Polar Biology 29, 445-453.

Newton, I. (1998). Population limitation in birds. Academic Press, London, U. K.

Newton, I., Wyllie, I. \& Rothery, P. (1992). Annual survival of sparrowhawks Accipiter nisus breeding in three areas of Britain. Ibis 135, 49-60.

NiCHOLS, J. D. (1992). Capture-recapture models: using marked animals to study population dynamics. BioScience 42, 94-102.

NiCHOLS, J. D. (1994). Estimating breeding proportions and testing hypotheses about costs of reproduction with capture-recapture data. Ecology 75, 2052-2065.

Nichols, J. D., Hines, J.E., Lebreton, J. D. \& PRADEL, R. (2000). Estimation of contributions to population growth: A reverse-time capture-recapture approach. Ecology 81, 3362-3376. 
1 Nicoll, M. A. C., Jones, C. G. \& NorRis, K. (2003). Declining survival rates in a reintroduced population of the Mauritius kestrel: evidence for non-linear density dependence and environmental stochasticity. Journal of Animal Ecology 72, 917-926.

Ottersen, G., Planque, B., Belgrano, A., Post, E. \& Stenseth, N. C. (2001). Ecological effects of the North Atlantic Oscillation. Oecologia 128, 1-14.

Owen-Smith, N. (1990). Demography of a large herbivore, the Greater kudu Tragelaphus Strepsiceros, in relation to rainfall. Journal of Animal Ecology 59, 893-913.

PARMESAn, C. (2006). Ecological and evolutionary responses to recent climate change. Annual Review of Ecology Evolution and Systematics 37, 637-669.

PARMESAN, C. \& YOHE, G. (2003). A globally coherent fingerprint of climate change impacts across natural systems. Nature 421, 37-42.

PEACH, W., BAILliE, S. \& UnderhILL, L. (1991). Survival of British sedge warblers Acrocephalus schoenobaenus in relation to west African rainfall. Ibis 133, 300-305.

PeACH, W. J., SiRiWARdEnA, G. M. \& GREgORY, R. D. (1999). Long-term changes in overwinter survival rates explain the decline of reed buntings Emberiza schoeniclus in Britain. Journal of Applied Ecology 36, 798-811.

PeACH, W. J., ThOMPSON, P. S. \& COUlson, J. C. (1994). Annual and long-term variation in the survival rates of British lapwings Vanellus vanellus. Journal of Animal Ecology 63, 6070.

Peñuelas, J., Filella, I. \& Comas, P. (2002). Changed plant and animal life cycles from 1952 to 2000 in the Mediterranean region. Global Change Biology 8, 531-544.

Perdeck, A. C., Visser, M. E. \& Van Balen, J. H. (2000). Great tit Parus major survival and the beech-crop index. Ardea 99, 99-108. 
Peterson, T. A., Ortega-Huerta, M. A., Bartley, J., SAnchez-Cordero, V., Soberon, J., BudDEMEIER, R. H. \& STOCKWELl, D. R. B. (2002). Future projections for Mexican faunas under global climate change scenarios. Nature 416, 626-629.

PIPER, S. E. (2002). Survival of adult, territorial longtailed wagtails Moticilla clara: the effects of environmental factors and individual covariates. Journal of Applied Statistics 29, 107-124.

Pledger, S., Pollock, K. H. \& NorRis, J.L. (2003). Open capture-recapture models with heterogeneity: I. Cormack-Jolly-Seber model. Biometrics 59, 786-794.

PRADEL, R. (1996). Utilization of capture-mark-recapture for the study of recruitment and population growth rate. Biometrics 52, 703-709.

Pradel, R. \& LEBRETON, J.-D. (1999). Comparison of different approaches to the study of local recruitment of breeders. Bird Study 46, 74-81.

Prévot-Julliard, A. C., Lebreton, J. -D. \& Pradel, R. (1998). Re-evaluation of adult survival of black-headed gulls (Larus ridibundus) in presence of recapture heterogeneity. Auk 115, 85-95.

Pryde, M. A., O'Donnell, C. F. J. \& BARKER, R. J. (2005). Factors influencing survival and long-term population viability of New Zealand long-tailed bats (Chalinolobus tuberculatus): Implications for conservation. Biological Conservation 126, 175-185.

QuINN, J. F., DunHAM, A. (1983). On hypothesis testing in ecology and evolution. The American Naturalist 122, 602-617.

RicE, W. R. (1989). Analyzing tables of statistical tests. Evolution 43, 223-225.

RICHARDS, S. A. (2005). Testing ecological theory using the information-theoretic approach: Examples and cautionary results. Ecology 86, 2805-2814.

RoBACK, P. J. \& ASKInS, R. A. (2005). Judicious use of multiple hypothesis tests. Conservation Biology 19, 261-267. 
1 Robinson, R. A., Green, R. E., Baillie, S. R., Peach, W. J. \& Thomson, D. L. (2004). Demographic mechanisms of the population decline of the song thrush Turdus philomelos in Britain. Journal of Animal Ecology 73, 670-682.

ROBINSON, D. H. \& WAINER, H. (2002). On the past and future of null hypothesis significance testing. Journal of Wildlife Management 66, 263-271.

SÆTHER, B.-E. (1997). Environmental stochasticity and population dynamics of large herbivores: a search for mechanisms. Trends in Ecology and Evolution 12, 143-149.

SÆTHER, B. E. \& BAKKE, O. (2000). Avian life history variation and contribution of demographic traits to the population growth rate. Ecology 81, 642-653.

SÆther, B.-E., Engen, S., Møller, A. P., Matthysen, E., Adriaensen, F., Fiedler, W., Leivits, A., Lambrechts, M. M., Visser, M. E., Anker-Nilssen, T., Both, C., Dhondt, A. A., Mc-Cleery, R. H., Mc-Meeking, J., Potti, J., Røstad, O. W. \& THOMPSON, D. (2003). Climate variation and regional gradients in population dynamics of two hole-nesting passerines. Proceedings of the Royal Society of London B 270, 2397-2404.

SÆther, B.-E., Grøtan, V., Tryjanowski, P., Barbraud, C., Engen, S. \& Fulin, M. (2006). Climate and spatio-temporal variation in the population dynamics of a long distance migrant, the white stork. Journal of Animal Ecology 75, 80-90.

SÆTher, B.-E., Sutherland, W. J. \& EnGEN, S. (2004). Climate influences on avian population dynamics. Advances in Ecological Research 35, 185-209.

SANDERCOCK, B. K. (2006). Estimation of demographic parameters from live-encounter data: a summary review. Journal of Wildlife Management 70, 1504-1520.

SANDVIK, H., ERIKSTAD, K. E., BARRETt, R. T. \& YoccoZ, N. G. (2005). The effect of climate on adult survival in five species of North Atlantic seabirds. Journal of Animal Ecology 74, 817-831. 
Sarno, R. J., Clark, W. R., Bank, M. S., PreXl, W. S., Behl, M. J., Johnson, W. E. \& FRANKLIN, W. L. (1999). Juvenile guanaco survival: management and conservation implications. Journal of Applied Ecology 36, 937-945.

Schaefer, H. C., Eshiamwata, G. W., Munyekenye, F. B., Griebeler, E. M. \& BöhningGEASE, K. (2006). Monthly survival of African Sylvia warblers in a seasonally arid tropical environment. Ibis 148, 411-424.

SCHAUB, M., KANIA, W. \& KÖPPEN, U. (2005). Variation of primary production during winter induces synchrony in survival rates in migratory white storks Ciconia ciconia. Journal of Animal Ecology 74, 656-666.

SCHLEsingeR, W. H. (2006). Global change ecology. Trends in Ecology \& Evolution 21, 348351.

SCHWARZ, C. J. (2002). Real and quasi-experiments in capture-recapture studies. Journal of Applied Statistics 29, 459-473.

SChWARZ, C. J., SChWEIGERT, J. F. \& ARnASOn, A. N. (1993). Estimating migration rates using tag-recovery data. Biometrics 49, 177-193.

SENDOR, T. \& Simon, M. (2003). Population dynamics of the pipistrelle bat: effects of sex, age and winter weather on seasonal survival. Journal of Animal Ecology 72, 308-320.

Sillett, T. S., HolmeS, R. T. \& SHERRY, T. W. (2000). Impacts of global climate cycle on population dynamics of a migratory songbird. Science $\mathbf{2 8 8 , 2 0 4 0 - 2 0 4 2 . ~}$

Singer, F. J., Harting, A., Symonds, K. K. \& Coughenour, M. B. (1997). Density dependence, compensation, and environmental effects on elk calf mortality in Yellowstone National Park. Journal of Wildlife Management 61, 12-25.

Sirabella, P., Guiliani, A., Colosimo, A. \& Dippner, J. (2001). Breaking down the climate effects on cod recruitment by principal component analysis and canonical correlation. Marine Ecology Progress Series 216, 213-222. 
1 SKALSKI, J. R. (1996). Regression of abundance estimates from mark-recapture surveys against environmental covariates. Canadian Journal of Fisheries and Aquatic Sciences 53, 196204.

SkAlski, J. R., HoffmAnn, A. \& SMith, S. G. (1993). Testing the significance of individualand cohort-level covariates in animal survival studies. In Marked individuals in the study of bird population. (eds. J. -D. Lebreton and P. M. North), pp. 9-28. Birkhäuser Verlag, Basel, Switzerland.

Smith, R. C., Ainley, D., BaKer, K., Domack, E., Emslie, S., Fraser, B., Kennet, J., LeVenter, A., Mosley-Thompson, E., Stammerjohn, S. \& Vernet, M. (1999). Marine ecosystem sensitivity to climate change. BioScience 49, 393-404.

SoKal, R. R. \& RoHLF, F. J. (1995). Biometry. Third edition. W. H. Freeman and Company, New York, NY.

SolOw, A. R. (1998). On fitting a population model in the presence of measurement error. Ecology 79, $1463-1467$

Spiegelhalter, D. J., Best, N. G., CARlin, B. P. \& VAn DeR Linde, A. (2002). Bayesian measures of model complexity and fit (with discussion). Journal of the Royal Statistical Society, Series B 64, 583-639.

Spiegelhalter, D. J., Thomas, A., Best, N. G. \& LunN. D. (2003). WinBUGS User Manual (Version 1.4). Cambridge: MRC Biostatistics Unit, www.mrc-bsu.cam.ac.uk/bugs/.

Stenseth, N. C., Mysterud, A., Ottersen, G., Hurrel, J. W., Chan, K.-S. \& Lima, M. (2002). Ecological effects of climate fluctuations. Science 297, 1292-1296.

Stenseth, N. C., Ottersen, G., Hurrel, J. W., Mysterud, A., Lima, M., Chan, K.-S., Yoccoz, N. G. \& ÅdLANDSVIK, B. (2003). Studying climate effects on ecology through the use of climate indices: the North Atlantic Oscillation, El Niño Southern Oscillation and beyond. Proceedings of the Royal Society of London B 270, 2087-2096. 
1 Stephens, P. A., BuskiRK, S. W. \& Del Rio, C. M. (2007). Inference in ecology and evolution. Trends in Ecology \& Evolution 22, 192-197.

Stephens, P. A., Buskirk, S. W., Hayward, G. D. \& Del Rio, C. M. (2005). Information theory and hypothesis testing: a call for pluralism. Journal of Applied Ecology 42, 4-12.

Stokke, B. G., Møller, A. P., SÆther, B. E., Rheinwald, G. \& Gutscher, H. (2005). Weather in the breeding area and during migration affects the demography of a small long-distance passerine migrant. Auk 122, 637-647.

Sturtz, S., Ligges, U. \& Gelman, A. (2005). R2WinBUGS: A Package for Running WinBUGS from R. Journal of Statistical Software 12, 1-16.

SUTHERLAND, W.J. (2006). Predicting the ecological consequences of environmental change: a review of the methods. Journal of Applied Ecology 43, 599-616.

Tavecchia, G., Pradel, R., Gossmann, F., Bastat, C., Ferrand, Y. \& Lebreton, J. -D. (2002). Temporal variation in annual survival probability of the Eurasian woodcock Scolopax rusticola wintering in France. Wildlife Biology 8, 39-48.

Thomas, C. D., Cameron, A., Green, R., E. G., Bakkenes, M., Beaumont, L. J., Collingham, Y. C., Erasmus, B. F. N., DE Siqueira, M. F., Grainger, A., Hannah, L., Hugues, L., Huntley, B., Van JaArsveld, A. S., Midgley, G. F., Miles, L., Ortega-Huerta, M. A., Peterson, A. T., Phillips, O. L. \& Williams, S. (2004). Extinction risk from climate change. Nature 427, 145-148.

Thomas, C. D., Franco, A. M. A. \& Hill, J. K. (2006). Range retractions and extinction in the face of climate warming. Trends in Ecology \& Evolution 21, 415-416.

TRAYLOR, J. J. \& ALISAUSKAS, R. T. (2006). Effects of intrinsic and extrinsic factors on survival of white-winged scoter (Melanitta fusca deglandi) ducklings. Auk 123, 67-81.

TuRChIN, P. (2003). Complex population dynamic. Princeton University Press, Princeton, NJ, and Oxford, UK. 
1 Viallefont, A., Cooke, F. \& Lebreton, J.-D. (1995). Age-specific costs of first-time breeding. Auk 112, 67-76.

VAIDA, F. \& BLANCHARD, S. (2005). Conditional Akaike information for mixed-effects models. Biometrika 92, 351-370.

Votier, S. C., HAtchwell, B. J., Beckerman, A., MC-Cleery, R. H., Hunter, F. M., Peliatt, J., TRinder, M. \& BirkhEAd, T. R. (2005). Oil pollution and climate have wide-scale impacts on seabird demographics. Ecology Letters 8, 1157-1164.

Walther, G.-R., Post, E., Convey, P., Menzel, A., Parmesan, C., Beebee, T. J. C., Fromentin, J.-M., Hoeg-Guldberg, O. \& BAirlein, F. (2002). Ecological responses to recent climate change. Nature 416, 389-395.

White, G. C. \& BuRnham, K. P. (1999). Program MARK: survival estimation from populations of marked animals. Bird Study 46 (suppl.), 120-129. http://www.cnr.colostate.edu/gwhite/software.html.

WIENS, J. D., NoON, B. R. \& REYNOLDS, R. T. (2006). Post-fledging survival of northern goshawks: The importance of prey abundance, weather, and dispersal. Ecological Applications 16, 406-418.

Williams, B. K., Nichols, J. D. \& CONROY, M. J. (2002). Analysis and management of animal populations. Academic Press, Sand Diego, CA.

Wright, S. P. (1992). Adjusted P-values for simultaneous inference. Biometrics 48, 10051013.

Yoccoz, N. G. (1991). Use, overuse, and misuse of significance tests in evolutionary biology and ecology. Bulletin of the Ecological Society of America 72, 106-111. 
1 Table 1. Meteorological stations in the Sahel region where rainfall data used in the white stork

2 Ciconia ciconia survival analysis were collected.

3

\begin{tabular}{cccc}
\hline \hline Station & N latitude & E longitude & Label \\
\hline Dakar & & & \\
Diourbel & 14.7 & -17.5 & Dak \\
Gao & 14.7 & -16.2 & Dio \\
Kandi & 16.3 & -0.1 & Gao \\
Kayes & 11.1 & 2.9 & Kan \\
Kita & 14.4 & -11.4 & Kay \\
Koutiala & 13.1 & -9.5 & Kit \\
Maradi & 12.4 & -5.5 & Kou \\
Mopti & 13.5 & 7.1 & Mar \\
Na Titingou & 14.5 & -4.1 & Mop \\
Ouahigouya & 10.3 & 1.4 & Na \\
Sikasso & 13.6 & -2.4 & Oua \\
Ségou & 11.4 & -5.7 & Sik \\
Tahoua & 13.4 & -6.2 & Seg \\
Tombouctou & 14.9 & 5.3 & Tah \\
& 16.7 & -3 & Tom \\
\hline \hline
\end{tabular}

4 
Table 2. Correlations among climatic covariates.

\begin{tabular}{|c|c|c|c|c|c|c|c|c|c|c|c|c|}
\hline \multirow[t]{2}{*}{ Climatic covariate } & \multirow[t]{2}{*}{ Label } & \multicolumn{11}{|c|}{ Correlation pattern (Pearson's $r$ below the diagonal; $P$-value of a $t$-test for $H_{0}: r=0$ above the diagonal) } \\
\hline & & WNAO & PBST & PBSRF & PBSNAO & PBSC & BST & BSRF & BSNAO & BSC & CNSRF & SSRF \\
\hline $\begin{array}{l}\text { North Atlantic oscillation, } \\
\text { December-February }\end{array}$ & WNAO & & 0.82 & 0.64 & 0.63 & 0.64 & 0.71 & 0.07 & 0.57 & 0.25 & 0.45 & 0.06 \\
\hline $\begin{array}{l}\text { Temperature anomaly, breeding } \\
\text { region, March-May }\end{array}$ & PBST & 0.06 & & 0.01 & 0.07 & $<0.001$ & 0.89 & 0.32 & 0.08 & 0.26 & 0.71 & 0.88 \\
\hline $\begin{array}{l}\text { Rainfall anomaly, breeding region, } \\
\text { March-May }\end{array}$ & PBSRF & -0.13 & -0.63 & & 0.13 & $<0.001$ & 0.36 & 0.96 & 0.91 & 0.73 & 0.92 & 0.41 \\
\hline $\begin{array}{c}\text { North Atlantic oscillation, March- } \\
\text { May }\end{array}$ & PBSNAO & 0.13 & 0.46 & -0.4 & & 0.001 & 0.56 & 0.64 & 0.41 & 0.79 & 0.53 & 0.98 \\
\hline $\begin{array}{l}\text { Integrative climatic index, } \\
\text { breeding region, March-May }\end{array}$ & PBSC & 0.13 & 0.87 & -0.84 & 0.73 & & 0.59 & 0.57 & 0.27 & 0.67 & 0.91 & 0.42 \\
\hline $\begin{array}{l}\text { Temperature anomaly, breeding } \\
\text { region, June-August }\end{array}$ & BST & -0.1 & -0.04 & -0.25 & 0.16 & 0.15 & & 0.005 & 0.19 & $<0.001$ & 0.60 & 0.35 \\
\hline $\begin{array}{l}\text { Rainfall anomaly, breeding region, } \\
\text { June-August }\end{array}$ & BSRF & 0.47 & 0.26 & 0.01 & 0.13 & 0.15 & -0.66 & & 0.03 & $<0.001$ & 0.95 & 0.32 \\
\hline $\begin{array}{c}\text { North Atlantic oscillation, June- } \\
\text { August }\end{array}$ & BSNAO & -0.16 & -0.46 & 0.03 & -0.22 & -0.29 & 0.34 & -0.55 & & $<0.001$ & 0.28 & 0.98 \\
\hline $\begin{array}{l}\text { Integrative climatic index, } \\
\text { breeding region, June-August }\end{array}$ & BSC & -0.3 & -0.3 & -0.09 & -0.07 & -0.12 & 0.82 & -0.91 & 0.74 & & 0.88 & 0.42 \\
\hline $\begin{array}{c}\text { Central and northern Sahel } \\
\text { rainfall index }\end{array}$ & CNSRF & 0.2 & 0.1 & 0.03 & -0.17 & -0.03 & 0.14 & -0.02 & -0.29 & -0.04 & & 0.45 \\
\hline Southern Sahel rainfall index & SSRF & -0.48 & -0.04 & -0.22 & -0.01 & 0.07 & 0.25 & -0.27 & -0.01 & 0.22 & -0.21 & \\
\hline
\end{tabular}

2

3 The two shaded areas highlight two sets of intercorrelated covariates: those describing climatic conditions in the breeding area during the pre-

4 breeding period and during the breeding period, respectively. Bold type highlights the covariates retained for the analysis of white stork Ciconia 

ciconia survival and the correlations among them. To avoid overloading the table, the 15 Sahel rainfall original covariates are not included here.

2 Instead, we only included the two Sahel rainfall integrative covariates (CNSRF and SRF). 
1 Table 3. Analysis of trends over time (linear and quadratic) in climatic factors

2

3

4

5

6

7 Statistics were obtained from linear regression models with the focal climatic factor as the

8 dependent variable and a linear temporal trend and, for quadratic temporal trend, that linear

9 trend squared, as predictors. $P$-values were obtained from an $F$-test of the hypothesis that the

10 slope(s) of the relationship(s) with the predictor(s) equal zero. $R^{2}$-LR is the coefficient of

11 determination of the linear regression model. Covariate abbreviations are defined in table 2. 
$1 \quad$ Table 4. Models used for describing survival $\left[f\left(\phi_{i}\right)\right]$

\begin{tabular}{|c|c|c|c|}
\hline Label & Formulation & Description & Parameters to be estimated \\
\hline$F_{c s t}$ & $f\left(\phi_{i}\right)=a$ & Survival is constant over years & - One constant parameter: $a$ \\
\hline$F_{t}$ & $f\left(\phi_{i}\right)=a_{i}$ & Survival varies over years & - One distinct parameter, $a_{i}$, for each time interval $i$ in the time series \\
\hline $\begin{array}{c}F_{T} \\
\left(F_{T_{-} q}\right)\end{array}$ & $f\left(\phi_{i}\right)=a+b T_{i}\left(+c T_{i}^{2}\right)$ & $\begin{array}{l}\text { Survival varies according to a linear (or } \\
\text { quadratic) trend }\end{array}$ & $\begin{array}{l}\text { - One parameter, } a \text {, for the intercept } \\
\text { - One (or two) parameter(s), } b \text { (and } c) \text {, for slopes of the linear }\left(T_{i} \text {, ) [and }\right. \\
\left.\text { quadratic }\left(T_{i}^{2}\right)\right] \text { trend terms }\end{array}$ \\
\hline$R_{t}$ & $f\left(\phi_{i}\right)=a+\varepsilon_{i}$ & $\begin{array}{c}\text { Survival shows stochastic variation over } \\
\text { years around a mean }\end{array}$ & $\begin{array}{l}\text { - One parameter, } a \text {, for the mean } \\
\text { - One parameter for the variance } \sigma^{2} \text { of the random term } \varepsilon_{i} \text { that describes } \\
\text { stochastic variation over years around the mean }\end{array}$ \\
\hline$F_{c o}$ & $f\left(\phi_{i}\right)=a+b_{j} x_{j i}\left(+c_{j} x_{j i}^{2}\right)$ & $\begin{array}{l}\text { Survival is totally determined by a linear (or } \\
\text { quadratic) relationship with the covariate } j\end{array}$ & $\begin{array}{l}\text { - One parameter } a \text { for the intercept } \\
\text { - One (or two) parameter(s) } b_{j} \text {, (and } c_{j} \text { ) for the relationship with covariate } \\
x_{j}\end{array}$ \\
\hline$R_{c o}$ & $f\left(\phi_{i}\right)=a+b_{j} x_{j i}\left(+c_{j} x_{j i}^{2}\right)+\varepsilon_{i}$ & $\begin{array}{c}\text { Survival is totally determined by a linear (or } \\
\text { quadratic) relationship with the covariate } j \text {. } \\
\text { The variation over years that remains } \\
\text { unexplained is stochastic }\end{array}$ & $\begin{array}{l}\text { - One parameter } a \text { for the intercept } \\
\text { - One (or two) parameter(s) } b_{j},\left(\text { and } c_{j} \text { ) for the relationship with covariate }\right. \\
x_{j} \\
\text { - One parameter for the variance } \sigma^{2} \text { of the random term } \varepsilon_{i} \text { that describes } \\
\text { stochastic variations over years unexplained by the climatic covariates }\end{array}$ \\
\hline
\end{tabular}

$3 F$ refers to models including only fixed effects. $R$ refers to models including random effects. Subscripts $c s t, t, T, T \_q, c o$, refer to constant, time

4 dependent, linear trend, quadratic trend, covariate respectively. 
Table 5. Selection of a reference model for the analysis of white stork adult survival.

\begin{tabular}{ccccc}
\hline Survival & Recapture & Dev & K & AIC c \\
\hline Time dependent $\left(F_{t}\right)$ & Constant $\left(F_{c s t}\right)$ & 249.28 & 17 & 1349.50 \\
Linear trend $\left(F_{T}\right)$ & Constant $\left(F_{c s t}\right)$ & 284.1 & 3 & 1355.61 \\
Constant $\left(F_{c s t}\right)$ & Constant $\left(F_{c s t}\right)$ & 286.60 & 2 & 1356.10 \\
Quadratic trend $\left(F_{T_{-} q}\right)$ & Constant $\left(F_{c s t}\right)$ & 283.51 & 4 & 1357.03 \\
Linear trend $\left(F_{T}\right)$ & Time dependent $\left(F_{t}\right)$ & 273.11 & 18 & 1375.41 \\
Time dependent $\left(F_{t}\right)$ & Time dependent $\left(F_{t}\right)$ & 241.58 & 31 & 1371.5 \\
Constant $\left(F_{c s t}\right)$ & Time dependent $\left(F_{t}\right)$ & 276.09 & 17 & 1376.30 \\
Quadratic trend $\left(F_{T_{-} q}\right)$ & Time dependent $\left(F_{t}\right)$ & 273.04 & 19 & 1377.43 \\
\hline \hline
\end{tabular}

$F$ : refers to models including only fixed effects. Subscripts $c s t, t, T, T_{-} q$, and $c o$ refer to constant, time dependent, linear trend, quadratic trend and covariate, respectively (see also Table 4). Dev: deviance; $K$ : number of parameters; AICc: Akaike Information Criterion corrected for small sample sizes. 
Table 6. Estimates obtained from random-, fixed- and mixed-effects models of the relationship between climatic covariates and white stork

Ciconia ciconia survival.

\begin{tabular}{|c|c|c|c|c|c|c|c|c|c|}
\hline \multirow[b]{4}{*}{$\begin{array}{l}\text { Intercept } \\
\text { Process variance }\end{array}$} & \multicolumn{3}{|c|}{ Fixed-effects model } & \multicolumn{3}{|c|}{$\begin{array}{c}\text { Mixed-effects model } \\
\text { (Method of moments) }\end{array}$} & \multicolumn{3}{|c|}{$\begin{array}{c}\text { Mixed-effects model } \\
\text { (Bayesian) }\end{array}$} \\
\hline & est & coi- & coit & est & coi- & coit & Est & cri- & crit \\
\hline & \multicolumn{3}{|c|}{ Model $F_{c s t}$} & \multicolumn{3}{|c|}{ Model $R_{t}$} & \multicolumn{3}{|c|}{ Model $R_{t}$} \\
\hline & 0.68 & $0.54(0.44 *)$ & $0.82(0.92 *)$ & $\begin{array}{l}0.69 \\
0.14\end{array}$ & $\begin{array}{l}0.46 \\
0.02\end{array}$ & $\begin{array}{l}0.93 \\
0.51\end{array}$ & $\begin{array}{l}0.72 \\
0.16\end{array}$ & $\begin{array}{l}0.50 \\
0.02\end{array}$ & $\begin{array}{l}0.98 \\
0.42\end{array}$ \\
\hline & \multicolumn{3}{|c|}{ Model $F_{c o}$} & \multicolumn{3}{|c|}{ Model $R_{c o}$} & \multicolumn{3}{|c|}{ Model $R_{c o}$} \\
\hline Linear effect of CNSRF & & & & & & & & & \\
\hline $\begin{array}{l}\text { Intercept } \\
\text { Slope } \\
\text { Residual process variance } \\
\text { Coefficient of determination }\end{array}$ & $\begin{array}{l}0.66 \\
0.23\end{array}$ & $\begin{array}{c}0.52\left(0.44^{*}\right) \\
0.08\left(-0.01^{*}\right)\end{array}$ & $\begin{array}{c}0.81(0.88 *) \\
0.39(0.47 *)\end{array}$ & $\begin{array}{l}0.68 \\
0.23 \\
0.09\end{array}$ & $\begin{array}{l}0.46 \\
0.01 \\
0.00 \\
0.33\end{array}$ & $\begin{array}{l}0.89 \\
0.45 \\
0.43\end{array}$ & $\begin{array}{l}0.70 \\
0.24 \\
0.12\end{array}$ & $\begin{array}{l}0.49 \\
0.01 \\
0.01 \\
0.29\end{array}$ & $\begin{array}{l}0.93 \\
0.46 \\
0.36\end{array}$ \\
\hline \multicolumn{10}{|l|}{ Quadratic effect of PBSC } \\
\hline $\begin{array}{l}\text { Intercept } \\
\text { Slope linear term } \\
\text { Slope quadratic term } \\
\text { Residual process variance } \\
\text { Coefficient of determination }\end{array}$ & $\begin{array}{l}1.08 \\
-0.17 \\
-0.35\end{array}$ & $\begin{array}{c}0.82\left(0.69^{*}\right) \\
-0.35\left(-0.44^{*}\right) \\
-0.54\left(-0.63^{*}\right)\end{array}$ & $\begin{array}{l}1.35(1.47 *) \\
0.02\left(0.10^{*}\right) \\
-0.16(-0.07 *)\end{array}$ & $\begin{array}{c}1.05 \\
-0.17 \\
-0.34 \\
0.08\end{array}$ & $\begin{array}{r}0.68 \\
-0.43 \\
-0.61 \\
0.00 \\
0.39\end{array}$ & $\begin{array}{c}1.42 \\
0.10 \\
-0.06 \\
0.41\end{array}$ & $\begin{array}{l}1.09 \\
0.17 \\
-0.34 \\
0.10\end{array}$ & $\begin{array}{r}0.73 \\
-0.11 \\
-0.60 \\
0.01 \\
0.38\end{array}$ & $\begin{array}{r}1.45 \\
0.46 \\
-0.07 \\
0.38\end{array}$ \\
\hline
\end{tabular}

$F_{c s t}, F_{c o}, R_{t}, R_{c o}$ are different types of CMR models for describing survival (Table 4). CNSRF, central and northern Sahel rainfall; PBSC, prebreeding season climate; coi- and coi+: lower and upper 95\% confidence intervals respectively; cri- and cri+: lower and upper credibility 
intervals, respectively; est: parameter estimate (posterior median in the Bayesian analysis). Coefficents of determination were estimated by $R^{2} \_$Dev, based on analysis of deviance, for fixed-effects models and by $R^{2}$ Var, based on analysis of variance, for mixed-effects models (see equations 6 and 7 in Section IV.5.a). * indicates that confidence interval limits were corrected by the scale parameter $\sqrt{\hat{c}}$ for over-dispersion due to the presence of residual process variation in models $F_{c s t}$ and $F_{c o}$ and based on a student distribution with 16,15 and 14 degrees of freedom, depending on the number of parameters in the model. 
Table 7. Statistics used to address the statistical support for the effect of climatic covariates on white Ciconia ciconia stork adult survival

\begin{tabular}{|c|c|c|c|c|c|c|c|c|c|c|}
\hline & \multicolumn{3}{|c|}{$\begin{array}{l}\text { Model statistical } \\
\text { characteristics }\end{array}$} & \multicolumn{2}{|c|}{$\begin{array}{l}\text { NHT approach fixed- } \\
\text { effects models }\end{array}$} & \multirow{3}{*}{$\begin{array}{c}\begin{array}{c}\text { NHT approach } \\
\text { mixed-effects } \\
\text { models }\end{array} \\
\text { Corrected } \\
P \text {-value } \\
W\left(R_{\text {co }}\right) \\
(\text { uncorrected) } \\
\end{array}$} & \multirow{3}{*}{$\begin{array}{c}\begin{array}{c}\text { Bayesian } \\
\text { approach }\end{array} \\
\begin{array}{c}95 \% \text { credible } \\
\text { region }\end{array}\end{array}$} & \multicolumn{3}{|c|}{ IT approach } \\
\hline & \multirow[b]{2}{*}{ Dev } & \multirow[b]{2}{*}{$K$} & \multirow[b]{2}{*}{$A I C c$} & \multirow{2}{*}{$\begin{array}{c}P- \\
\text { value } \\
L R T_{\text {co/t }}\end{array}$} & \multirow{2}{*}{$\begin{array}{c}\text { Corrected } \\
\text { P-value } \\
\text { Ftest } \text { cst }_{\text {colt }} \\
\text { (uncorrected) }\end{array}$} & & & \multicolumn{2}{|c|}{ AICc differences } & \multirow{2}{*}{$\begin{array}{l}\text { Evidence ratio } \\
\qquad w_{c o} / w_{c s t}\end{array}$} \\
\hline & & & & & & & & $\Delta_{c o / c s t}$ & $\Delta_{c o / t}$ & \\
\hline Time dependent $\left(F_{t}\right)$ & 249.28 & 17 & 1349.5 & & & & & & & \\
\hline Constant $\left(F_{c s t}\right)$ & 286.60 & 2 & 1356.1 & & & & & & & \\
\hline \multicolumn{11}{|c|}{ Covariate models $\left(F_{c o}\right)$} \\
\hline PBSC_q & 275.44 & 4 & 1348.96 & 0.0382 & $0.468(0.047)$ & \multirow{3}{*}{$0.305(0.061)$} & {$[0 ; 0]$ excluded } & -9.99 & -3.39 & 147.78 \\
\hline CNSRF & 277.93 & 3 & 1349.44 & 0.0116 & $0.293(0.059)$ & & $0.01 \quad 0.46$ & -6.66 & -0.06 & 27.9 \\
\hline CNSRF_q & 286.53 & 4 & 1360.06 & 0.0162 & $0.33(0.099)$ & & {$[0 ; 0]$ included } & -7.14 & -0.54 & 35.45 \\
\hline WNAO & 286.58 & 3 & 1358.09 & 0.0016 & $0.837(0.335)$ & \multirow{2}{*}{$1.259(0.503)$} & $-0.34 \quad 0.16$ & -0.47 & 6.13 & 1.26 \\
\hline WNAO_q & 272.58 & 4 & 1346.11 & 0.0009 & $1.259(0.629)$ & & {$[0 ; 0]$ included } & 1.47 & 8.07 & 0.48 \\
\hline PBSC & 286.08 & 3 & 1357.59 & 0.0008 & $1.106(0.664)$ & $1.271(0.762)$ & $-0.32 \quad 0.21$ & 1.5 & 8.1 & 0.47 \\
\hline BS & 285.61 & 4 & 1359.14 & 0.0007 & $1.149(0.804)$ & $0.944(0.661)$ & -0.34 & 3.04 & 9.64 & 0.22 \\
\hline BS_q & 286.43 & 3 & 1357.94 & 0.0005 & $1.049(0.839)$ & & {$[0 ; 0]$ included } & 1.84 & 8.44 & 0.4 \\
\hline SSRF & 284.04 & 4 & 1357.56 & 0.0007 & $1.032(0.929)$ & $1.005(0.905)$ & -0.33 & 1.99 & 8.59 & 0.37 \\
\hline SSRF_q & 284.12 & 3 & 1355.63 & 0.0004 & $0.988(0.988)$ & & {$[0 ; 0]$ included } & 3.96 & 10.56 & 0.14 \\
\hline
\end{tabular}

NHT, null hypothesis testing; IT, information theoretic; Dev, deviance; AICc, Akaike information criterion corrected for small sample sizes; $K$, number of parameters;. $L R T_{c o / t}$ tests for variation unexplained by the climatic covariates in model $F_{c o}$. The threshold $P$-value for this test was set at 0.05 . Ftest $t_{c s t / c o / t}$ and $W\left(R_{c o}\right)$ test the null hypothesis that the focal climatic covariate has no effect on survival. The threshold $P$-value used for these tests is 0.20 and the observed $P$-values have been corrected so that the false discovery rate is maintained at 0.20 . Uncorrected observed $P$ - 
values are also provided between brackets. The criterion for covariate selection considered in the IT approach was $\Delta_{c o / c s t}<-2$ and, $\Delta_{c o / t}<2$ where $\Delta_{c o / c s t}=\operatorname{AICc}\left(F_{c o}\right)-A I C c\left(F_{c s t}\right)$ and $\Delta_{c o / t}=A I C c\left(F_{c o}\right)-A I C c\left(F_{t}\right) . w_{c o} / w_{c s t}$ is the evidence ratio for the focal covariate model $\left(F_{c o}\right)$ as compared to the constant survival model $\left(F_{c s t}\right)$._q indicates a quadratic relationship between survival and the focal covariate. See Table 2 for climatic covariate definitions. See Table 4 for model descriptions. 
Table 8. Performance of statistical procedures used to assess statistical support for effects of climatic covariates.

\begin{tabular}{|c|c|c|c|c|c|c|c|}
\hline \multirow[b]{3}{*}{ Slope $(b)$} & & \multicolumn{6}{|c|}{ Residual process variance over years $\left(\sigma^{2}\right)$} \\
\hline & & $\mathbf{0}$ & 0.01 & $\mathbf{0 . 0 3}$ & 0.05 & 0.1 & 0.3 \\
\hline & & & & & & & \\
\hline & \multicolumn{6}{|c|}{$\begin{array}{l}\text { A) NHT, fixed-effects models } \operatorname{Pr}\left(\text { rejection of } H_{0}: b=0 \text {, by } L R T_{c s t / c o} \text { if }\right. \\
\left.L R T_{\text {co/t }} \text { NS and by Ftest } t_{c s t / c o / t} \text { if } L R T_{c o / t} \mathrm{~S}\right)\end{array}$} \\
\hline $\mathbf{0}$ & $\mathbf{L}$ & 0.04 & 0.05 & 0.08 & 0.07 & 0.06 & 0.05 \\
\hline 0.1 & Pw & 0.45 & 0.39 & 0.32 & 0.30 & 0.16 & 0.11 \\
\hline 0.15 & Pw & 0.77 & 0.72 & 0.55 & 0.42 & 0.32 & 0.17 \\
\hline 0.2 & Pw & 0.92 & 0.89 & 0.74 & 0.71 & 0.45 & 0.20 \\
\hline 0.3 & Pw & 1.00 & 0.99 & 0.95 & 0.90 & 0.76 & 0.46 \\
\hline \multirow[t]{2}{*}{0.5} & Pw & 1.00 & 1.00 & 1.00 & 1.00 & 0.98 & 0.84 \\
\hline & & \multicolumn{6}{|c|}{ B) NHT, fixed-effects models: $\operatorname{Pr}\left(\right.$ rejection of $H_{0}: b=0$ by Ftest $\left.t_{c s t / c o / t}\right)$} \\
\hline $\mathbf{0}$ & $\mathbf{L}$ & 0.05 & 0.05 & 0.06 & 0.05 & 0.05 & 0.05 \\
\hline 0.1 & Pw & 0.40 & 0.35 & 0.26 & 0.26 & 0.15 & 0.11 \\
\hline 0.15 & Pw & 0.71 & 0.66 & 0.50 & 0.39 & 0.31 & 0.17 \\
\hline 0.2 & Pw & 0.89 & 0.87 & 0.71 & 0.68 & 0.44 & 0.20 \\
\hline 0.3 & Pw & 0.99 & 0.98 & 0.95 & 0.89 & 0.76 & 0.46 \\
\hline \multirow[t]{2}{*}{0.5} & Pw & 1.00 & 1.00 & 1.00 & 1.00 & 0.98 & 0.84 \\
\hline & & \multicolumn{6}{|c|}{ C) NHT, mixed-effects models: $\operatorname{Pr}\left(\right.$ rejection of $H_{0}: b=0$ by $\left.W\left(R_{c o}\right)\right)$} \\
\hline 0 & $\mathbf{L}$ & 0.04 & 0.04 & 0.06 & 0.05 & 0.05 & 0.06 \\
\hline 0.1 & $\mathbf{P w}_{\mathbf{w}}$ & 0.38 & 0.33 & 0.28 & 0.21 & 0.17 & 0.10 \\
\hline 0.15 & $\mathbf{P w}$ & 0.70 & 0.62 & 0.48 & 0.41 & 0.28 & 0.14 \\
\hline 0.2 & Pw & 0.90 & 0.84 & 0.75 & 0.59 & 0.46 & 0.19 \\
\hline 0.3 & $\mathbf{P w}_{\mathbf{w}}$ & 0.98 & 0.99 & 0.95 & 0.91 & 0.77 & 0.41 \\
\hline \multirow[t]{2}{*}{0.5} & Pw & 1 & 1 & 1 & 1 & 0.97 & 0.80 \\
\hline & & \multicolumn{6}{|c|}{ D) $\mathrm{B}: \operatorname{Pr}(0$ is not in the $95 \%$ credible interval $)$} \\
\hline $\mathbf{0}$ & & 0.03 & 0.04 & 0.09 & 0.09 & 0.11 & 0.19 \\
\hline 0.1 & & 0.36 & 0.39 & 0.32 & 0.28 & 0.26 & 0.27 \\
\hline 0.15 & & 0.71 & 0.66 & 0.53 & 0.49 & 0.4 & 0.32 \\
\hline 0.2 & & 0.89 & 0.86 & 0.81 & 0.66 & 0.59 & 0.37 \\
\hline 0.3 & & 0.99 & 0.97 & 0.96 & 0.94 & 0.85 & 0.63 \\
\hline \multirow[t]{2}{*}{0.5} & & 1.00 & 1.00 & 1.00 & 1.00 & 1.00 & 0.89 \\
\hline & & \multicolumn{6}{|c|}{ E) IT: $\operatorname{Pr}\left(\Delta_{c o / c s t}<-2\right.$ and, $\left.\Delta_{c o / t}<2\right)$} \\
\hline 0 & & 0.04 & 0.05 & 0.11 & 0.11 & 0.04 & 0.00 \\
\hline 0.1 & & 0.46 & 0.42 & 0.32 & 0.24 & 0.08 & 0.00 \\
\hline 0.15 & & 0.74 & 0.73 & 0.54 & 0.35 & 0.10 & 0.01 \\
\hline 0.2 & & 0.92 & 0.89 & 0.65 & 0.49 & 0.12 & 0.00 \\
\hline 0.3 & & 0.98 & 0.95 & 0.72 & 0.48 & 0.15 & 0.00 \\
\hline 0.5 & & 1.00 & 0.97 & 0.74 & 0.56 & 0.18 & 0.00 \\
\hline
\end{tabular}


NHT, null hypothesis testing; B, Bayesian; IT, information theory; L, level; Pw, power; Pr, probability; $H_{0}$, null hypothesis; NS, non significant; S, significant . $L R T_{x / y}, \Delta_{x / y}, F t e s t_{x / y / z}$, $W\left(R_{c o}\right)$ are statistics to assess statistical support (Table 7 and Sections IV.1-IV.3). 
Table 9. Pitfalls in studies of the impact of climatic factor on survival. ESR, ecological studies reviewed; PCA, principal component analysis.

$\begin{array}{llll}\begin{array}{l}\text { Characteristics of survival } \\ \text { estimates and climatic } \\ \text { covariates }\end{array} & \begin{array}{l}\text { Associated methodological problem }(\mathrm{CS}=\text { case } \\ \text { studies })\end{array} & \text { Detrimental consequences } & \text { Advice }\end{array}$

estimates and climatic
Survival estimates may be biased and

Survival probabilities are not

A measured directly, but inferred from monitoring data at the individual scale.

\section{Monitoring programs at the} individual scale usually cover less than 30 years and most often do not allow studying survival variation at infra-annual time

B scales.

Numerous covariates are needed in order to describe fully local climatic conditions. the bias can differ among years because of variation among years in detection probability.

-Survival estimated from models that do not account for detection probability (7/78).

-Annual survival estimates derived from model $F_{t}$ (see Table 4) used in standard regression models. Sampling variance-covariance structure of estimates ignored (9/78). effects.
High probability of detecting spurious
Ratio of number of statistical units to number of candidate time-varying covariates $\leq 5 / 1(\mathbf{4 9 / 7 8})$. Correction for multiple tests applied in 2/49 ESR where multiple time-varying covariates considered (mentioned in $\mathbf{6}$ others).
If proper correction of the threshold $P$-value for multiple tests is not applied, the probability of detecting spurious climatic covariates effects is high.

If correction for multiple tests: low statistical power.
Use a statistical framework specific to the analysis of monitoring data collected at the individual scale.
Keep the ratio climatic covariates to statistical units low.

Apply corrections for multiple tests.

Combine candidate covariates (for example using PCA) to generate integrative indices.
-Selection among regression models including highly correlated covariates is problematic.

Covariates describing local

C climatic conditions are often inter-correlated (i.e. collinearity among explanatory covariates).
Relationship among climatic covariates not examined (43/62 ESR where effect of several time-varying covariates addressed).
-Spurious estimates can be obtained from multiple regression models including highly correlated covariates.

-Simple regression models with distinct correlated covariates may not reflect distinct causal relationships.
Select non-redundant candidate covariates.

Combine candidate covariates (for example using PCA) to generate few independent integrative indices from a large number of interdependent covariates. 


\section{Characteristics of survival and climatic covariates

Variation in survival arise from the influence of multiple factors, some of which might be unsuspected by the investigator.

Relationships between survival

D and candidate climatic covariates are often indirect (climatic covariates are proxies)

Covariate models unlikely to explain most variation in survival.
-In 10/15 CS where residual variation in survival was detected, the information-theoretic approach that deals poorly with unexplained variation was adopted. In $\mathbf{7}$ of these $\mathbf{1 0}$, conclusion on climate effect based on misleading criteria.

- The hypothesis testing approach was adopted but statistical support for climatic covariate effects was assessed using statistics that deal poorly with unexplained variation (5/24 CS where the hypothesis testing approach was adopted and where unexplained variation was detected or not tested).
Spurious climatic covariate effects can be detected.

Trends in survival were not investigated

\section{(61/78).}

Trends in the climatic covariates were not investigated $(66 / 78)$.
Spurious effects resulting from the cooccurrence of trends in survival and the climatic covariate time series can be wrongly interpreted as causal relationships.
Spurious climatic covariate effects can be detected and/or probability of detection of genuine climatic covariate effects can be low.
Heterogeneity among individuals in survival and/or detection parameters generates

E spurious trends in time series of survival estimates.

Time series of climatic covariates do often exhibit trends.
Favour the hypothesis testing approach over the informationtheoretic approach when variation in survival is large.

When the hypothesis testing approach is adopted and significant unexplained variation is detected, use test statistics that account for this unexplained variation.
The slope estimates from regression models are sensitive to the link function chosen for

F survival and to the possible transformations that can be applied to the climatic covariates.
The only measure of the impact of climatic covariates provided were slope estimates (35/78).
Results cannot be used in metaanalyses addressing general issues on the impact of climate on ecological systems.
Test for the effects of trends in the climatic covariate and the survival time series. If trends are detected, use statistics that assess the fraction of the variation in the demographic parameter about the trend.
Assess the fraction of temporal variation in survival explained by climatic covariates. 


\section{FIGURE LEGENDS}

Fig. 1. Yearly estimates of adult survival for Baden-Würtemberg white storks Ciconia ciconia. Error bars indicate $95 \%$ confidence intervals.

Fig. 2. Correlation circles of the principal components analyses (PCA) for building integrative climatic indices. The fifteen meteorological stations plotted in A are identified in Table 1. Climate covariate abreviations are as in Table 2.

Fig. 3. Time series for integrative climatic indices considered as candidate covariates in the analysis of adult survival of Baden-Würtemberg white storks.

Fig. 4. 95\% joint credible region obtained with a Bayesian approach for the slopes of the linear and quadratic terms in relationships between white stork Ciconia ciconia survival and five climatic covariates. For descriptions of climatic covariates see Table 2 and Fig. 2.

Fig. 5. Estimation of the fraction of temporal variation in the adult survival of Baden-Würtemberg white storks Ciconia ciconia accounted for by candidate climatic covariates based on analysis of deviance $\left(R^{2} \_\right.$Dev; see equations 6 in Section IV.5.a), or on analysis of variance $\left(R^{2}\right.$ Var; see equation 7 in Section IV.5.a). Climatic covariate abbreviations are as in Table 2._q indicates a quadratic relationship between survival and the focal covariate.

Fig. 6. Relationships detected between climatic indices and adult survival of white storks Ciconia ciconia breeding in Baden-Würtemberg. NAO, north Atlantic oscillation, PBSC, pre-breeding climatic index, CNSRF, central and northern Sahel rainfall index. 
Figure 1




Figure 2

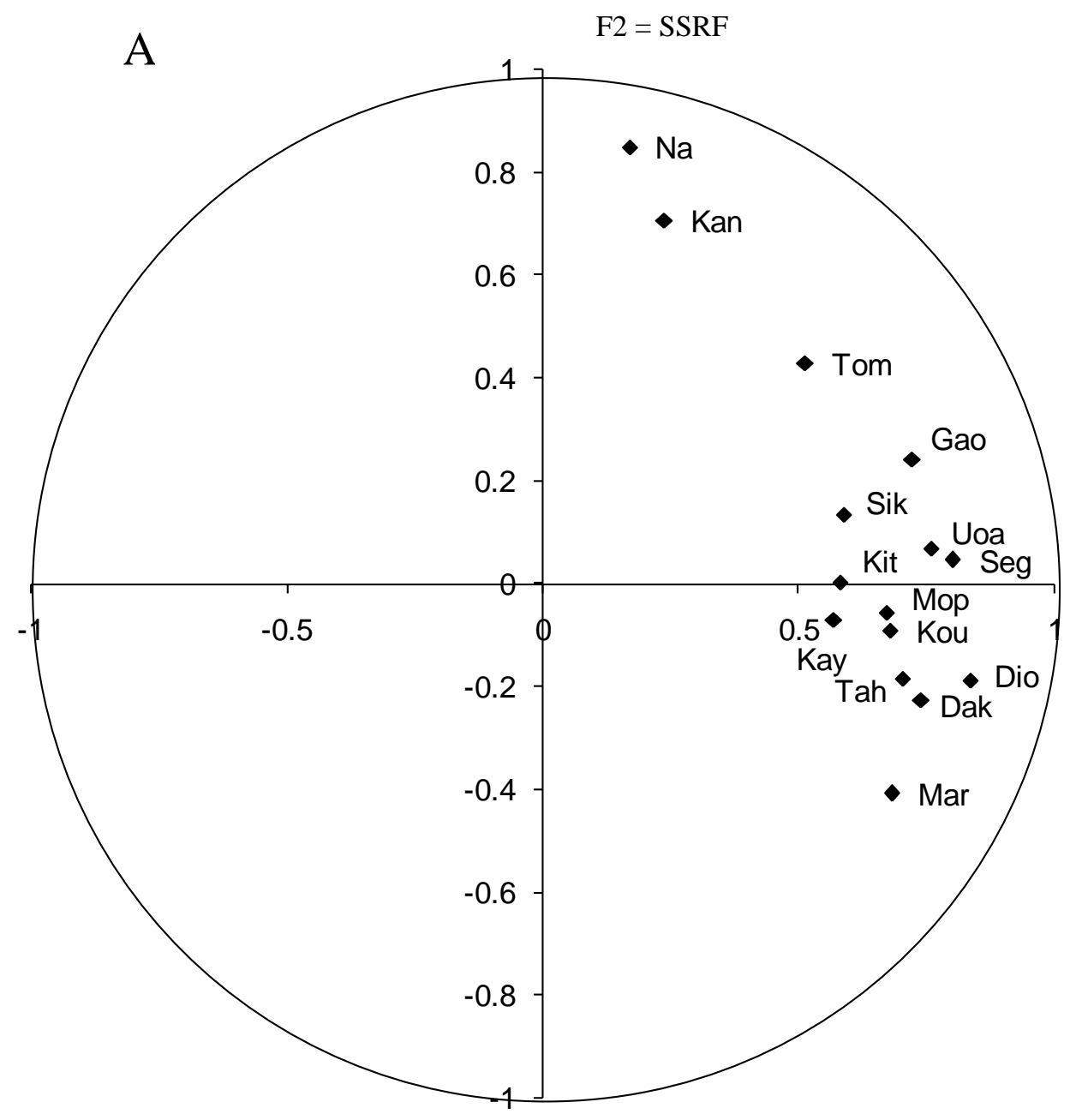

$\mathrm{F} 1=\mathrm{CNSRF}$

B

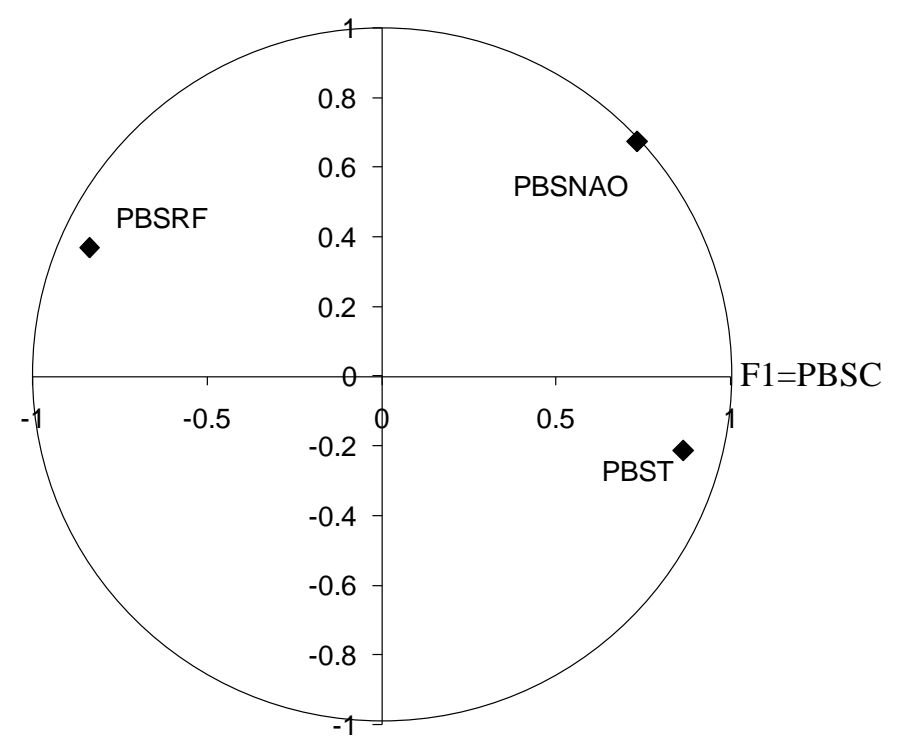

C

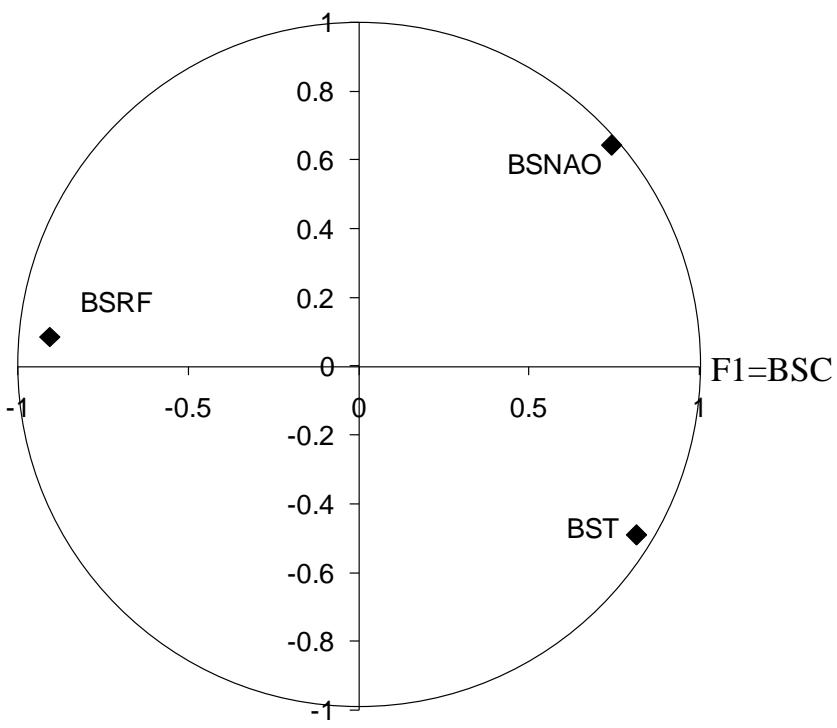


Figure 3

Central and northern Sahel rainfall (CNSRF)

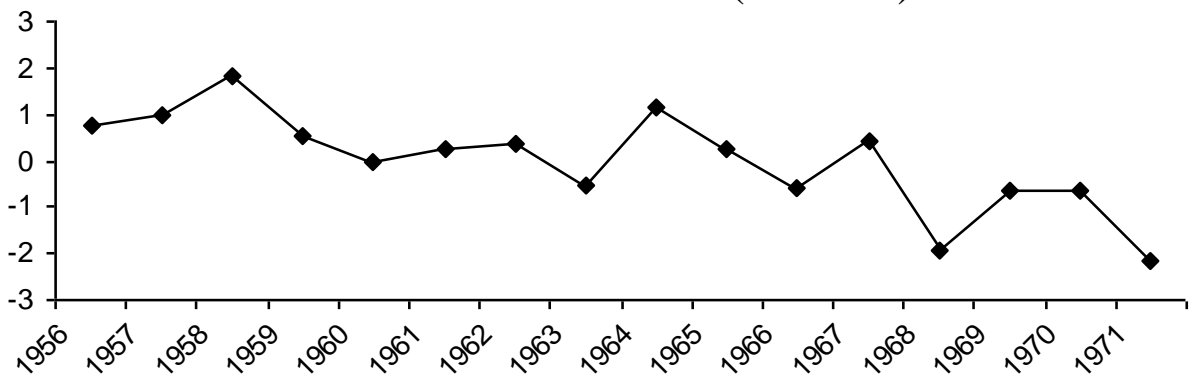

Southern Sahel rainfall (SSRF)

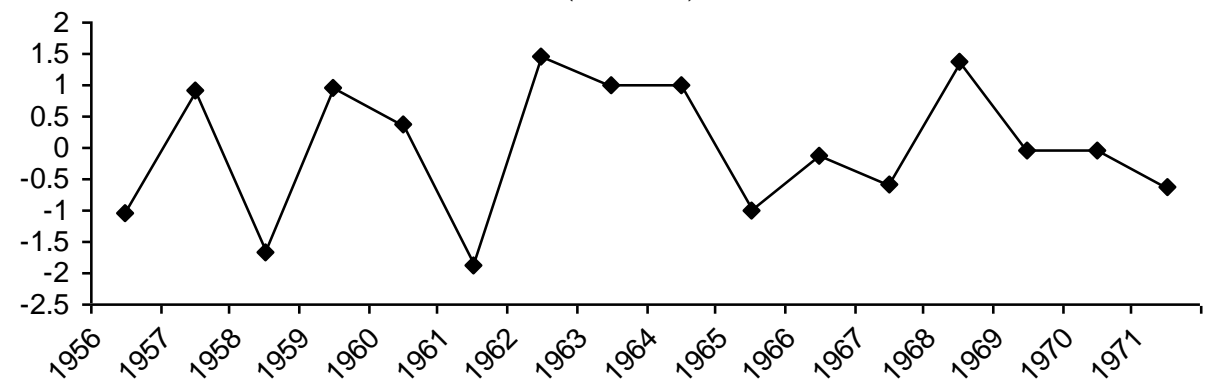

Winter north Atlantic oscillation (WNAO)

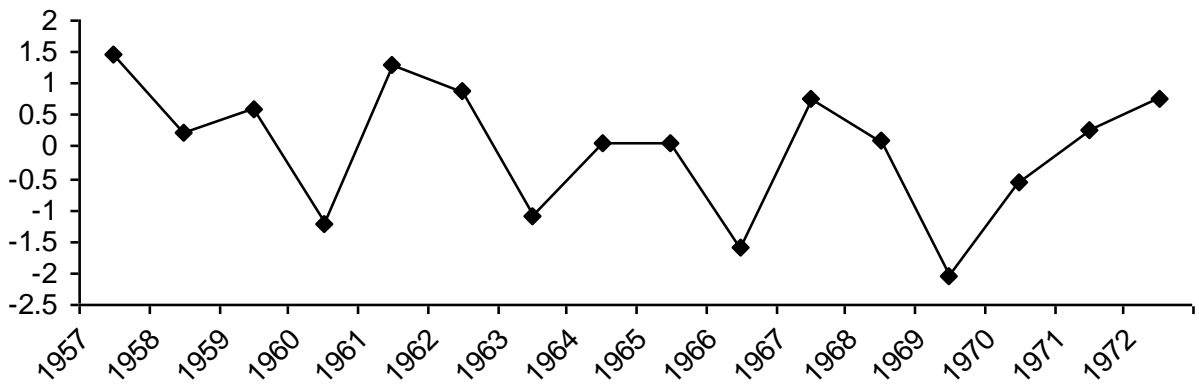

Pre-breeding season climate (PBSC)

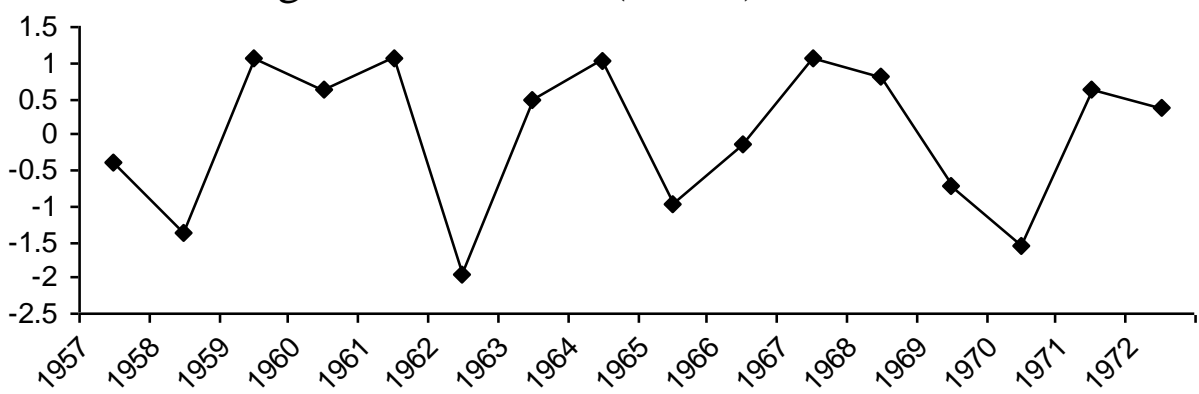

Breeding season climate (BSC)

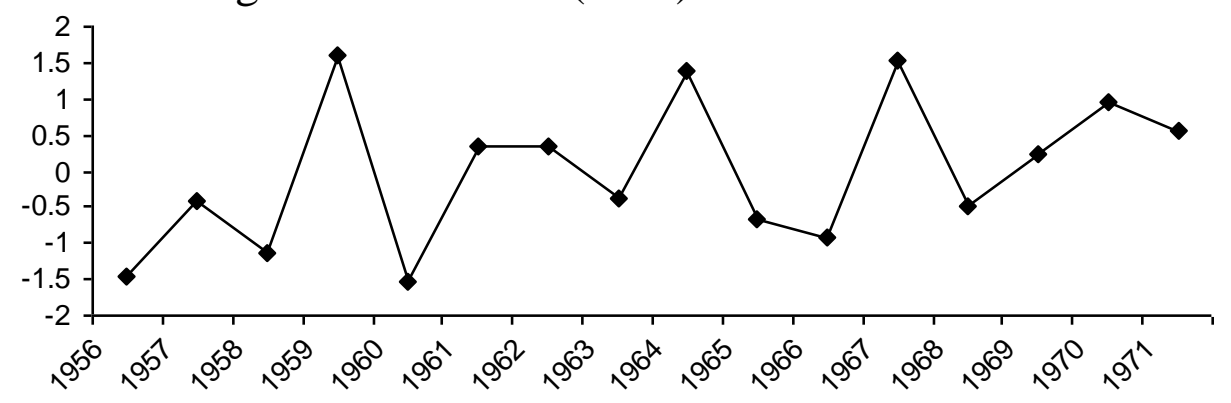


Figure 4
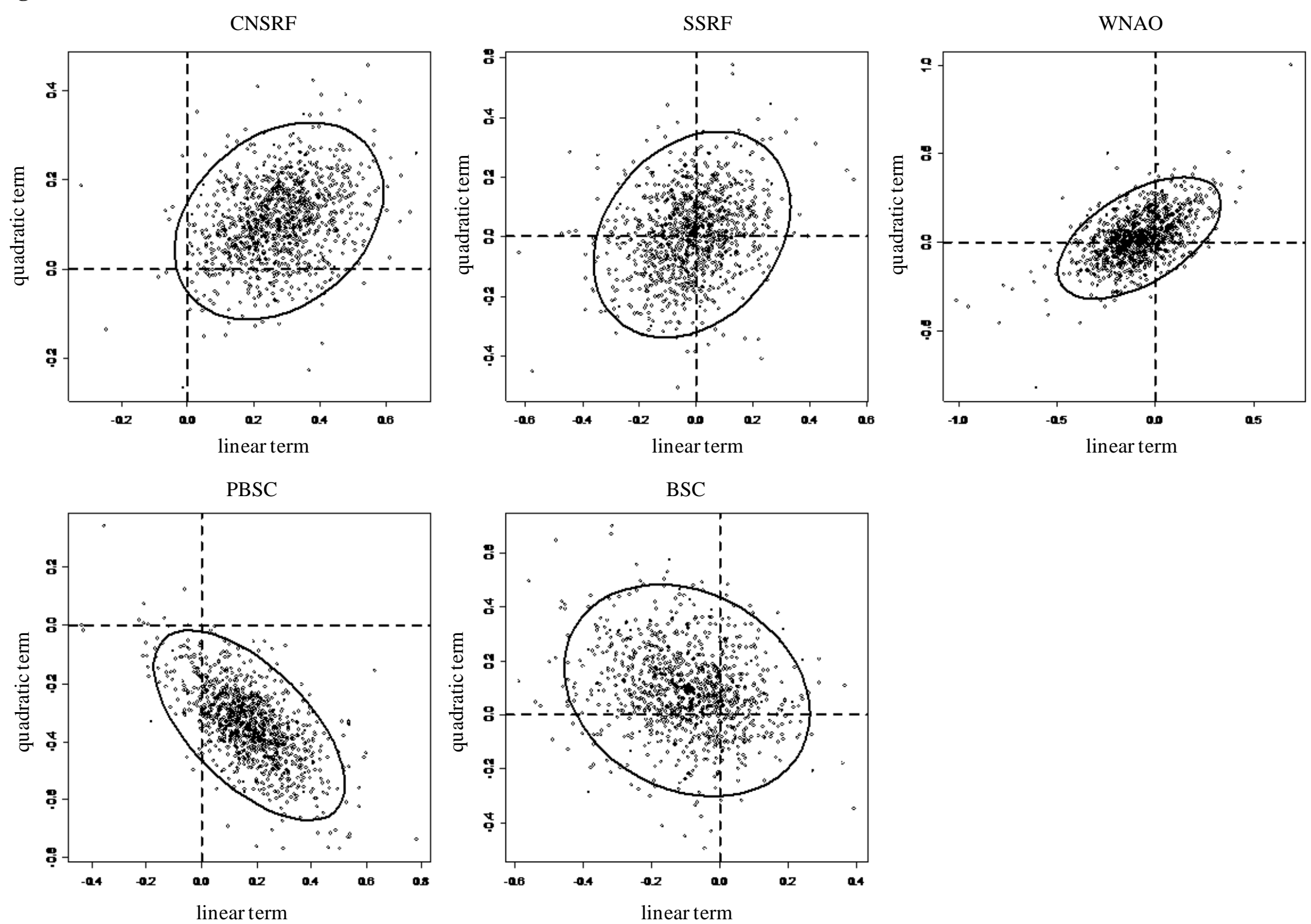
Figure 5

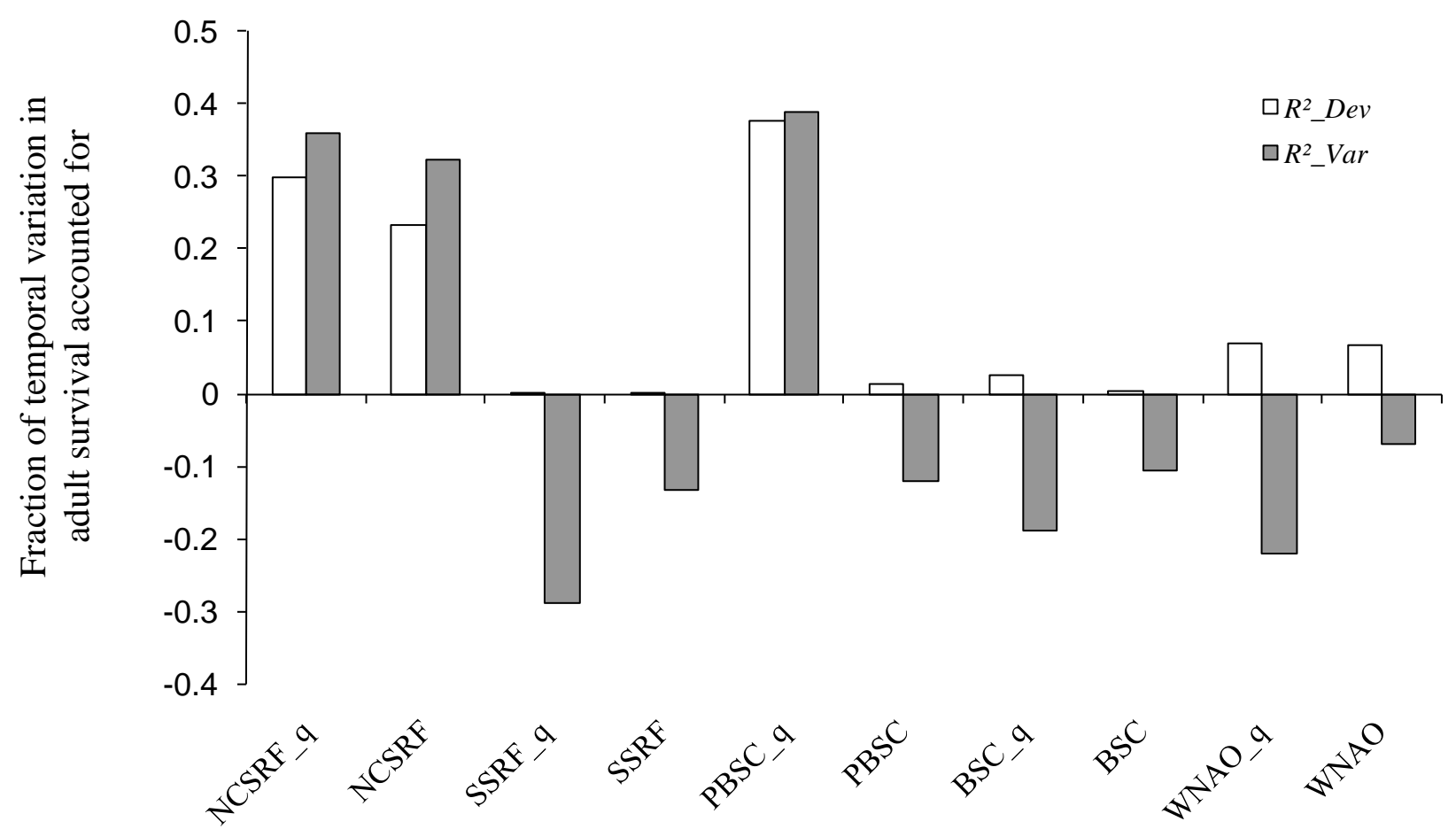


Figure 6
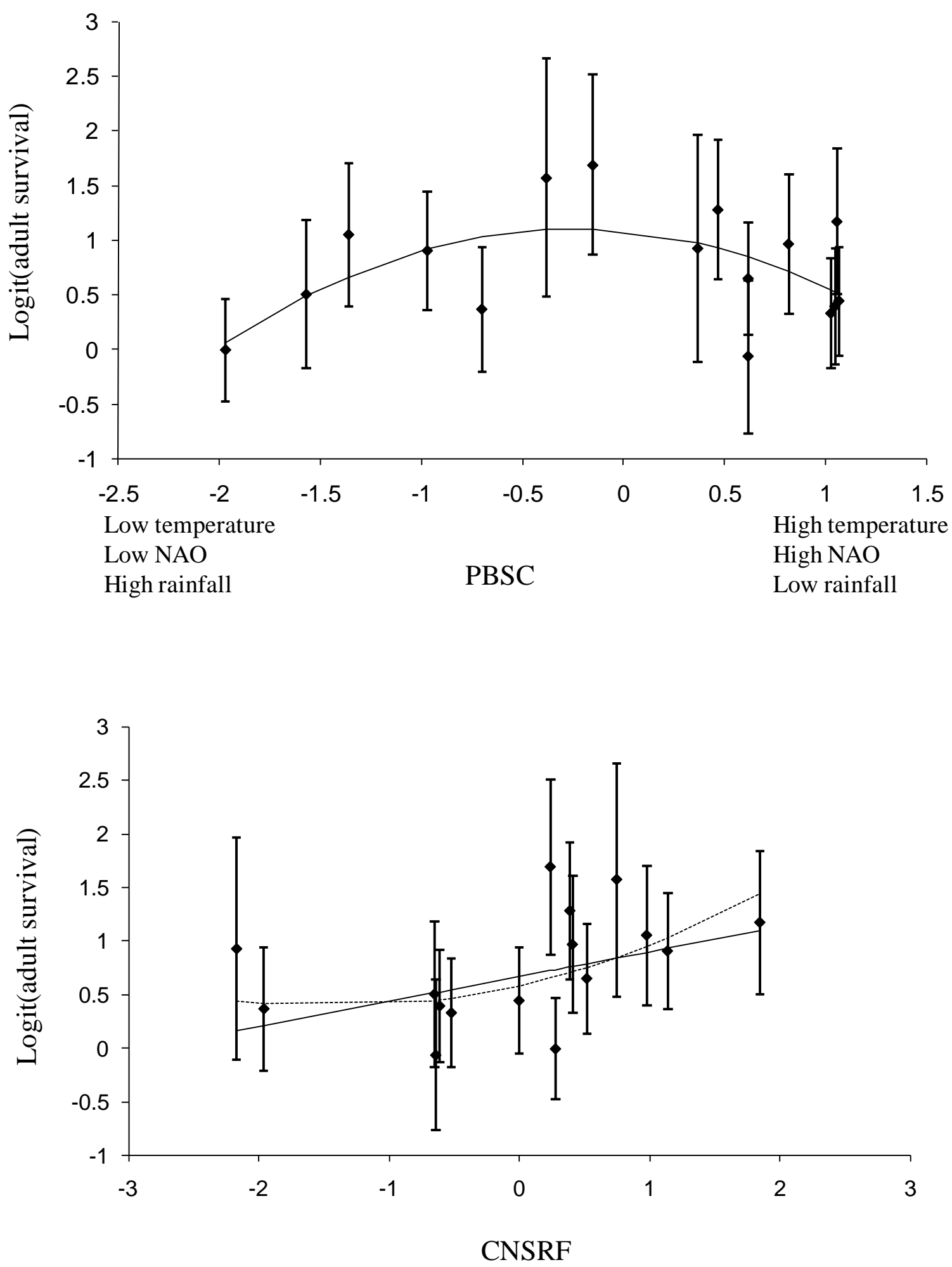